UNITED STATES DEPARTMENT OF THE INTERIOR

J. A. Krug, Secretary. GEOLOGICAL SURVEY W. E. Wrather, Director.

EQUIPMENT FOR RIVER MEASUREMENTS

STRUCTLRES FOR CABLEWAYS

By

Charles H. Pierce

WASHINGTON, D. C. 



\section{UNITED STATES DEPARTMENT OF THE INTERIOR J. A. Krug, Secretary. GEOLOGICAL SURVEY W. E. Wrather, Director.}

EQUIPMENT FOR RIVER MEASUREMENTS

\section{STRUCTURES FOR CABLEWAYS}

By

Charles H. Pierce

WASHINGTON, D. C. 

Introduction ............................ 1 Cableway across Columbia River above Celllo Falls, Oregon . . . 2

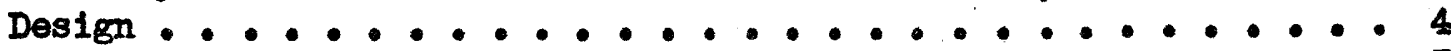
Measurement of the span .................... 5 Loads ................................ 5 Types of construction ........................ 8 Wire rope ............................ 9 $6 \times 7$ wire rope ....................... 10 $6 \times 19$ wire rope ....................... 10 Tramway track strand ...................... 10 Grades of steel ............................ 11 Fatigue due to vibration ....................... 11 Computations .............................. 12

Formulas ............................ 12 Elongation under load ....................... 14 Modulus of elasticity ..................... 15 Erection sag ........................... 16 Supports at different elevations . . . . . . . . . . . 20 Tension in becklines ....................... 21 Bending moment in towers and A-frames ............. 21

Effect of changes in temperature . . . . . . . . . . . 21 Yessurement of length ......................... 24 Factors of safety . . . . . . . . . . . . . . . . . . . 25 Specifications ............................. 26 Anchorege connections ........................ 27

Thimble-and-clip connections .............. 28

Sockets .............................. 29

Take-up at socket connections ................ 30 Galvanizing ........................... 30 Anchoreges ............................... 31

Design .............................. 31 Supporting structures ................. . . . . . . . 33 Heights of supports ....................... 33 Towers ............................. 33 Steel A-fremes ....................... 34 Steel post support ....................... 35 Timber A-frames ....................... 35 Footings ............................... 35 Grounding ......................... 36 Bearings at tops of supports . . . . . . . . . . . . . . 37 Sherres ............................ 37

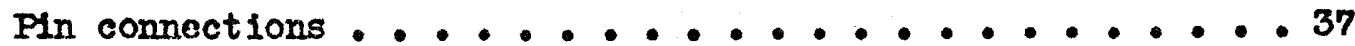

Saddles ........................... 37 Gaging cars .............................. 37 Type-A gaging car ........................ 38 Type-B gaging car .......................... 38 Accessories ........................... 38 


\section{ILIUSTRATIONS}

Page

Plate 1. Columbia River above Celilo Falls, Oregon . . . . . . 2

2. Sag diagrams for improved plow-steel $6 \times 7$ wire rope . . 14

3. Sag diagrams for extra high strength tramway track

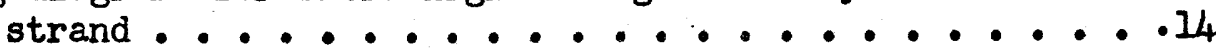

4. Computation of erection sag for extra high strength

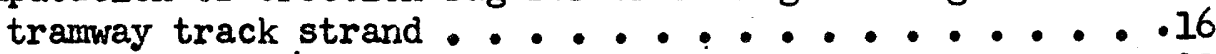

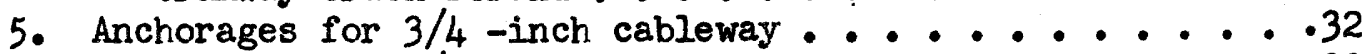

6. Anchorages for $7 / 8$-inch cableway ........... . 32

7. Anchorages for 1 -inch cableway ........... . 32

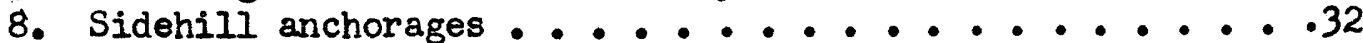

9. T-beam anchorage for $3 / 4$-inch cableway ........ . 32

10. Square steel tower, Wilsonville, Oregon ........ 34

11. Square steel tower, Wilsonville, Oregon; bill of material .......................... 34

12. Square steel tower, Maryhill, Washington ....... 34

13. Square steel tower, saddle for $13 / 8$-inch tramway

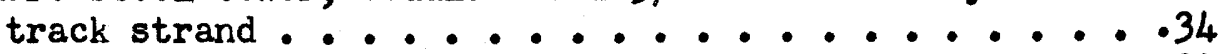

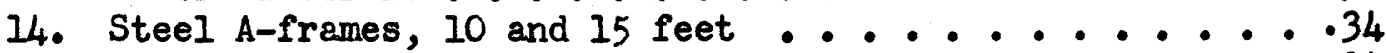

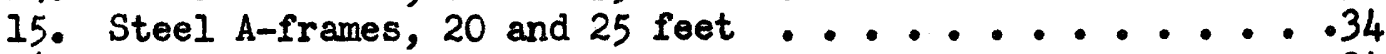

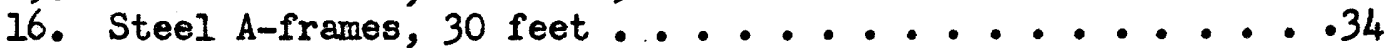

17. Steel A-frames, 35 feet .............. . . . . . . . . . .

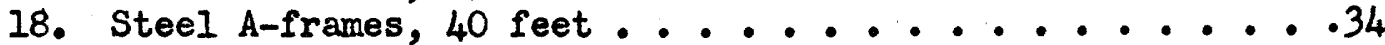

19. Steel post support ................. . . . . . . . . . . . .

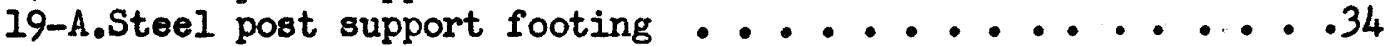

20. Timber A-frames . . . . . . . . . . . . . 34

21. Type-A gaging car, with roof ....................

21-A.Type-A gaging car, with roof; bill of

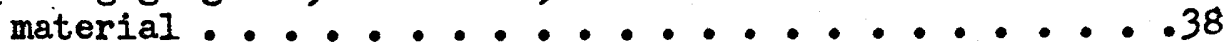

22. Type-B gaging car, structural aluminum ........ . 38

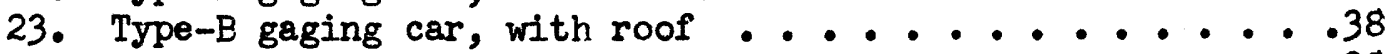

24. Colorado River type gaging car ............38

25. Gaging car puller, Colorado River type ....... 38

TABLES

Table 1. Weight per foot, net cross-sectional area, and breaking strength of galvanized plow-steel $6 \times 7$ wire rope. .7

2. Weight per foot, net cross-sectional area, and breaking strength of smooth-coil round-wire galvanized tramway track strand ............... 7

3. Erection sag d required for a specific loaded sag $D$ for $E=20,000,000$ and $22,000,000$. Extra high strength tramway track strand with safety factor of $4 \ldots 16$

4. Allowable soil pressure in tons (2,000 pounds) per square foot 


\title{
STRUCTURHS FOR CABLEWAYS
}

\author{
By Charles H. Ploree
}

\section{Introduction}

Cableways and other structures that are used in connection with measurements of river discharge are designed for definite and specific purposes, and the various conditions that may affect their use require careful consideration. The selection of the site for a cableway should be made with due regard to the hydraulic conditions of the river as woll as to the formation of the river banks. In current-meter measurements, the direction and patterm of the stream flov and its possible effect on the perfornance of the current meter are of major importance. The channel should be straight at the place of measurement and the river should be flowing smoothly, without eddies or cross-currents. It is desirable that the flow should be in one channel at all stages; sections having overilow or diversions into old channels should be avoided if poesible. Particles of drift in suriace plotation that may be observed from the river banks or a boat should move in parallel straight lines and in a direction that is parallel with the river banks. The section should be freo of large rocks and boulders; the bottom should be as smooth as is obtainable. It is always desirable to observe conditions at various stages of the river, especially at medium and high stages, before deciding upon the site.

The fundamental principles that underlie the proper use of the current moter in making discharge measurements are fairly-well established, although the methods of procedure may differ with the various conditions that are encountered and with the available equipment. To obtain an accurate measurement of the discharge it is necessary to determine the depth at definite places in a cross section of the channel and to measure the velocity at each of those places. Therefore, the method of procedure should permit the placement of the current meter at definite and specific positions in the cross section.

Current-meter measurements are made from bridges or cableways, by wading, from ice cover, from boats, or from improvised structures in accordance with the circumstances and conditions at the place of measurement. The generel procedure to be employed in each of these types of measurement has been described elsewhore 1 .

Because of the more satisfactory conditions of velocities and stream bed that are generally obtainable at sites selected for cableway installations, as well as the more convenient arrangements for the suspension and placement of the current meter, cableways are preferred to bridges or boats for rivers that can be safely spanned with ordinary types of structures. Outstanding examples of cableway construction are the $11 / 4-$ inch

1) See Water-Supply Paper 888 - Stream-gaging procedure, pp. $13-28$. 
galvanized tramuy track-strand cableway with a clear span of 1,554 feet at the gaging station on the Columbia River at Trinidad, Wash. $2 /$, and the $13 / 8$-inch gelvanized tramway track-strand cableway with a clear span of 1,727 feet at the neasuring section on the Columbia River 9 miles upstream from Celllo Falls, Oreg., that is shown in the photograph. (Plate 1).

\section{Cableway across Columbla River above Celllo Falls, Oregon}

The cableway above Celilo Falls, Oreg. is an outstanding example of crisleway construction, not only for the length of span and the height of th towers but also because of the unusual features of its design and operation. It was constructed under the supervision of George I. Canfield, district engineer, and is used for discharge measurements in determining the flow of the Columbia River at The Dalles, Oreg. The first measurement ercen this cableway was made on January 28, 1937. The following are some of the interesting features of its design and construction.

The clear span betwoen centers of towers is 1,727 feet. A $13 / 8$-inch galvanized extra-high-strength tramway track strand of 37 wires furnishes the track for the gaging car. Above this strand there is a $5 / 8$-inch galvanized extra-hlgh-strength tramway track strand of 19 wires that was used as a messenger cable in the erection of the $13 / 8$-inch strand. After that erection was completed, the $5 / 8$-inch strand was cut to the desired length, field socketed, and erected for an electrical conductor to provide current for the airways warming lights. It is insulated from the towers by strain insulators. The other side of the circuit is grounded to the $13 / 8$-inch strand. Stockiriage vibration dempers on both the $5 / 8$-inch and the $13 / 8$-inch strends prevent destructive resonent ribrations. The four individual strands shown in the photograph (pl. 1), which was taken from the Washington side of the river looking toward 0regon, may be described as follows:

1. The upper is a $3 / 4$-inch galvanized extra-high-strength steel strand that is attached at the tower to a plate-fitting to which the $5 / 8$-inch tramway track strand (electrical conductor) is dead-ended. At the lower end it is attached to a turnbuckle that is connected to an eyebolt in a $I$-type concrete anchorage.

2. The second, downward, of the inclined strands is the $13 / 8$-inch strand mentioned above. It passes continuously over a saddle in the tower to an open briage socket with 9 feet 4 inches take-up to an eyebolt in the same T-type concrete anchorage on the Oregon side of the river that is used for the anchorage of the $3 / 4$-inch strand. On the Washington side of the river an open socket is used for attachment to a T-type concrete anchorage which is also the same anchorage that is used for the $3 / 4$-inch strand.

3. The third, downward, is also a $3 / 4$-inch steel strand that is the same as the upper strand except that 1ts upper end is five feot lower whero it is attached to the base of the main saddle.

2/ See Water-Supply Paper 962, plate 1, for photograph. 

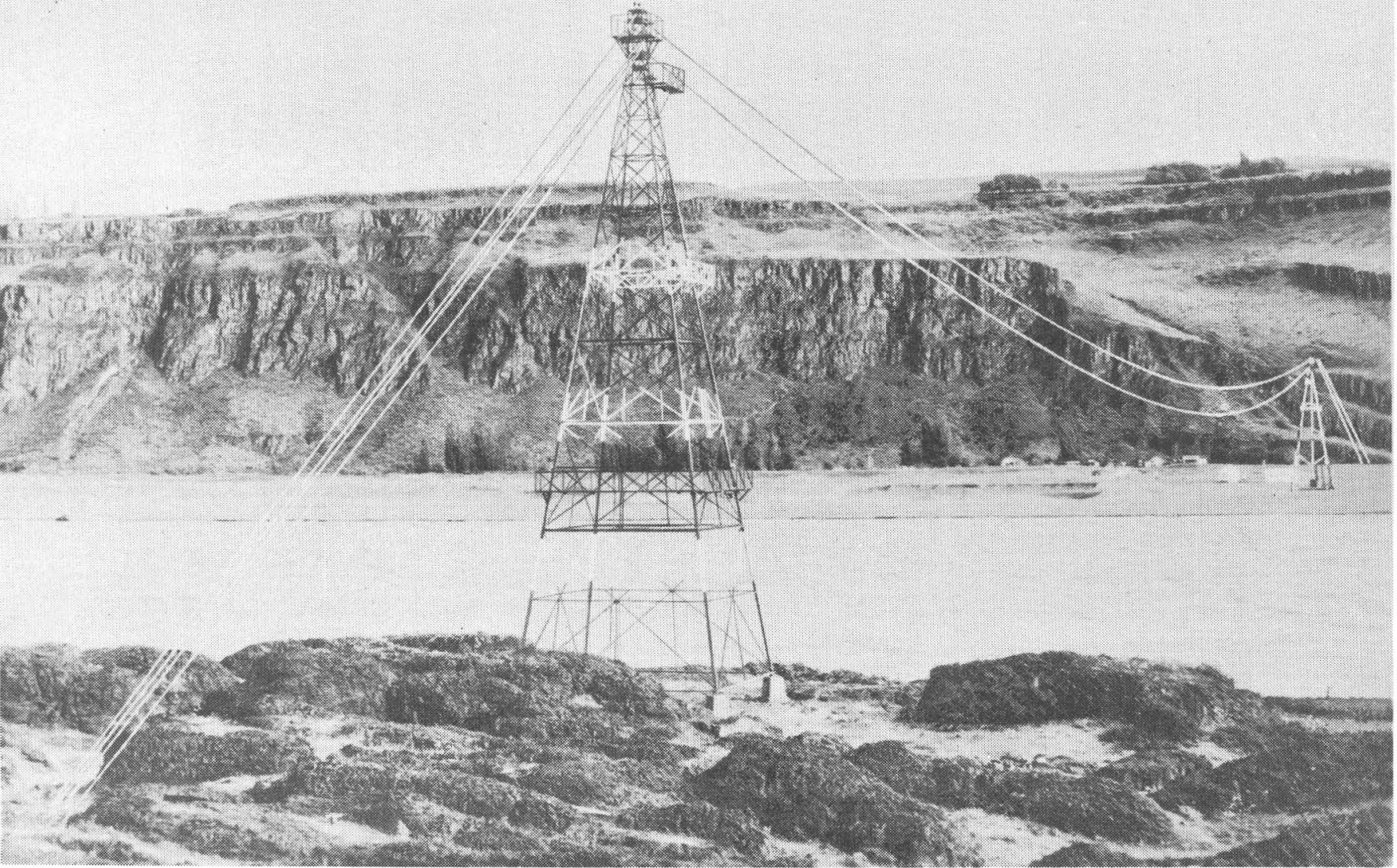

Columbia River above Celilo Falls, Oregon

STRUCTURES FOR CABLEWAYS, PLATE I 
4. The lowest of the four strands is a $1 / 2$-inch galvanized standard-steel strand that is attached to the tower at its upper end and to a separate concrete anchorage at 1ts lower end. It carries a sheave to which is attached a 140-pound counterreight. A $1 / 4$-inch galvanized w1re rope about 200 feet in length is attached to the counterweight. The other end of the wire rope is provided with a lever clamp for attachment to the $13 / 8$-inch tramway track strand at the cable car after the rapid descent of the car down the incline has been sufficiently checked by the action of the counterreight. On the return to the landing platform at the tower, the pull exerted by the counterweight assists the occupants of the car in the ascent of the steep slope adjacent to the tower.

The towers are 101 feet in height above the tops of the concrete piers which are at an elevation of 174.00 feet above mean sea level. The tope of the piers on the Washington side of the river show in the foreground (pl. I) axe 5 peet above the ground surface; those on the Oregon side are 13 feet.

In accordance with the requirements of the Bureau of Air comerce, Depertment of Commerce, wich were mandatory under the provisions of the permit issued by the War Department, each tower was painted throughout its helght with altermate bands of international orenge and white, the widths of the orange bends being one-seventh of the height of the tower and the widths of the white beands one-half of the orange. The towers were required to be lighted in accordance with the following specifications :

At the top of each tower there shall be installed two 50-uratt lamps so equipped with a relay for instant switchover in the event of lomp failure.

At both the one-third and two-third levels of each of the towers there shall be installed two 50-watt lanps, these lamps being placed at each level in such a manner that there will always be at least one light visible at each level.

All lamps shall be inclosed in red Holophano globes and shall burm from dusk to dawn.

Compliance with the last specification was made by installing one pair of 60-watt lights in red Holophane globes on diagonally opposite cormers of the tower at the one-third and two-thirds heights, the lights at each height being on the opposite corners from those at the other height.

As the nearest source of cormercial power was 12 miles distant, it was necessary to provide power at the site. This power consists of two Model D $1700 \mathrm{~S}$ fully-autconatic 800 watt, 110 rolt D.C. Kohler alr-cooled gasoline-engine-driven electric generators. 
The cost of the complete cablewas installation was $\$ 15,000$, including the two electric-generator plants, the air-conditioned power house, the astronomical clock and time switch, the switchboards and wiring for the airways warning lights, the obstruction markings, and the warehouse with living quarters for engineers visiting the station for alscharge measurements. Because of the strong winds prevalent in the area fron about $10 \mathrm{a.m}$. to $8 \mathrm{p.m.}$. It is necessary to begin a alscharge measurement in the early morning as soon as there is light enough to see.

\section{Design}

Important considerations in the design of cableway atructures are tice clear span between the supports, the weight of the wire rope or strand and the concentrated load, the loaded and the unloaded sag, the effect of changes in temperature, and the heights of the supports required for the necessary clearance above low water and extreme high water. The design of the wire rope or strand consists of the detemination of the necessary length; the correlation of sag and allowable stress for any loading that may occur when the cableway is in use, including an allowance for the effect of changes in temperature; and the selection of the size and kind of wire rope or strand that will met the requirements most satisfaetorily.

As the sereral perts of the design are interrelated to a considerable extent, some preliminary computations may be required before the final decision 18 made as to the size and the necessary sag. The use of sag diagrams, similar to those shown in plates 2 and 3 , may be helpful in the preliminary computations. In some circumstances, especially for lons spans, it may be found desirable and economical to place the supports for a minimm length of spen, even though high supports are required; whereas for short spans a saving of a few feet in the length of spen may not be of as great importance as a reduction in the heights of the supports. The physiography of the river banks and the approaches to the cableway may deterrine the positions of the supporting structures and, therefore, the length of the span as well as the size and shape of the footings and anchorages. If possible, these should be on ground not subject to submergence.

It is generally desirable to have the supports at the same elevation, although the necessity for clearance orer a railroad, highway, or electric porver line along one side of the river, or the desirability for greater ease of operation on the near side, may be sufficient reason for a difference in elevation.

In the design of a cableway structure, alferent factors of safety may be used for its several parts, as the uncertainties will vary with the nature of the meterial and the methods of Its fabrication, the conditions of loading, and in some instances, with the physical conditions at the site 3/. The parts of the structure for which individual designs

3/ Information regarding the factor of safety in engineering design may be found in the peper by Freudenthel and the subsequent discussions. See Freudenthal, Alfred M., The Safety of Structures: ASCE Proc., October 1945; discussions in Proceedings for January, February, and June, 1946, and February 1947. 
are necessary are (I) the wire rope or strand, comonly called the "cable," (2) the supports, which are usually A-frames or towers, (3) the anchorages, usually imbedded in the ground, (4) footings for the supports, (5) anchorage connections, and (6) backlines, stays, and guys. Varlous accessories may require special consideration in the design to such an extent that standard plans can be used only to a limited degree. If the river is classed as "navigable," the Corps of Engineers, U. S. Arruy, may establish certain requirements as to clearance for which information, as well as the necessary permit, should be obtained through the officer in charge of the local district. The permit from the War Department usually specifies compliance with requirements issued in accordance with law by any department of the Federal Government for the aid or protection of aerial navigation (see p.33). These requirements should be ascertained in advance, as far a possible, and observed in the desien of the structure.

\section{Meesurement of the span}

Some of the preliminary studies, such as the investigations of the relative economies of different spans and the corresponding heights of the supports, may be based on approximate measurements of the spen but a careful determination of the distence between supports and the distance from each support to the corresponding anchorage connection should be made before beginning the finel computations. For short spans, the distance between supports may be measured with steel tapes or a tag line, but for spens of several hundred feet the distence should be determined by triangulation from a carefuliy measured base line, one end of which should be at the site selected for one end of the spen. The base line should be approximately as long as the span and all three angles of the triangle should be measured. If socket connections are to be used, the measurements of the base line and the angles should be sufficiently exact so that the length of span may be computed with a reasonable desree of eccuracy.

As an error in determination of the span produces an error in the length of the wire rope or treck strend as parchesed, and this error must be compensated by take-up adjustments in order to obtain the desired sag, it follows that an uncertainty in the measurement of the spen necessitates provision for a greater take-up than otherwise would be required. With the instruments that ordinarily are available for measurements of angles and distences it should be possible to determine the spen with an allowable error not exceeding 1 in 2,000 .

Loads

In any structural design, the enticlpeted loads are given primary consideration and the structure should be designed to carry those loads with a reasonable frctor of safety. If there is large uncertainty in regerd to the loads, a large fector of safety beyond that incident to uncertainty in the strength of the materiel is needed. Howerer, the meximum load on a cablewey when it is in use for current-meter measurements can be cetermined very closely. Loads caused by falling trees 
or other objects striking the wire rope or strend may be in excess of those assumed in the design, but those loads are not likely to occur when the cebleway is in use. There is no record of a Geological Survey cableway having failed under the loads for which it was designed. Such fallures as heve occurred because of falling trees or from other causes when the cablewey was not in use generelly have been at the anchorage connections or have been due to upsetting of the supports.

The loads to be considered in the design of cableway structures are (1) the dead-load weight of the wire rope or strand, which may be the de 2 ssive or limitine load for long spens, (2) the concentrated load cartied by the gaging car or produced by tension on the meter cable attached to the car, and (3) loads caused by wind and ice. The weights per foot for various sizes of galvenized plow-steel $6 \times 7$ wire rope* and galvanized smooth-coil round-wire trampay track strand that mas be used in cableway design are given in tables 1 and 2 .

The concentrated load that is carried by the gaging car on two traveller sheaves** consists of the weight of the car and the equipment and possibly two men, the sur of which ordinarily may be taken as 500 pounds; also the puli that may be exerted by the current-meter suspension cable. The breaking strength of the 0.10-inch reverse-ley cable that is commonly used with reels is $f$ rom 800 to 1,000 pounds. The breaking strength of the 0.125 -inch reverse-lay cable which is used with 200-yound and 300-pound vreights is about 1,500 pounds. A concentrated load of 1,500 pounds applied at the point of maximum sag is cormonly used in design except in those instances where it is expected that the 0.125-inch meter cable will be used or additional heavy equipment will be carried on the gaging car. In those cases, the design should be made for a concentrated load of 2,000 pounds or whatever amount wlll include the welght to be carried plus the breaking strength of the meter cable.

Wind load should be considered in the deslgn of towers, guy cables, and footings, especially if the span is long. The possible effect of ice covering should also be investigated if the structure is in a region subject to freezing temperetures. In the design of the cableway structures for the station on the Columbia River at Trinidad, Wesh., the effects of wind load and ice covering were investigated as stated by Arthur Johnson in his report $4 /$ :

Two conditions were investigated; first, with the wind normal to the cable, and second, with the wind 45 degrees from normal. In considering the wind stress, the cable and all members of the tower were considered as having a coating of ice extending $1 / 4$ inch beyond each edge, or a totel increase of $1 / 2$ inch in width (N.E.I.A. class B loading); a 3/4-inch cable supported two feet above the main cable

* Add about 7 percent to the weight given for $6 \times 7$ wire rope to obtain the weight for a corresponding size of 6 × 19 wire rope. ** For the spacing of the sheaves see plates $21,22,23$, and 24. 4/ Unpublished report entitled "Construction of a gaging station on Columbie River at Trinidad, Wash." by Arthur Johnson, assistent engineer, May 1931. 
Table 1. -- "eight per foot, net cross-sectional area, and breaking strength of galvenized plow-steel $6 \times 7$ wire rope*

\begin{tabular}{|c|c|c|c|c|c|}
\hline \multirow[t]{2}{*}{ Diemeter } & \multirow{2}{*}{$\begin{array}{l}\text { Anproz- } \\
\text { imate } \\
\text { weight } \\
\text { per foot }\end{array}$} & \multirow{2}{*}{$\begin{array}{l}\text { Net area } \\
\text { of cross } \\
\text { section }\end{array}$} & \multicolumn{3}{|c|}{$\begin{array}{l}\text { Breaking strength (with deduction of } 10 \text { percent } \\
\text { for effect of galvanizing) }\end{array}$} \\
\hline & & & $\begin{array}{l}\text { Improved } \\
\text { plow steel }\end{array}$ & Plow steel & $\begin{array}{c}\text { Mild } \\
\text { plow steel }\end{array}$ \\
\hline Inches & Pounds & $\begin{array}{l}\text { Square } \\
\text { inches }\end{array}$ & Pounds & Pounds & Pounds \\
\hline $3 / 4$ & 0.84 & 0.215 & 40,800 & 35,600 & 30,900 \\
\hline $7 / 8$ & 1.15 & .294 & 55,200 & 48,000 & 41,700 \\
\hline 1 & 1.50 & .380 & 71,400 & 62,100 & 54,000 \\
\hline $11 / 8$ & 1.90 & .484 & 89,600 & 77,900 & 67,800 \\
\hline $11 / 4$ & 2.34 & .596 & 109,800 & 95,400 & 83,000 \\
\hline
\end{tabular}

Teble 2. - Veight per foot, net cross-sectional area, and breaking strength of smooth-coil round-wire galvanized tramway track strand.

\begin{tabular}{|c|c|c|c|c|c|}
\hline \multirow[t]{2}{*}{ Diameter } & \multirow{2}{*}{$\begin{array}{l}\text { Wires } \\
\text { In } \\
\text { strand }\end{array}$} & \multirow{2}{*}{$\begin{array}{l}\text { Approx- } \\
\text { imate } \\
\text { weight } \\
\text { per foot }\end{array}$} & \multirow{2}{*}{$\begin{array}{l}\text { Net aree. } \\
\text { of cross } \\
\text { section }\end{array}$} & \multicolumn{2}{|c|}{$\begin{array}{l}\text { Breaking stren th (with deduction of } \\
10 \text { percent for effect of galvanizing) }\end{array}$} \\
\hline & & & & $\begin{array}{c}\text { Btre } \\
\text { high strength }\end{array}$ & HIgh strength \\
\hline Inches & Nunber & Pounds & $\begin{array}{l}\text { Square } \\
\text { inches }\end{array}$ & Pounds & Pounds \\
\hline $3 / 4$ & 19 & 1.24 & 0.301 & 58,500 & 49,700 \\
\hline $7 / 8$ & 19 & 1.69 & .438 & 79,900 & 67,700 \\
\hline 1 & 19 & 2.20 & .576 & 104,400 & 88,600 \\
\hline $11 / 8$ & 37 & 2.70 & .723 & 127,300 & 108,000 \\
\hline $11 / 4$ & 37 & 3.23 & .897 & 152,300 & 129,200 \\
\hline $13 / 8$ & 37 & 4.01 & 1.081 & 189,000 & 159,800 \\
\hline $11 / 2$ & 37 & 4.88 & 1.292 & 229,500 & 195,100 \\
\hline
\end{tabular}

* For $6 \times 19$ wire rope the veight is about 7 percent greater and the breaking strength is about 5 percent greater than that of the $6 \times 7$ wire rope. NOIE. -- The values of breakine strength and weight in table 1 are those given by the National Bureau of Standards: Wire Rope, Simplified Practice Recommendation R198--43, page 1 , table 1 .

The breaking strength and weight per foot of tremway track strend have not been officielly standardized. The values given in table 2 re those generally used. In ordering tremwey track strand of a given diameter, the required minimur breaking strength should be specified. 
wes also considered. Such a cable will probably be required at some future date for supporting lights and streamers to mark the obstruction to aerial navigation. A wind pressure of 8 pounds per square foot on projected area of cebles and 20 pounds per square foot on twice the projected area of the tower was used. The wind normal to the cable gave the greatest overturning force or uplift on the footings and the wind 45 degrees 1 rom normal gave the greatest compression on the footings. Although side guys were used, the footings were designed to resist uplift due to wind pressure. Consequently, in this design the wind loed normal to the cable was used when considering uplift and 45 degrees from normal when considering compression.

\section{Types of construction}

Various types of construction are used in cableways and the appurtenant structures. For long spans, high towers may be required similar to those shown in the photograph of the cableway across the Columbia River (see pl. 1) for which the designs are given in plates 12 and 13.

Steel or timber A-frames may be used as supports for cableways across streams of ordinery size where the span is not too great and the helght of the support is less than about 40 feet. Designs for steel A-frames of various helghts are shown in plates 14 to 18 . Designs for timber A-frames are shown in plate 20.

The steel post support that is shovm in plate 19 has been found very satisfactory. It is simple in design and ordinarily the steel can be readily obtained. An H-berm support 27 feet in height for a cableway of about 700-foot span has been designed and used in the Boston district.

In some instances where the use is expected to be temporary, wire rope is carried by sheaves supported by trees, the end connection being made to a suitable anchorage or to the lower part of another tree. If trees are used, either for supports or anchorages, four or more blocks should be placed between the wire rope and the bark of the tree to protect the tree from injury that might cause the failure of the support or anchorage. The use of trees as cableway supports is not recomiended, except as a temporary expedient until more permanent structures can be erected.

Anchorages nay be constructed of mass concrete whereby the weight of the concrete and the soil resistance to moremont are the principal factors in the security of the anchorage, or they may be of the T-beam type, suitably reinforced, with most of the load carried by the resistance of the soil in direct compression. The latter type is more economical of concrete but the forms are more expensive than those required for the mass type of construction.

In places where the river banks contain ledgerock of sufficient height, anchorage rods set in the rock are sometimes used. Owing to uncertainties as to its strength and reliability, this type of anchorage it is not recommended. 
In some cirewmetances, where timber is plentiful and the cost of concrete is prohibitive, the use of a timber deadman as an anchorage for a short span may be acceptable. If timber is used, it should be an unsawed $\log$ with the bark removed. A vire-rope connection between the turmbuckle and the log should be provided with bearing plates between the rope and the $\log$ and at least three turns of the wire rope around the $\log$ and the bearing plates.

In all cases where a rigid connection is made to an anchorage by means of an anchor bolt, care should be taken that the anchor bolt is set in a direct line and in the same plane with the connecting back stay or backline of the wire rope or strand so thet there will be no bending moment in the rod.

Wire rope and its connections, or the connections for any type of construction, should not be exposed to contact with the ground. If below the surface, suitable waterproofing should be applied. A wrapping of burlap covered with asphaltum is scmetimes used.

Two different types of material, with respect to the methods of their fabrication, are used in the tracks of cableways. These are (1) wi re rope and (2) trambay track strand. Because of the difference in their flexibility, due to their design and methods of fabrication, different methods of connection to the anchorages are customary.

Although the physical properties and tensile strengths of these two types of material differ, certain general practices and procedures in connection with their use are common to both typos. It is considered good practice to use a size at least $3 / 4$ inch in diameter, even for short spans, as the greater ease in operation of the gaging car with the smaller sag required for the $3 / 4$-inch size, instead of a smaller size, will more than compensate for the small additional cost. Another reason for specifying a minimum diameter of $3 / 4$ inch for the cableway track is that the smaller sizes would require the use of small wires that would be more vulnerable to abrasion and atmospheric corrosion.

\section{Wire rope}

The wre rope that is used for cableways consists of several individual strands, usually six, each of which is composed of a number of wires. The number of wires in a strand of this type is generally 7 , 19, or 37, although others are obtainable. A strand of 7 wires has been commonly used in cableways for river measurements, but a 19-wire strand is often preferred because of the greater flexibility and scmewhat greater strength of the rope with that method of fabrication. However, the smaller size of the wires in a 19-wire strand as compared with a 7-wire strand renders the 19-wire strand more vulnerable to abrasion and corrosion.

A rope with a hemp core is ordinarily used and is so understood in the designation of "wire rope" unless a different core is specified or is required by the method of fabrication. It is preferable that the 
hemp core should not be lubricated, but a wire rope with a dry core is not always obtainable. A wire rope has the advantage of flexibility and is adapted to the use of thimble-and-clip connections to the turmbuckles and anchorages. For these reasons and because of its general availability, simplicity of connections, and ease of erection, hemp-center wire rope is often used in cableways of short and mediun span. The thimble-andclip connections are the greatest sources of weakness in this type of construction.

Various other types of wire ropes are avallable, among which are ropes with wire centers. These may be either independent wire-rope centers or wire-strand centers. This type of rope has the advantage of somewhat greater strength and is subject to less uncertainty in stretch and elongation than is the hemp-center rope.

\section{$6 \times 7$ wire rope}

Wire ropes composed of 6 strands around a hemp core with 7 wires in a strand are comnonly known as transmission or haulage ropes, but have sometimes been listed as "yacht rigging rope" by wire ropo compenies.

As the wires are relatively large in the $6 \times 7$ type of fabrication, the rope is well qualified to withstand abrasion but it is less flexible then some other types of wire rope. Because of its general availability, the $6 \times 7$ wire rope has been often used in short-span cableways. The weight per foot, net cross-sectional area, and breaking strength of ordinary sizes of different grades of galvenized plow-steel $6 \times 7$ wire rope are given in table 1.

\section{$6 \times 19$ wire rope}

Severel different designs of $6 \times 19$ wire rope are available, all of which are generally listed under the heading of hoisting rope. They differ in flextbility and other properties with the various methods of fabrication, but the so-called "Standard Hoisting Rope" is more generally used then any of the others. In this design there are 6 smaller intermediate wires in addition to the 19 main vires. As the $6 \times 19$ wire rope has a breaking strength about 5 percent greater than that of the $6 \times 7$ wire rope, with a weight per foot about 7 percent greater, if it is given a sag corresponding to that shown in the diagrams in plate 2 the factor of safety for ordinary spans will be slightly greater than that of the $6 \times 7$ wire rope with the same sag except that its greater vulnerability to abrasion and corrosion may have an adverse effect. Its modulus of elasticity is somewhat lower than that of the $6 \times 7$ wire rope.

\section{Trampay track strand}

Tramway treck strand, because of its sreater smoothness of operation, greater strength and reliability, higher modulus of elasticity and less sag, is generally preferred for river cableways, even though the span may be within the limits of use of ordinary sizes of wire rope. The stiffness 
and lack of flexiblifty of trambay track strand, as compared with wire rope, necessitates the use of socket connections. (See p.29). This type of connection facilitates erection of the cableway but it requires careful measurements of lengths in order to avoid the necessity for an excessive length of take-up at the sockets. (See p.30). The weight per foot, net cross-sectional area, and breaking strength of ordinary sizes of smooth-coil, round-wire, galvanized tramway track strand are given in table 2. As track strand has not been as fully standardized as wire rope, the suppliers of that material should be invited to furnish a listing of its characteristics.

\section{Grades of steel}

Plov steel that is generally specified for cableways is an acid open-hearth steel so treated and dram as to yleld a wire unexcelled in uniformity, strength, and toughness. The three standard grades of plow steel that are used in the fabrication of wire ropes where strength, toughness, and resistance to abrasion are of primary importance are "Improved Plow Sterl," "Plow Steel," and Mild Plov Steel." 5/. OP these three, Improved Plow Steel is the strongest, toughest, and most wear resistant. The use of Mild Plow Steel is limited to installations requiring high fatigue resistance where strength is not of primary importance. The grede desigmated as Plow Steel is intermediate between Improved Plow Steel and Mild Plow Steel; the difference in strength between each grade is approximately 15 percent. Smooth coil tramway track strand is fabricated only from two grades of steel which are now designated as "Hxtra High Strength" and "High Strength." The comparative strengths of the two grades are show in table 2.

A grade of steel that has a higher unit strength than those mentioned above is sometimes used in suspension bridges of short and medium span, and for guys to towers, masts, stacks, and similer structures where high strength is the principel consideration. Bridge strand, which is made of that grade of steel, is not recormended for use in cableways because of its unusually long lay and its resultant vulnerability to wire aisplacement.

\section{Fatigue due to vibration}

Engineers experienced in the design and use of tranway track-strand structures have found that fallure of wires in the strand may occasionally occur at the entrance to the socket if the socket is at the end of a long iree span and is not free to rotate. These failures have been attributed to rapid changes in the angle of the strend where it enters the socket, such as may be caused by rariations in the conditions of loading or by vibrations induced by wind or other causes. If the socket is not free to rotate, the flexure of the strand at the mouth of the socket may cause

5/ See N. B. S. Wire Rope, Simplified Practice Reconmendation RI98-43. Various trade names are used by the different manufacturers in their designations of these grades of steel. 
fatigue fallure of some of the wires. A standard open socket presumably is free to rotate because of its pin connection but, if the pin is attached to a rigid anchorage or tower top, the bearing pressure produced by the tension may prevent rotation. Therefore, with open sockets, it is desirable to introduce a link between the socket and the fixed anchorage. If vibration is noticeable, such as might be caused by the passage of trains near the cableway support or anchorage, it may be alleviated by the use of Stockbriage dampers. The fallure of an eye-bolt connection that was attributed to fatigue induced by vibration in a cablemay across the Yakima River has been described as follows 6/:

The bolt was rigidly anchored in rock and had been in service for about 15 years. The cableway equipment had been used repeatediy for making high-water measurements, when the strain on the meter-suspension cable was great, and with two engineers in the gaging car. Only one engineer was in the car when the bolt broke, and the river wes at medium stage, so that the strain on the meter-suspension cable was slight. Framination of the fracture seemed to indicate progressive failure due to fatigue.......

Fatigue of tramway strand may not occur, or if it does occur the process is undoubtedly slower than in an eye-bolt. Even so, undue vibration $1 \mathrm{~s}$ disconcerting, and cableway measuring equipment at many gaging stations may be in service for 50 years or more.

\section{Computations}

The following formulas are based on the principles of mechanics and are similar to those cormonly used by wire-rope companies. The supports are assumed to be at the same elevation unless otherrise stated. In the formulas for length and slope, it is assumed that the wire rope or strand takes the form of a parabolic arc instead of the catenary. This assurnption greatly simplifies the computations and the error in results is negligible.

\section{Formulas}

$W=$ weight of the wire rope or strand per foot of length.

$P=$ concentrated load at center of span or at point of maximum sag.

$S=$ clear span between supports.

H $=$ horizontal component of the tension,

= tension at the point of maximm sag.

$$
=\frac{W S^{2}}{8 D}+\frac{P S}{4 D}=\frac{S(W S+2 P)}{8 D} \cdot \cdots \cdot \cdots \cdot \cdot \cdots \cdot \cdot \cdot \cdot \cdot
$$

6/ Unpublished report by engineers in the Tacoms district, February 1935. 
Correspondingly, for the individual loads $W$ and $P$ :

$\mathrm{H}_{\mathrm{w}}=\frac{\mathrm{W} \mathrm{S}^{2}}{8 \mathrm{D}_{\mathrm{w}}}$, and $\mathrm{H}_{\mathrm{p}}=\frac{\mathrm{P} S}{4 \mathrm{D}_{\mathrm{p}}} \ldots \ldots \ldots \ldots$

$D=$ loaded sag $=\frac{S(W S+2 P)}{8 \mathrm{H}} \cdots \cdots \cdot \cdots \cdot \cdots \cdot$

d = erection sag; to be computed.

$T=$ meximum tension $=H \sec \beta \ldots . . . . .$.

$\beta=$ angle between the horizontal and the tangent to the curve at the support.

$\tan \beta$, for loads and $P,=\frac{2(D+4 Q)}{S} \cdots \cdots$

where $Q$ is the sag in the half spen from the chord joining a support and the load at midspen. The equation that is generally used for $\tan \beta$ is:

$$
\tan \beta=\frac{W S+P}{2 H} \cdots \cdots \cdots \cdots \cdots \cdots
$$

$I=$ length along the catenary (or parabolle arcs) between supports. For load W (welght per foot) the following approximate formulas are used:

$$
I_{w}=s+\frac{w^{2} s^{3}}{24 F_{w}^{2}}=s\left(1+\frac{w^{2} s^{2}}{24 H_{w}^{2}}\right)=s\left(1+\frac{8 D_{w}^{2}}{3 s^{2}}\right) \ldots . . \cdot
$$

where $D_{w}$ is the sag corresponding to the tension $H_{w}$ for the load $W_{0}$

Formula (5) is comonly used as:

$$
\mathrm{I}_{\mathrm{w}}=s\left(1+\frac{8}{3} \mathrm{k}^{2}\right) \ldots \ldots \ldots
$$

where $k$ is the ratio of the sag to the span for the load $\mathrm{w}$. The derivation of equation (5) and also an exact formula for the computation of the length are given by Steimen $\eta /$.

An approximate formula that gives the erection length $I_{e}$ for a level span sufficiently close for prectical purposes is:

$$
I_{e}=2 \sqrt{\left(\frac{s}{2}\right)^{2}+\frac{4}{3} a^{2}} \cdots \cdots \cdots
$$

I) Steinman, D. B., A practical treatise on suspension bridges, $2 d$ ed., p. 5. 1929. 
By formule (5b) the length of the parabola for a span of 1,000 foet and $a \mathrm{seg}$ of 45.0 feet is $1,005.39$ feet, whereas it is $1,005.40$ feet by formula $(5 a)$.

With a load $P$ at the center of the spen, the length may be computed by the formula:

$$
I=2\left[s_{1}+\frac{w^{2}\left(\frac{s}{2}\right)^{3} \cos ^{3} \theta}{24 \pi^{2}}\right] . . \cdot \cdot \cdot \cdot \cdot \cdot \cdot
$$

where $S_{1}$ is the chord length Irom the center of span to the support and

is the angle that the chord makes with the horizontal.

$I_{1}=$ length along the catenary (or parabolic ares) plus the sum of the alstances from the supports to the anchorage connections. (See eq. (9)).

The above relations do not take into consideration the elasticity of the material or the small changes in arrangement of the component parts of the rope or strand that may result in permanent stretch when load is applied. The sag diagrams in plates 2 and 3 show the loaded sag $D$ corresponding to the allowable tension $T$ for a safety factor of 4 for improved plow-steel tramway track strand and a safety factor of 5 for improved plow-steel wire rope.

\section{Elongation under load}

From preliminary computations or by the use of diagrams, a wire rope or strand of a certain size and strength may be selected and the corresponding values of $D$ and $T$ determined from equations (1), (2), (3), and (4). The results of those computations may indicate that a change should be made in the selection. After satisfactory trial values have been obtained, the elastic elongation due to load and the change in length due to temper ature changes can be computed.

The elongation due to the loads $W$ and $P$ may be computed from the equation:

$$
e=\frac{T L}{A E} \text {, or } \theta=\frac{H L}{A E} \text { for tension } H \cdot \cdots \cdot \cdots \cdot \cdot \cdot
$$

If the support is hinged at the base or is otherwise nonrigid in position, $I_{1}$ should be used for the length. Same engineers prefer to use the formula:

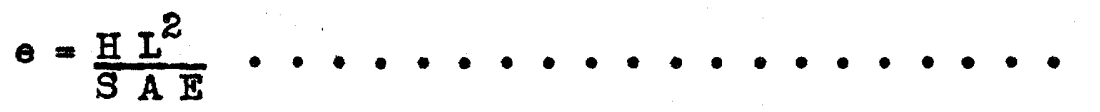

In equation (7), and likewise in equations (8) and (9), the area $A$ is the sum of the net cross-sectional areas of the several individual wires that ccmpose the rope or strend. The values of A given in the tables published by the various wire-rope companies may differ slightly for the same nominal diemeter of the rope or strand.

As new wire ropes and, to a lesser degree, tramway track strand are subject to small changes in the positions of their component parts 


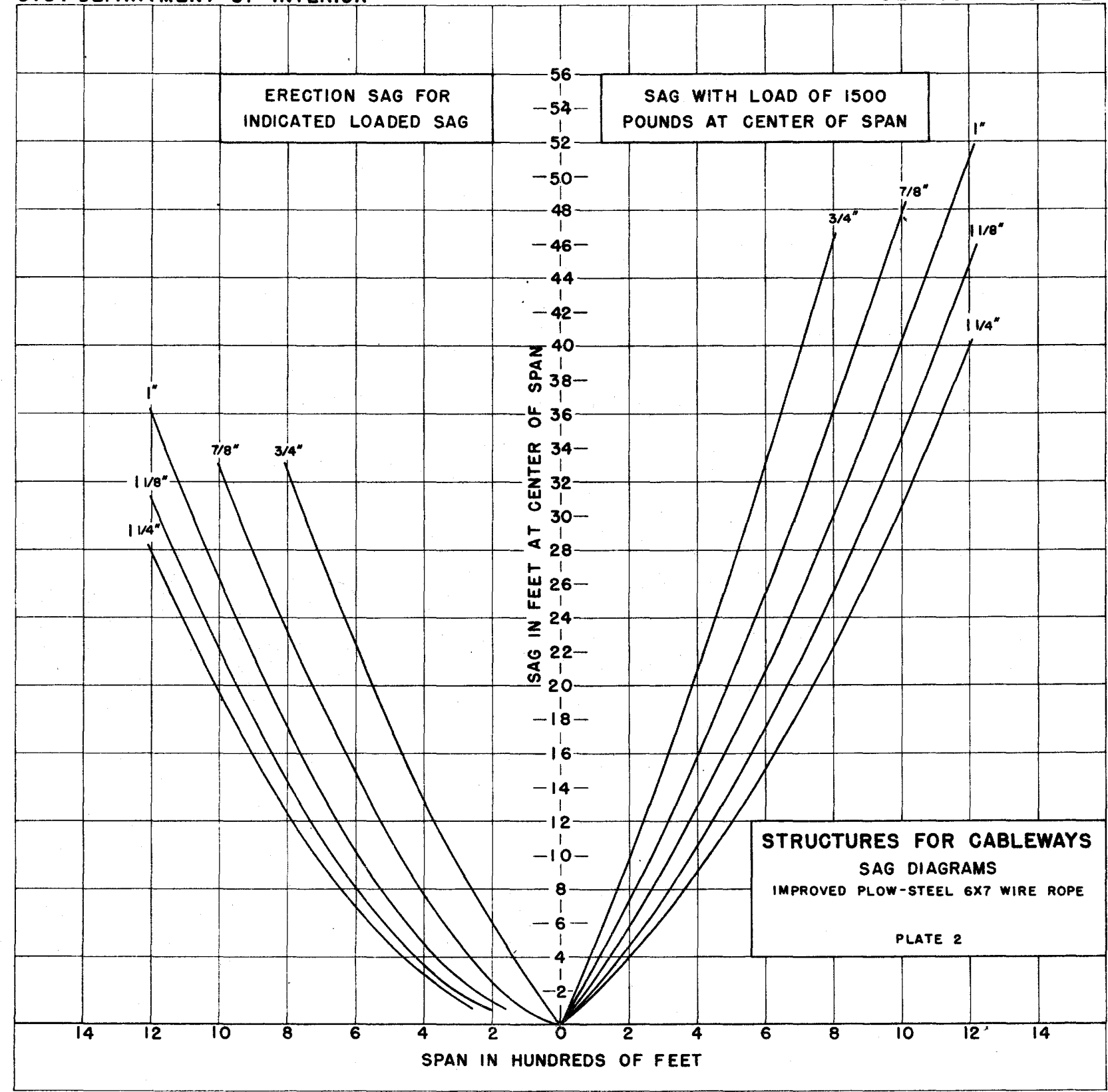




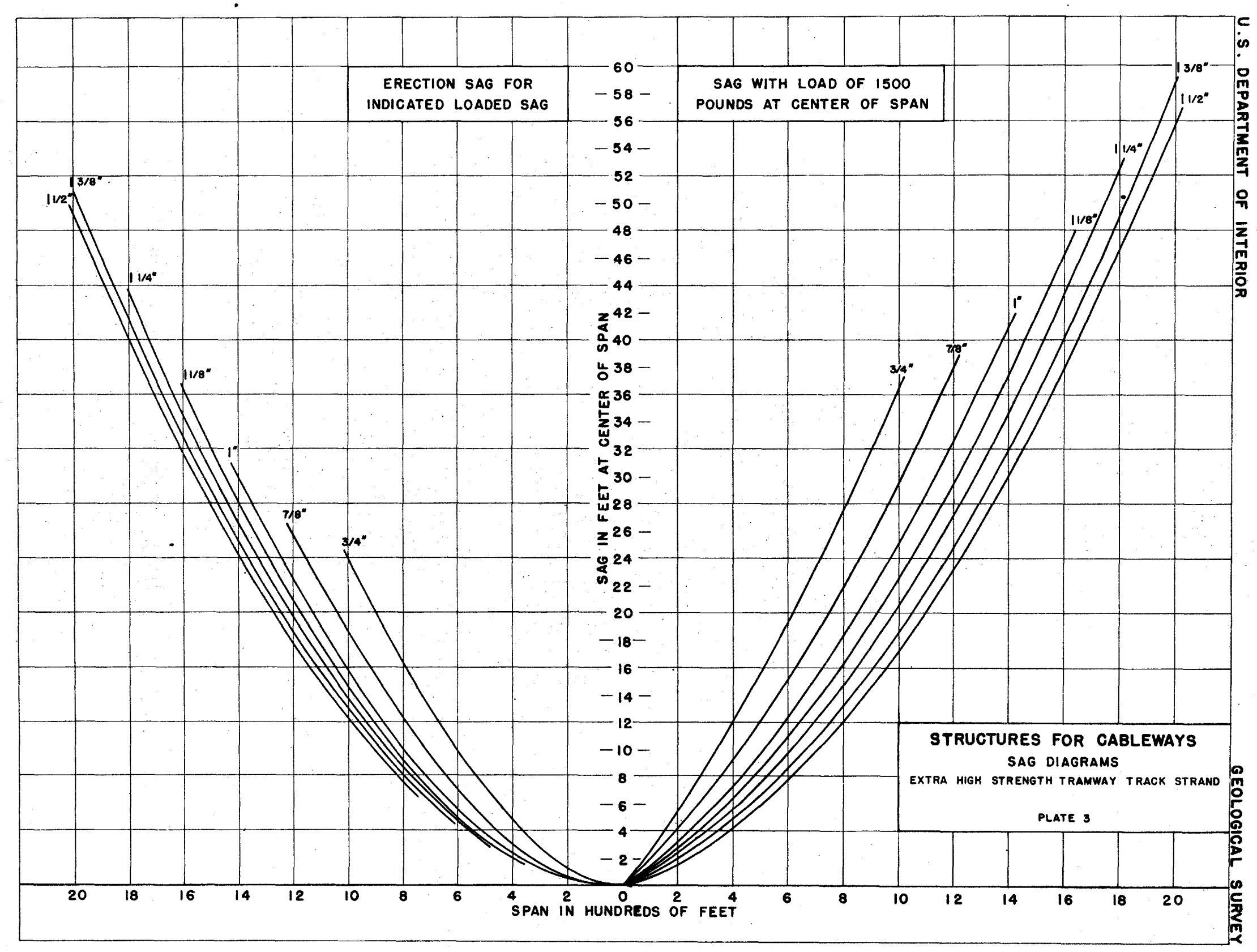


when the loads are first applied and these changes result in what may be called "permanent stretch," the final adjustment of take-up to give the desired erection sag should be postponed until heavy loads have been applied and removed. For wire ropes with turnbuckles, the turnbuckles may be tightened beyond the designed position and then slackened off to the position that gives the correct sag. It may be desirable to make an allowance for the permanent stretch when placing the turmbuckles or bridge sockets, unless the materlal has been subject to previous use or to a prestressing process.

The permanent stretch will vary with the kind of material and the nature of its construction and is greater for wire rope than for tremway track strand. Wire rope may be expected to have a stretch anywhere from 0.5 percent to 1.0 percent of 1 ts length, depending upon the method of fabrication and the conditions of loading. For light loads, such as the operation loads on cableways used for river measurements, an allowance of 0.005 times the length may be sufficient. This elongation is additional to the elastic elongation shown in equation ( 7 ).

A prestressing process that is offered by some wire rope compenies is desirable for tramway track strand as, by the prestressing process, a permanent stretch is given the strand and the modulus of elasticity is stabilized for working tensions that do not exceod the prestressing tension. It should be noted that the effects of prestressing diminish rapidly for tensions above that of the prestressing. For this reason, It is common practice to prestress tramway track strand to 50 percent of its ultimate strength in order that there may be a liberal margin to the prestressine effects. The length of time in wich the prestressing should be maintained varies with the material, but for tramway track strend one hour should be sufficlent.

Although prestressing of hemp-center wire rope for the purpose of stabilizing its modulus of elasticity is not generally practiced by wire rope compenies, the prestressing would be helpful in giving the rope a permanent stretch and thereby eliminete some of the uncertainties as to the loaded sag under operating conditions. For the prestressing of wire rope to be effective, it should be maintained for at least four hours at a tension of 40 percent of the ultimate strength of the rope.

The factory measurement of length (see p 24) should be made under a tension equal to that in the cableway when its erection sag is adjusted to the erection sag specified in the design. The length would then correspond to the length of the cetenary at the time of erection. The erection tension $F_{W}$ may be found from equation ( $1 Q$ ) where $D_{w}$ is the erection sag d that may be found from equation (8) or by the methods described on pages 17 to 20 .

Modulus of elasticity

As may be seen from equation (7), the elongation a varies inversely with the modulus of elasticity $\mathbb{E}$. Values of $\mathbb{E}$ for galvanized tramray track strand may differ as much as 15 percent, depending on the condition 
COMPUTATION OF ERECTION SAG FOR EXTRA HIGH STRENGTH TRAMWAY TRAGK STRAND

U.S. DEPARTMENT OF INTERIOR

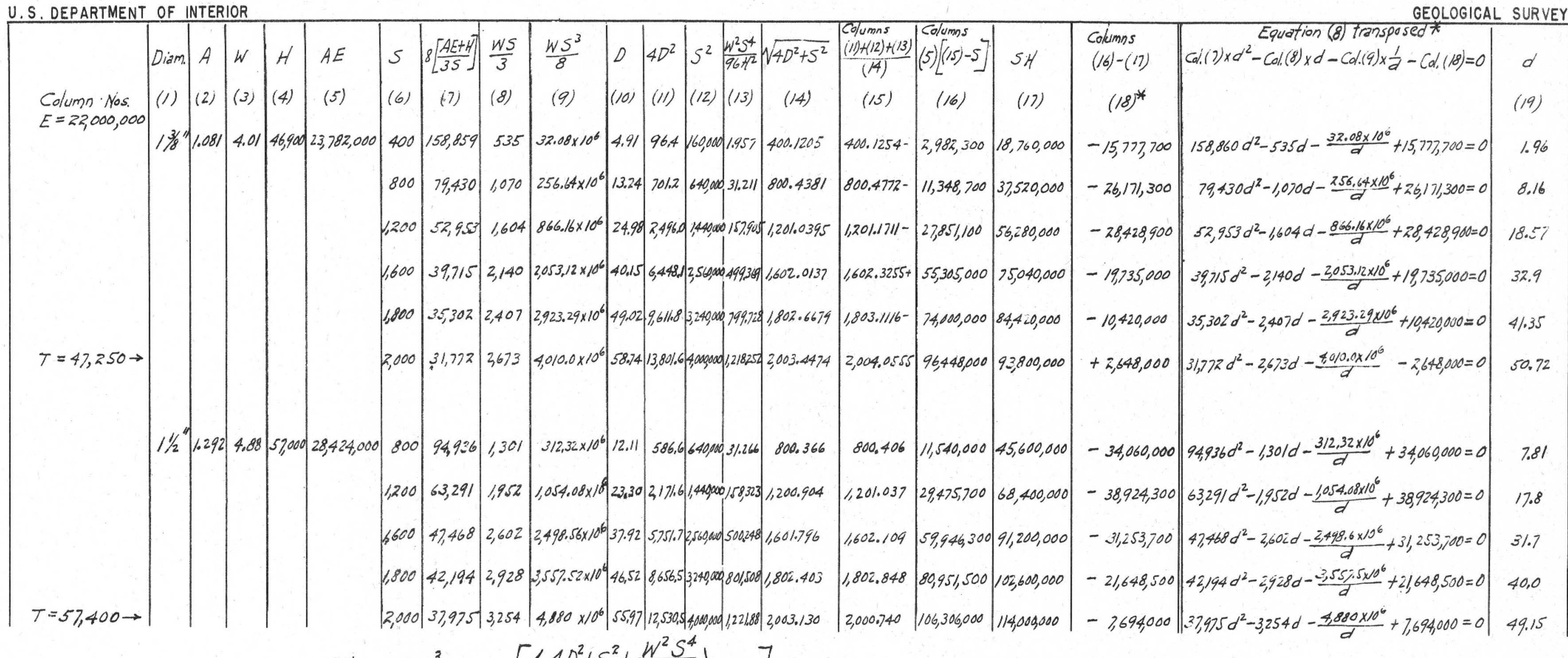

Equation (8): $\quad 8\left(\frac{A E+H}{3 S}\right) d^{2}-\left(\frac{W S}{3}\right) d-\frac{W S^{3}}{8 d}=A E\left[\left(\frac{4 D^{2}+S^{2}+\frac{W^{2} S^{4}}{96 H^{2}}}{\sqrt{4 D^{2}+S^{2}}}\right)-S\right]-S H$

* Col. (18) is the right-hand member of Equation (8).

STRUCTURES FOR CABLEWAYS

COMPUTATION OF ERECTION SAG

EXTRA HIGH STRENGTH TRAMWAY TRACK STRAND 
of the strand, and for wire rope the variation in $B$ may be as much as 20 percent. Values of $E$ ranging from 19,000,000 to 2\%,000,000 for tranway track strand and from $12,000,000$ to $14,000,000$ for $6 \times 7$ wire rope have been used in design. Because of the uncertainties, engineers of wire rope companies generally favor the lower values.

It should be noted that the erection sag a for a specific loaded sag $D$ increases somewhat with an increase in the assumed value of the modulus of elasticity. The difference in the erection sag d due to the se of $22,000,000$ instead of $20,000,000$ for $\mathrm{E}$ in the computations for

ns of 1,200 and 2,000 feet, using $13 / 8$-inch and $11 / 2$-inch extra high strength tremway track strand, is shown in table 3. A value of $22,000,000$ was used in the computations for plates 3 and 4 in the 1933 edition of "Structures from which discharge measurements are made" 8/ and also in the computations for plates 3 and 4 of this edition.

Table 3. --Erection sag a required for a specific loaded sag D for $\mathbf{E}=$ $20,000,000$ and 22,000,000. Wrtra high strength tramway track strand with safety factor of 4 .

$\begin{array}{lcccc}\text { Size of Spen } & \begin{array}{l}\text { Loaded } \\ \text { strand }\end{array} & \begin{array}{l}\text { Modulus of elasticity E } \\ \text { sag D }\end{array} & \begin{array}{c}\text { Difference } \\ \text { In d }\end{array}\end{array}$

\begin{tabular}{rrrrrr}
\hline Inches & Feet & Feet & Feet & Feet & $\begin{array}{l}\text { Feet } \\
7 / 8\end{array}$ \\
& 800 & 22.0 & 11.9 & 12.3 & 0.4 \\
$13 / 8$ & 1,200 & 25.0 & 18.4 & 18.6 & .2 \\
& 2,000 & 58.7 & 50.5 & 50.7 & .2 \\
$11 / 2$ & 1,200 & 23.3 & 17.7 & 17.8 & .1 \\
& 2,000 & 56.0 & 48.8 & 49.1 & .3
\end{tabular}

Erection $8 a g$

The erection sag a that should be given a wire rope or strand in order that the loaded sag $D$ and the maximum tension $T$ may not exceed the limitations of the given specifications can be determined by means of formulas representing the several factors that must be considered. For convenience in systematizing computations in the preperation of sag diagrams, the relations between the various forces and dimensions that produce static equilibrium in the loaded cableway may be represented by the following equation:

$8\left(\frac{A E+H}{3 S}\right) d^{2}-\left(\frac{W S}{3}\right) d-\frac{H S^{3}}{8 d}=A E\left[\left(\frac{4 D^{2}+S^{2}+\frac{W^{2} S^{4}}{96 H^{2}}}{\sqrt{4 D^{2}+S^{2}}}\right)-S\right]-S$ H... (8)

8/ Computations by C. H. Plerce, S. K. Jackson, and L. L. Harrold, July 1933. 
In equation (8) the fraction on the right hand side of the equation represents the length of a perabolic curve with the dead weight $W \mathrm{~S}$ replaced by W S sec $\varnothing$ to obtain a closer approximetion of the effect of

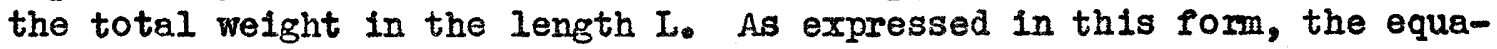
tion may not be as familiar to many engineers as are the equations containing trigonometric terms. In this equation, whlch is used after $H$ and $D$ have been determined, the only unknown quantity is the erection sag d. The fundamental relations in equation (8) are similar to those in equation $(8 a)$.

The diagrams in plates 2 and 3 that show the erection sag $d$ for a specific loaded sag $D$ were prepared by use of the ebove equation (8). The grouping of constants in the coefficients of $\mathrm{d}^{2}, \mathrm{a}$, and $\mathrm{d}^{-1}$ in the manner shown in plate 4 simplifies the work in making a series of computations. The solution is then made by substitution of trial values of $d$ until a value is found that satisfies the equation. Plate 4 shows the computations for the erection sag a for $13 / 8-$ inch and 1 1/2-inch extra high strength tramray track strand that are plotted in plate 3. It should be noted that the values given in these computations and diagrams correspond to the length between supports. The effective length $I_{1}$ would, of course, depend upon conditions at the site.

Sag diagrams are useful in preliminary computations, and values taken Irom them are often used in designs for short and medium-spen cableways. However, for spans of 1,000 feet and more, the computations should be made for the specific problem under consideration with proper allowance for the backlines and guys.

Formulas developed by Carstarphen 9/ have been applied to cableway computations with results in close agreement with those obtained by the use of equation (8).

In the application of the theory of elasticity to cableway problems, the erection sag a may be found by first determining the erection tension $H_{e}$ that satisfies the equation for elasticity stability expressed in the form:

$$
I-I_{\theta}=\frac{\left(H-H_{\theta}\right) I}{A E}=J\left(H-H_{\theta}\right) \cdot \cdots \cdot \cdots \cdot \cdot \cdot \cdot \cdot
$$

After finding the value of $\mathrm{H}_{e}$ that satisfies the above equation, the erection sag d can be detemined from the equation

$$
\mathrm{d}=\frac{W \mathrm{~s}^{2}}{8 \mathrm{H}_{e}}
$$

In the above nomenclature, $J$ is the elastic change in length for each pound of change in tension and $I_{\theta}$ is the length corresponding to the erection tension $\mathrm{H}_{e}$.

9/ Carstarphen, F. C., Aerial tramways: ASCE Trans., rol. 92, p. 875. 


$$
\begin{aligned}
& \text { As } I_{e}=S+\frac{w^{2} s^{3}}{24 H_{e}^{2}} \text {, the elastic relation may be expressed as } \\
& J H_{e}+I-(J H+S)-\frac{w^{2} s^{3}}{24 H_{e}^{2}}=0 \cdot \cdots \cdot \cdots \cdot \cdot \cdot \cdot \cdot(8 \mathrm{~b})
\end{aligned}
$$

I is a maximum when the load $P$ is at the center of the span and for that condition:

$$
L=2\left[s_{1}+\frac{w^{2}\left(\frac{S}{2}\right)^{3} \cos ^{3} \theta}{24 H^{2}}\right] \cdot \cdots \cdot \cdot \cdot \cdot \cdot(6)
$$

The above equation is for a level span where $S_{1}$ is the chord length from the center of span to the support and $\theta$ is the angle that the chord makes with the horizontal.

An application of this method to a $11 / 2$-inch tramray track strand with a clear span of 1,800 feet, assuming that the supports are rigid and fixed in fixed in position, is as follows:

$$
\begin{aligned}
& P=1,500 \text { pounds. } \\
& W=4.38 \text { pounds per foot. } \\
& A=1.292 \text { square inches. } \\
& D=46.52 \text { feet. } \\
& H=57,000 \text { pounds. } \\
& \mathbf{E}=22,000,000 \\
& s_{1}=\sqrt{\left(\frac{s}{2}\right)^{2}+D^{2}}=901.201 \text { feet. } \\
& \cos \theta=\frac{S}{2 S_{1}}=\frac{1,800}{1,802.402} \\
& =0.99866 ; \cos ^{3} \theta=0.9960 \\
& I=2\left[901.201+\frac{(4.88)^{2}(900)^{3}(0.996)}{24(57.000)^{2}}\right] \\
& =2[901.201+0.222]=1802.846 \text { feet. } \\
& J=\frac{I}{A E}=\frac{1,802,846}{1.292 \times 22,000,000}=0,000,063,43
\end{aligned}
$$




$$
\begin{aligned}
& J H=0.000,063,43 \times 57,000=3.6155 \\
& \frac{\mathrm{w}^{2} \mathrm{~s}^{3}}{24}=5,786,900,000
\end{aligned}
$$

Substitution of the above ralues in equation for elastic stability $(8 b)$ gives the following ecuation for $\mathrm{H}_{e}$ :

$$
0.000,063,43 \mathrm{H}_{\theta}^{3}-0.770 \mathrm{H}_{\theta}^{2}-5,786,900,000=0
$$

The solution of this equation gives a value of $\mathrm{H}_{\theta}$, to the nearest 10 pounds, as 49,450 pounds.

The corresponding value of the erection sag d is

$$
\mathrm{d}=\frac{\mathrm{iS^{2 }}}{8 \mathrm{H}_{e}}=40.0 \text { feet (to the nearest tenth of a foot), }
$$

which is the same as was obtained by the use of equation (8). (See plate 4).

In the determination of the erection sag where the conditions are known, the length $I_{1}$ should be used in place of $I$ in the formulas for elasticity. (See eq. 7) The stresses in the backlines for the angle $Y$ should also be investigated. (See page 2l).

The tiomulas given below are used by some engineers. They are somewhat simpler than those giren on pages 17-18, and give results sufficiently exact for most cases.

$$
\begin{aligned}
\Delta I & =\frac{H_{p} S}{A B}\left(1+\frac{16}{3} k^{2}\right) \\
\Delta D & =\frac{15 L}{16\left(5 k-24 k^{3}\right)} \\
d & =D-\Delta D
\end{aligned}
$$

A solution of the above problem, using the data given on page 18, is as follows:

$$
\begin{aligned}
& \mathrm{H}_{\mathrm{p}}=\frac{1,500 \times 1,800}{4 \times 46.52}=14,510 \mathrm{lbs} . \\
& \mathrm{k}=\frac{\mathrm{D}}{\mathrm{S}}=\frac{46.52}{1,800}=0.02584 \\
& \mathrm{k}^{2}=0.000,668 \\
& \mathrm{k}^{3}=0.000,017
\end{aligned}
$$




$$
\begin{aligned}
\Delta I & =\frac{14,510 \times 1,800}{1.292 \times 22,000,000}(1.0036)=0.922 \text { foot } \\
\Delta D & =\frac{15 \times 0.922}{16(0.129,2-0.000,4)}=6.71 \text { feet } \\
d & =46.52-6.71=39.81 \text { feet }
\end{aligned}
$$

which is about 0.2 foot less than obtained by the first two methods.

The value of $\triangle D$ may also be found directly from the equation:

$$
\begin{aligned}
\Delta D & =\frac{15 \mathrm{PS}^{2}\left(I+\left(\frac{16}{3}\right) \mathrm{k}^{2}\right)}{64 \mathrm{DAE}\left(5 \mathrm{k}-24 \mathrm{k}^{3}\right)} \\
& =\frac{73,162,440,000}{10,899,867,440}=6.71 \text { feot }
\end{aligned}
$$

As the elongation under load cannot be exaetly determined mathemat1cally because of the "permanent stretch" of the rope or strand that is mentioned on page 15, and some uncertainty in regard to the value of $E$, a cholce of the above methods of cormuting the erection sag may be made without any appreciable difference in accuracy. The smaller erection sag that is obtained by the last described method might be considered as providing some allowence for the permanent stretch, although the larger sag obtained by the first two methods would give a larger factor of safety.

\section{Supports at different elevations}

As 1 is is sometimes necessary or desirable for the supports to be at different elevations (see p. 4), the following additional terros and formulas are given for use in those clrcumstances.

$$
\begin{aligned}
\mathrm{h} & =\text { afference in elevation of supports, in feet. } \\
\mathrm{D}_{1} & =\text { total deflection at low point from the elevation of the highest } \\
\text { support. } & \\
& =\frac{\mathrm{S}(\mathrm{W}+2 \mathrm{P})}{8 \mathrm{H}_{1}}+\frac{\mathrm{h}}{2} \\
\mathrm{H}_{1} & =\frac{\mathrm{S}(\mathrm{W} \mathrm{S}+2 \mathrm{P})}{8 \mathrm{D}_{1}-4 \mathrm{~h}} \\
\beta_{1} & =\text { angle between the horizontal and the tangent to the curve at the } \\
\beta_{2} & =\begin{array}{l}
\text { angle between the horizontal and the tangent to the curve at the } \\
\text { lowest support. }
\end{array}
\end{aligned}
$$




$$
\begin{aligned}
& \tan \beta_{1}=\frac{W S+P}{2 H_{1}}+\frac{h}{S} \\
& \tan \beta_{2}=\frac{W S+P}{2 H_{1}}-\frac{h}{S} \\
& T_{1}=H_{1} \sec \beta_{1}=\text { maximum tension at highest support. } \\
& T_{2}=H_{1} \sec \beta_{2}=\text { maximum tension at lowest support. }
\end{aligned}
$$

A mathematical treatment of the condition of supports at different elevations from which the above equations may be derived has been given by Carstarphen 10/.

An approximate method for the solution of cableway problems where the supports are at different elevations has been published by Pittman 11/.

Tension in backlines

The total tension in the backlines from the support to the anchorage is $\mathrm{H} \mathrm{sec}$ where is the angle between the backline and the horizontal. This load should be investigated and back guys provided for insuring the stability of the support and for taking the excess load so that the tension in the rope or strand between the support and the anchorage will not exceed the allowable tension $T$ in the main span.

Where pin-and-socket connections are used at the supports, as indicated in the plans for steol A-frames (pls. 14 to 18), a larger-size strand nay be used for the backline so that the factor of safety will not be reduced.

Bending moment in towers and A-frames

Becruse of the conditions of loading at the supports and the difference in the angles $\beta$ and $\gamma$, a bending moment may be developed in the supports. These stresses may be investigated by graphical methods and the best position for a back guy selected. The stresses due to wind load should also be investigated (seo p. 6 ).

The computations up to this point do not teke in consideration the effect of changes in temperature as that subject can be treated more satisfactorily as a separate problem.

Ffect of changes in temperature

The change in length of a cableway and the corresponding change in sag due to change in temperature should be considered after completing

$10 /$ Carstarphen, F. C., op. cit., p. 917.

II Pittman, Harrison $\nabla_{\bullet}$, Construction cableways on Norfolk Dam. Fngr. News-Record, December 27, 1945, p. 67 . 
the provisional computations of length and sag. The inmediate effect of a change in temperature, say from a temperature of 0 degrees $F$ to a temperature of 100 degrees $F$, would be a change in length ( $(\Delta I)$ of $\epsilon$ It where $f$ is the temperature coeficicient and $t$ is the change in degrees $F$, so that there would be a tendency for the wire rope or strand to assume a new length that differed from the previous length by $\epsilon$ It. If the cablewey was Iree to take this new length under its own meight, a rise of 100 degrees in temperature and \& value of $0.000,006,6 \mathrm{12} /$ for $\epsilon$ would change a length of 800.51 feet along the catenary to a length of 801.04 feet. However, with the increase in the length ond the resulting increase in the sag, there would be a decrease in tension that would tend to limit the change in length and would affect the sag accordingly.

From the theory of elasticity and the formulas for length and saf of cableways, an equation for $\Delta d$, the change in the sag d due to a change in temperature, was developed by the writer and was used by him in the computations for the diagrams shown in plate 5 of the 1933 edition of "Structures from which discharge measurements are made." For convenience in the computations, the equation was arranged to show the following relations :

$\frac{8 d}{3 S}(\Delta d)^{3}+\frac{8 d^{2}}{S}(\Delta d)^{2}+\left[-I \in t d+\frac{16 d^{3}}{3 S}+\frac{1 S^{2} L}{8 A}\right] \Delta d-I \in t d^{2}=0 \ldots(9)$

The application of equation (9) to a definite set of conditions is shown in the solution of the following problem, using a safety factor of 4.

Assume that a $7 / 8$-inch improved plow-steel tramray track strend has been selected for use at a clear span of 800 feet. The supports are to be at the same elevation and hinged at the base. The backlines from the tops of the supports to the anchorages have a total length of 100 feet. The data are as follows:

$$
\begin{aligned}
& S=800 \text { feet. } \\
& W=1.69 \text { pounds per foot. } \\
& P=1,500 \text { pounds. } \\
& A=0.438 \text { square 1nch. } \\
& T=20,000 \text { pounds; } H=19,800 \text { pounds. } \\
& D=22.00 \text { feet by equation (2). } \\
& d=12.36 \text { feet by oquation }(8) . \\
& k=\frac{12.36}{800}=0.0154 \text { for the strand under } 1 \text { ts own weight. }
\end{aligned}
$$

12/ This value was used in computations for plate 5 of the 1933 pemphlet. A value of $=0.000,006,89$ for wire rope is used by some engineers. 


$$
\begin{aligned}
I_{e} & =800\left[1+\frac{8}{3}(0.0154)^{2}\right] \text { by equation }(5 a) \\
& =800.51 \text { feet for } \mathrm{d}=12.36 \text { feet. } \\
I_{1} & =800.51+100=900.51 \text { feet. Use } I_{1} \text { for } \mathrm{L} \text { in equation }(9) . \\
E & =22,000,000 .
\end{aligned}
$$

The procedure to be followed in the solution of equation (9) for the abore conditions is as follows:

First, determine the value of $L \in t d^{2}$ and the constants that are the coefficients of the terms containing the first, second; and third powers of $\Delta d$.

$$
0.0412(\Delta d)^{3}+1.528(\Delta d)^{2}+18.032(\Delta d)-90.797=0
$$
equation.

Next, ascertain by trial the value of $\Delta d$ that will satisfy the

$\operatorname{Try} \Delta \mathrm{d}=4:$

$$
2.64+24.45+72.13-90.80=8.42 ; \text { therefore, } 4 \text { is too large. }
$$

$\operatorname{Try} \Delta \mathrm{d}=3.6:$

$$
1.92+19.80+64.92-90.80=-4.16 \text {; therefore, } 3.6 \text { is too small. }
$$

Try $\Delta d=3.74:$

$$
2.16+21.38+67.43-90.80=0.17 \text {; this is very close. }
$$

Try $\Delta d=3.73$

$$
2.138+21.239+67.259-90.797=-0.161
$$

Therefore, the value of $\Delta \mathrm{d}$ is between 3.73 and 3.74 .

Another method of determining the change in sag due to a change in temperature has been described by Barmes 13/. Using the same problem and date given above, the method of solution makes use of two terms, $a$ and $b$, that may be described as follows:

$a=$ change in length due to change in ternperature alone, the tension being considered constent, = I $6 t . . . . . . . .$. (10)

13/ Barnes, B. S., assistent engineer, Portland distriot, "Solution of three problems in cable design." Unpublished manuscript (1935). 
$b=$ change in length due to change in tension elone; ( $a$ and $b$ are opposed in direction, but will be treated as positive quantities),

$$
=\frac{\Delta H_{\mathrm{L}}}{\mathrm{A} \mathrm{E}} \ldots \ldots \ldots \ldots \ldots
$$

Assume that $\Delta I_{1}=\Delta I=a-b$, and compute a oquation (10).

From formula $(5 \mathrm{~b})$ for the length of the aro of a parabola:

$$
I=\sqrt{s^{2}+(16 / 3) d^{2}} \text { and } d=\sqrt{(3 / 16)\left(I^{2}-s^{2}\right)} \ldots \ldots
$$

For the above problem, $a=900.51 \times 0.000,66=0.59$ foot change in length due to the change in temperature alone.

$\Delta I=0.59-b$; assume a ralue for $b$ and substitute the assumed value of $I+\Delta I$ for $I$ in oquation (12) to find a now cell this $d_{1}$ :

Compute $H_{w}$ by equation ( $1 a$ ). Substitute the relue of $d_{1}$ for $D_{w}$ in equation ( $(a)$ to obtain $H_{I}$; then $b=\left(H_{W}-H_{I}\right)$ I/AE by equation (II). If this equation is satisfied by the aseumed value of $b$, the difference between $d$ and $d_{1}$ is the change in the sag due to the change in temperature. Continue the use of trial values of $b$ until a value is found that satisfies the equation. After several velues have been tried in the above problem:

Try $b=0.237:$ then $\Delta I=0.59-0.237=0.353$;

$$
\begin{aligned}
& I+\Delta I=800.51+0.353=800.863 ; \\
& d_{1}=\sqrt{(3 / 16)\left[(800.863)^{2}-(800)^{2}\right]}=\sqrt{259.04}=16.10 \\
& H_{1}=\frac{1,081,600}{8 x 16.10}=8,400 . \\
& b=\frac{(10,940-8,400) 900.51}{9,636,000}=0.237 \text { as assuried. }
\end{aligned}
$$

Therefore, the change in sag ( $\Delta$ d) due to a ohenge of 100 degrees in temperature as computed by this method is $16.10-12.36=3.74$ feet, which is practically the same as was obtained by the method Iirst described.

\section{Measurement of length}

In the factoxy moasurement of length coxwesponding to a specifled tension (seo p.15) and a specified tempereture the procedure followed by some wire rope compenies is as follows:

If the specifled temperature coincides with the temperature at which the tape is calibrated, the specified tension is applied and the speciffed length is measured directiy, assuming that the wire rope or strand will have equal chenges in temperature under surrounding atmospheric conditions. If 
a different temperature is specified, a new length is computed in order to change the specified length to the length corresponding to the temperature at wioh the tape is callbrated and the measurement is then made as above.

It is customary to design the cableway for the lowest temperature that is Iikely to occur at the site and to compute the corresponding $\Delta d$ for the temperature at the time of erection. The tension and temperature at which the required length is to be measured should be spec1fied in the order to the manufacturer. In designing the supports, allowence should be made for a sag corresponding to the temperature specified in the requirement for clearance above low water if the stream is navigable and under the jurisdiction of the War Department.

\section{Factors of safety}

The factor of safety of a cablevfay structure, including that of the wire rope or tramway track strand, and the supports, footings, anchorages, and anchorage connections, should be large enough to provide ample protection against any unsuspected weakness of the material or possible working loads in excess of those used in the design. Because of the differences in the materials and methods of construction of the several component parts, it is logical to decide upon the individual factor of safety that should be allowed for each part after consideration of the uncertainties that may affect the material and loads applicable to that part.

With proper design and construction, the uncertainties affecting concrete anchorages and footings can be so reduced that a relatively small factor of safety beyond those ordinerily used in determining the allowable working stresses of the concrete and the steel reinforcement is needed. It is customary to design anchorages and footings for twice the working loads that may be anticipated, but with very favorable conditions where allowable bearing pressures and frictional resistances of the soll are known, the ratio of the design load to the working load may be taken as 1.5 .

A-fremes and towers that are constructed of galvenized light-weight structural shapes should be designed for twice the expected working loads and the allowable tensile stress used in the design should not exceed 16,000 pounds per square inch, although higher values are commonly used in the designs for heavy steel construction. The $1 / x$ ratio for columns and struts should not exceed 120 for mein compression members and 200 for bracing and other secondary members.

As may be seen from the weights listed in table 2, for the sizes of strand required for apans greater than 1,000 feet the weight of the strand between supports exceeds the concentrated load. Equation (1) shows that the relative importance of the dead losd in 1 ts effect on the design increases rapidly with the increase in spen and size of strand 
The practical limitation to the size of strand that can be economically used has been graphically demonstrated by various survey engineers 14/ who have called attention to the economic advantages to be gained in cableway construction, especially for long spans, by the use of a safety factor of four for tramway track strand with socketed connections instead of five as formerly specified. As is stated in that article, one purpose of a factor of safety is to insure against fallure due to indeterminate live loads. If the design is carefully made, and the loods and stresses are properly analyzed, there would seem to be little uncertainty beyond that incident to the material and its fabrication.

Ingineering practice, as shown by the literature on the subject and the experience of Survey engineers, Indicates that the use of one-fifth the breaking strength of galvanized improved plowrsteel wire rope and one-fourth the breaking strength of galvanized tramway track strand as the maximum allowable tension $T$, after an allowence of 10 pereent in each case for the effect of galvanizing, provides a reasonable factor of safety for the wire rope or strand if due consideration is given to all the forces acting on the structure.

Anchorage connections provided by the wire-rope compenies as accessories with orders for wire rope or tremway track strand are intended to be able to develop the full strength of the rope or atrand. However, as experience has shown that those connections are the places of greatest weakness in the structure, it is recommended that sockets, eyebars, turnbuckles, and anchorage rods be designed for a working load at least 20 percent greater than the allowable working load of the wire rope or strand to which the connection is made.

\section{Spec1fications}

In preparing specifications for cableway design and construction, consideration should be given to the conditions of the installation as well as to the loads and the nature of the material. If It is expected that the cableway will be continued in use as a permanent installation, as is the expectation for the installations on the Columbia River previously mentioned, it is a matter of business economy to see that every possible precaution is taken to obtain the best possible design consistent with good engineering practice and that the construction meets minimum standards in every respect. On the other hand, if the conditions warrent only a temporary installation, or if the region is remote from transportation facilities so that the costs of first-ciass construction will be prohibitive, it mas be allowable to design struetures of a less permanent nature with a view to replacement after a fer years if a noed for their continued use is then apparent. Howerer, it 18 well known that a gaging station intended as temporary may continue in use for many years if it is found that a long-time record of strean flow at that place is needed.

14/ Engineers in the Portland and Tacoma distriets, unpublished manuscript (1934). 
Under no circumstances should the expected temporary nature of the installation or its remoteness from transportation facilities be considered as justiflcation for a design or construction that will not be safe for the users of the cableway. The safety of the engineer workinj in a remote place is of even greater importance than his safety when working near a much-travelled highway, and he should be fully as safe on a temporary installation as he is on an installation designed for long-time use.

\section{Anchorage connections}

Anchorage connections include the sockets, ejebars, turmbuckles, rods, and pins that transmit the tension fron the wire rope or strand to the fixed anchorage. As previously mentioned (page 9 ), the difference in the physical properties of wire rope and tramway track strand suggest the use of different methods of connection to the anchorages, these methods are the thimble-and-clip connection for wire rope and the socket connection for tranway track strand. The socket connections that are required for the track strand may likewise be used for wire rope.

No welds should be permitted on any perts of eyebars, anchorage rods, turmbuckles, or the take-up bars of sockets. The specifications should require that each of the individual parts that enter into the finished product, such as the oye and bar of a turmbuckle, shall be forged in one piece. Although welded connections may be made that will develop the full strength of the bar or rod, positive assurance is not readily available as to the efficiency of an individual weld. The required minimum breaking strength of the finished eyebar or anchorage rod should be specified by the purchaser.

Field experience has show that particular care is necessary in the selection of material for anchorage connections and in the heat treatment incident to their fabrication. For spans of unusual length where the eyebars, rods, and other connections are to be forged to meet specific requirements the following procedures are applicable:

1. The specifications should call for a steel suitable for forging and of a known origin for which physical and chemical analyses aro available. Its composition should be similar to S. A. E. 1040 or to that used for bridge eyebars as described by Bain and Ilewellyn 15/.

2. In case of doubt as to the quality of the steel that is offered, physical and chemical tests of specimens taken from the bars should be required.

15/ Bain, I. C., and Ilewellyn, F. T., Low-alloy structural steels: ASCE Trans., vol. 102, pp. 1240 - 1256. 
3. After completion of all forging operations, that portion of the bar which has been forged should be relieved of internal stresses due to heating and shaping by reheating to about 1,600 degrees F. and allowing it to cool slowly in air.

4. If the fabricated bar or assembly is to be permanently subjected to the full load of the cableway, it should be given a tension test under a load that is twice the maximum design load.

Thimble-and-clip connections.

The connections between the wire rope and the turnbuckles and between the turnbuckles and the anchorages for the sizes of wire rope commonly used for cableways are generally made by means of thimbles and clips; the size of thimble and number of clips that should be used for various sizes of wire rope are listed in the catalogues of wire rope compenies for the types of clip furmished by them. The number of clips for each rope end should be at least five for $3 / 4$-inch diameter rope with a minimum spacing of 5 inches between clips and six for 1 -inch diameter rope with a minimu specing of $61 / 2$ inches. The precautions that should be observed in making a thimblo-and-clip connections are as follows:

1. Before cutting a wire rope wind both sides of the contemplated cut with wire to prevent the strands from separating or the individual wires from spraying loose.

2. Always use a thimble of the proper size in the loop of the rope except when the rope is carried around a bar or rod of a diameter equal to or greater than the size of a thimble.

3. Place the free end of the rope a distance from the center of the $100 \mathrm{p}$ as determined by the number of cllps and the required spacing and fasten the thimble in its proper positions in the loop with temporary wiring.

4. With the thimble held in position, slip it over the free end of a bar or rod and bend the loop into place around the thimble, then add additional temporary wiring around the loop at the open end of the thimble.

5. Have the desired number of clips at hand ready to apply. The first clip to be placed is that farthest from the loop. Thls clip should be about six inches from the end of the rope and should be turned up tight when it is first put on. The threads in the bolts and nuts should be ofled before the clips are applied. (Some engineers prefer to apply the clip nearest the loop first, in place of the temporary wiring).

6. The clip nearest the loop should be put on next. This clip should be four inches from the thimble and should be only partially tightened at first. 
7. Add the additional clip or clips so that they will be equally spaced at the specified minimum distance apart between the first two. Before completely tightening the second and the subsequent clips place some stress upon the rope to take up the slack and equalize the tension on all the clips.

8. Tighten the nuts on all the clips unfformly, alternating with a few turns on each until all are tight.

9. Clips should be put on straight, without twist or crookedness, and in true alinement. It is important that the "live" or long rope rest upon the broad bearing surface of the base of the clip with the U-bolt bearing against the "dead" or short end of the rope. All of the clips should be applied in this way.

10. After the load has been applied the nuts should be tested and possibly tightened again, as the adjustment of the strands under load may change their position slightly. The tests should be repeated from time to time after the cableway has been put into use.

The thimble-and-clip connection is easy to make and is constantly exposed to view where it is subject to easy inspection, but its efficiency may be only 85 percent or less 16/. Two turmbuckles that were tested for the Geological Survey at the Bureau of Standards in 1915 both broke at less than the specified minimum breaking strength, the ratio of the actual to the specified breaking strength being 82 percent for the 1 -inch turnbuckle and 91 percent for the $11 / 2-1$ ch turmbuckle. If the wire rope is one inch or larger in diameter, the socket connection would be preferable.

Sockets

Connection sockets for use on tramway track strand are of four kinds: (1) open sockets without take-up, (2) closed sockets without take-up, (3) open bridge sockets, and (4) closed bridge sockets. For the connections of the main spen and the backlines to the pins at the tops of steel A-f ranes having hinge-pin connections at the base, sockets without take-up are preferable. Those on the main span should be closed sockets and those on the upper ends of the backlines should be open sockets. Bridge sockets with the specifled take-up should be used at the anchorages, open briage sockets generally being preferred although their cost is somewhat greater than the cost of closed bridge sockets. The possibility of fatigue due to vibration at socket connections has been mentioned on page 11 .

As the lengths are measured to the outer faces of the sockets when they are assembled at the factory, an allowance should be made for the distances from the faces of the sockets to the connection pins when specifying the length to be purchased. The dimensions of standard sockets are given in catalogues of the wire rope companies.

16/ Committee on Rules and Regulations for Metal Mines, Bureau of Mines Bulletin 75, p. 121, lst ed. 1915. 
The factory installation of sockets is recomended end is generally specifled, although it hes been found by laboratory tests that, with the proper tools and correct methods of procedure, field Installations of sockets can be made that will develop the full strength of the strand 17/. Imphasis should be placed on the necessity for correct procedure in the field installation of sockets, especially in the method of seizing the ends of the strend and in pouring the zinc spelter. These methods are described in the catalogues of the various wire rope manufacturers and elsewhere 18/. Field installation of sockets should be attempted only by those having the proper equipment and experience in such work. This is especially important in the case of tramway track strand where the bonding area between the wires and the zinc spelter is less than it is for. the larger number of smaller-size wires in wire rope.

Take-up at socket connections

A Ilberal allowance should be made in the take-up at each socket connection so that any necessary adjustment can be made to obtain the correct sag or to allow for a small inaccuracy in length. An unexpected amount of stretch in the wiro rope or strand may require a corresponding take-up. If there is some uncertainty in the measurement of the span the erection should be made at one-half of the total take-up after which the sag can be adjusted as desired. For a span of 1,000 feet, a take-up of 48 inches at each anchorage connection is not unusual. A careful measurement of the span, as mentioned on page 5 , will assist in the deternination of the length to be specified.

The eye-bars for open bridge sockets and U-bars for closed bridge sockets ordinarily listed by the wire rope campanies may not have as much take-up as is desired for the cableway instellation, therefore, it may be necessary to order special eye-bars or U-bars. Those orders should specify that the eye-bars or U-bars with a specified take-up are to be forged in one piece, without welding.

The hole in the head of the eye-bar should be 1/32 inch larger than the pin of the open bridge socket.

\section{Gelranizing}

Galvanized wire rope and strand have the individual wires protected by a coating of commercially-pure zinc. The specifications should require all tramway track strand, wire rope, or other material used in cableways, guys, or anchorage connections, and also all sockets, pins, bolts, eyebars, U-bars, and turnbuckles to be galvanized by the hot-dip process. The galvanizing to consiat of a continuous coating of comorcially-pure zinc of uniform thickness applied so that it adheres fimly to the surface of the indiridual wires, pins, or bars. The coating to be of first-class commercial quality and free from injurious defects. It is to be nonpeeling and non-crecking, and shall have sufficient toughness to resist weathering and corrosion.

17. Unpublished report on "Tield installation of sockets on tramway cables," by F. C. Ames. 1938. 18/ Committee on Rules and Regulations for Metal Mines, op. cit., p. 121. 
Although the individual fittings, except for threaded connections, may be sufficlently protected by an occasional coat of paint, the longtime use of most cableway installations warrents a correspondinglypermanent method of protection.

\section{Anchorages}

Anchorages should be designed to safely withstand any and all loads that may be transmitted by the cableway comnections. For purposes of design, these loads are conmonly taken as twice the working loads of the cableway and the supporting structures and connections, although a lower ratio may be used for exceptionaliy good conditions (see p. 25). It should be noted that the load transmitted to the anchorage from the cableway is $\mathrm{H}$ sec $\gamma$ where $\gamma$ is the angle between the backline and the horizontal. If the wire rope or tramway track strand of the cableway is continuous over saddle supports and additionel guys are used for the towers or A-fremes, it may be found desirable to compute the Individuel loads and to design the enchorages on the basis of those computations. For long spans and high towers, wind and ice loads should be considered in the design of towers and footings (see "Loads," p. 5 ). Reinforced-conerete anchorages are recormended for all permenent installations.

\section{Design}

The following requirements should be observed in the design of reinforced-concrete anchorages.

1. Weight of concrete is taken as 150 pounds per cubic foot.

2. The strength of concrete in compression is assumed to be 2,000 pounds per square inch at 28 days. Allowable working stress, 500 pounds per square inch.

3. The coefficient of friction between concrete and earth may be safely assumed as 0.40 for ordinary soll but if the concrete rests on clay or shaley material, a smaller coefficient should be used. For medium to coarse gravel, a coefficient of 0.50 is allowable. The following statement is given by Hanna 19/:

The coefficient of friction of concrete on masonry or masonry on rock generally varies from about 0.60 to 0.75 , for concrete on concrete it is about 0.60 to 0.70 , for concrete on gravel about 0.60 , for concrete on sand about 0.40 , and for concrete on clay or shale about 0.33. Adhesion of the concrete to bedrock, earth and rock above the plene of contact, and roughness of the foundetion bringing shear into play greatly increases resistance to sliding.

19/ Hanna, Frank W., The Design of Dams, p. 1. 1931. 
4. The U-bars should be embedaed in the concrete for a distance not less than 30 times thelr diemeter and shouid have 6 -inch hooks at the ends.

5. Longltudinal and trensverse reinforcement should be such as will properly transmit the loads into the anchorage.

6. The connection at the anchorage chould be open to inspection and well drained.

7. The front face of concrete anchorages should be placed against undisturbea earth without beckf11l of any kind along this surface. This is especially necessary where the passive resiatance of the earth in front of the concrete is considered in the design.

8. The U-bars should be set in the direct line to the cableway support so that there will be no bending moment at the anchorage connection.

Designs for reinforced-ooncrete anchorages that were originally prepared in the Columbus district office for use with tramway track strand cableways having a safety factor of five are shown in the following illustrations:

Plate 5. Anchorage for 3/4-inch cebleway.

Plate 6. Anchorage for 7/8-inch cableway.

Plate 7. Anchorage for 1-inch cableway.

Plate 8. Sidehill enchorages.

In the above designs, an increase in the allowable working load in the tramway track strand corresponding to a factor of safety of four instead of five gives an increase in the horizontel soll pressure for maximum loads. Therefore, the retio of the design load to the working load is somewhat less than two (see p. 25). If the anchorage is subject to submersion, a special design should be made.

A T-type anchorage that has a transverse orosebeam of reinforced concrete into which the load is transmitted by the U-bar connections that extend through a square conorete stem is more econcmical of material than those shown in the above desiens, but the forms are more expensive. For the T-type anchorage, the top of the transverse crossbeam is placed about four feet below the ground surface or at a sufficlent depth to obtain satisfactory bearing conditions. A design of a T-type enchorege for a 3/4 -inch extra high strength tramway track strand that has been used in the Tecoma district is shown in plate 9.

Unless otherwise specified, the design and construction of reinforced-concrete anchorages should be in accordence with "Reconmended Practice and Standara Specifications for Concrete and Reinforced Concrete" as given in Proceedings ASCE, No. 6, Part 2, June 1940. 

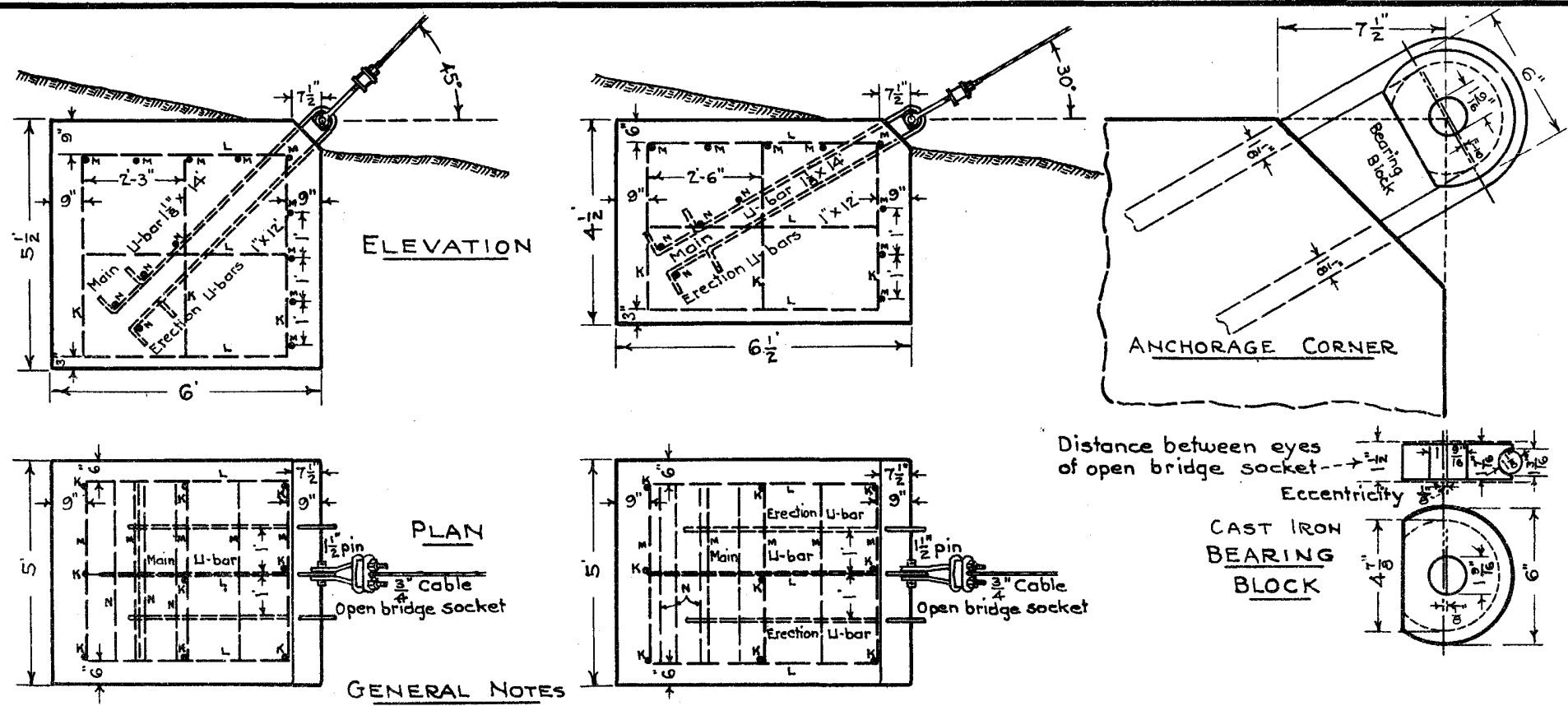

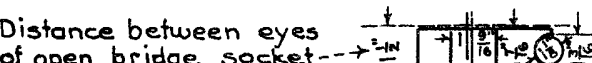

open bridge socket - $\rightarrow-1+10$

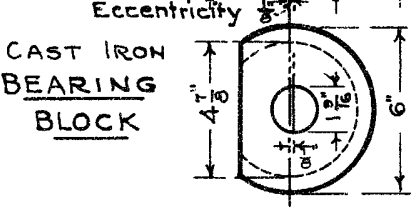

1. Coefficient of friction between concrete and earth ossumed 40

2. Concrete strength assumed 2,000 lb/in²@ 28 days. Use of some clean local material is permissible it strength is not decreased.

3. Any open space, between vertical sides of anchor and adjacent earth, should be carefully filled and well tamped or puddled before load is applied

4. Connection between cable and anchorage should be open to inspection and well drained.

5. Where soil conditions are poor use larger anchorage or bury anchor deeper.

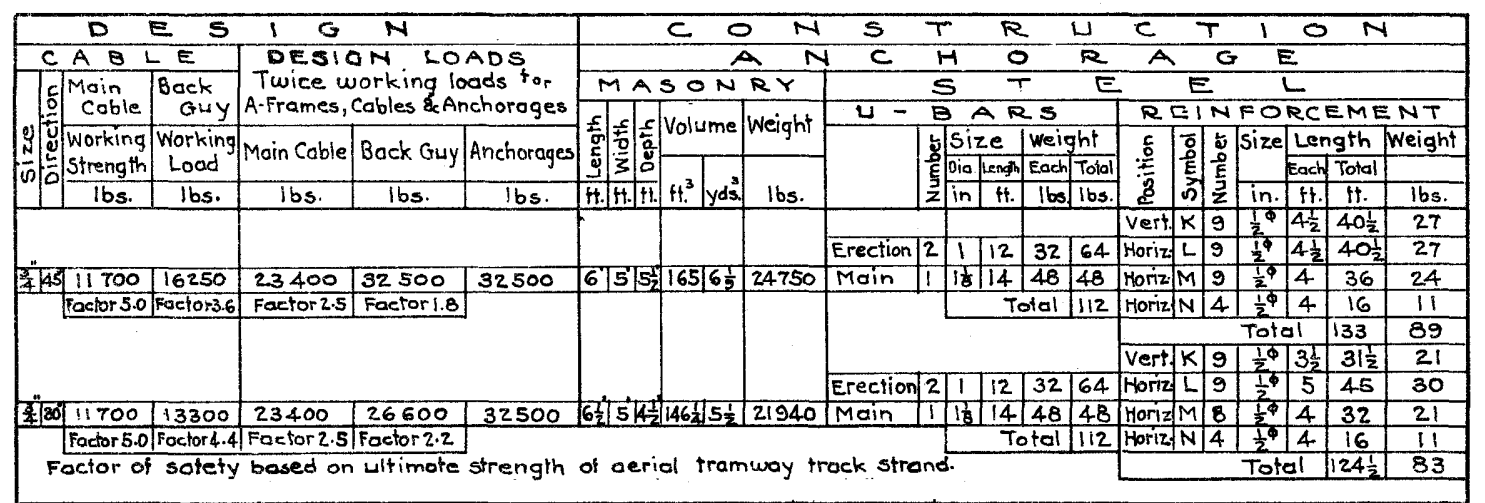

STRUCTURES FOR CABLEWAYS

ANCHORAGES FOR $3 / 4-I N C H$ CABLEWAY

Designed in Columbus District

PLATE 5 

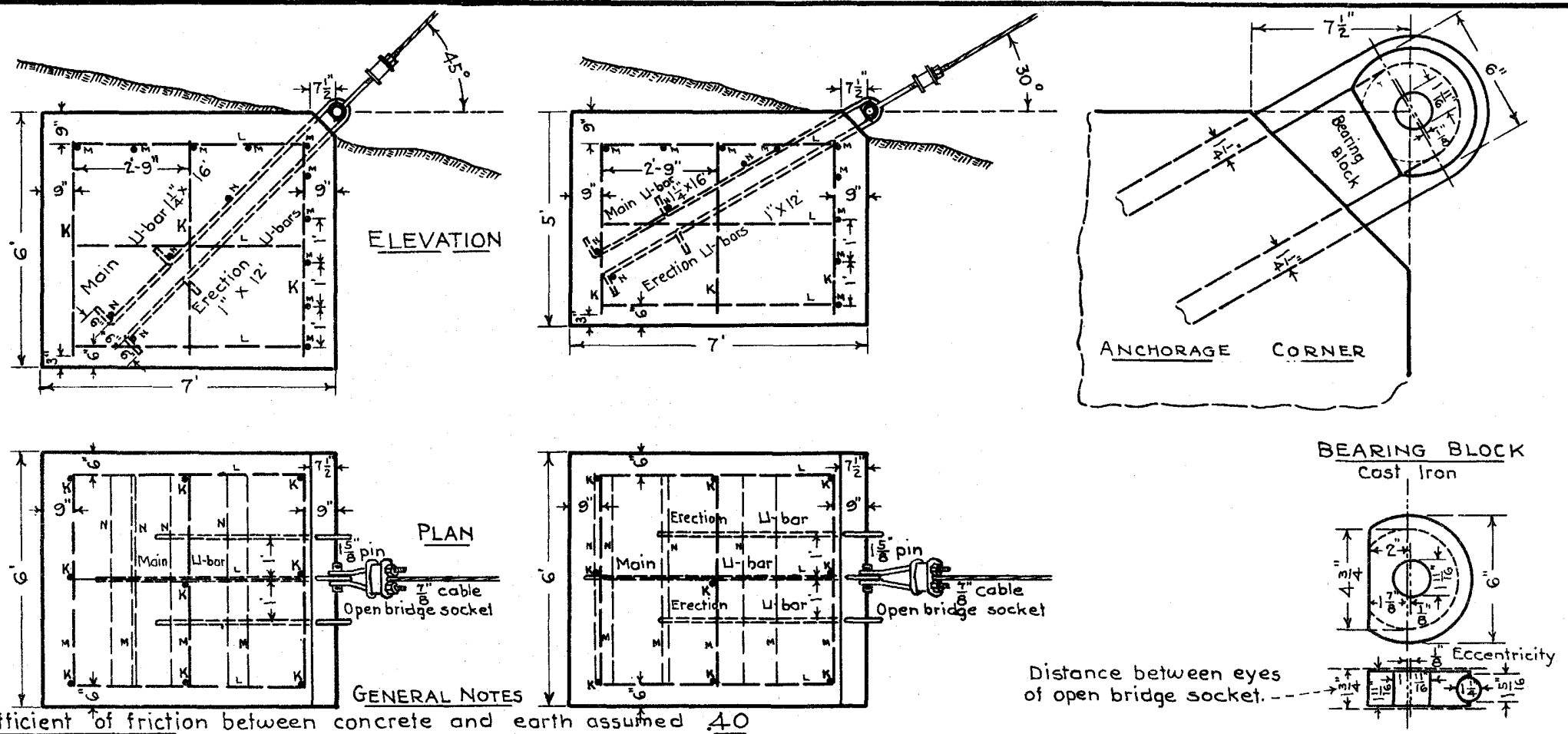

1. Coefficient of friction between concrete and earth assurined 40

2. Concrete strength ossumed $2000 \mathrm{lb} / \mathrm{in}^{2} @ 28$ days. Use of some clean local material is permissible if strength is not decreased.

3. Any open space, between vertical sides of anchor and adjacent earth, should be carefully filled and well famped or puddled before lood is applied.

4. Connection between cable and anchorage should be open to inspection and well drained.

5. Where soil conditions are poor use larger anchorage or bury anchor deeper.

\begin{tabular}{|c|c|c|c|c|c|c|c|c|c|c|c|c|c|c|c|c|c|c|c|c|}
\hline \multicolumn{6}{|c|}{$D \overline{E S}$} & \multicolumn{15}{|c|}{$\mathrm{CONS}$} \\
\hline \multicolumn{3}{|c|}{$C A B L E$} & \multirow{3}{*}{\multicolumn{3}{|c|}{$\begin{array}{l}\text { DESIGN LOADS } \\
\text { Twice working loads tor } \\
\text { A-rromes, cables ho Anchorages. }\end{array}$}} & \multicolumn{5}{|c|}{$N \quad C \quad H$} & \multirow{2}{*}{$\frac{0}{T}$} & \multirow{3}{*}{\multicolumn{2}{|c|}{$\frac{R}{E}$}} & \multirow{2}{*}{\multicolumn{3}{|c|}{$A_{E} G$}} & \multicolumn{4}{|l|}{$E$} \\
\hline & \multirow{2}{*}{$\begin{array}{l}\text { Main } \\
\text { coble }\end{array}$} & \multirow{2}{*}{$\begin{array}{r}\text { Bock } \\
\text { Guy }\end{array}$} & & & & \multicolumn{3}{|c|}{ MASONRY } & \multicolumn{2}{|c|}{5} & & & & & & & 느 & & & \\
\hline & & & & & & & & \multirow{3}{*}{ Weight } & $\omega=$ & \multicolumn{2}{|c|}{$B A R S$} & & & \multicolumn{7}{|c|}{ REINFORCEMENT } \\
\hline & \multirow{3}{*}{$\begin{array}{l}\text { Working } \\
\text { Strenglh } \\
\text { bs. }\end{array}$} & \multirow{2}{*}{$\begin{array}{l}\text { Working } \\
\text { Load }\end{array}$} & \multirow{2}{*}{ Moin Cable } & \multirow[t]{2}{*}{ Back Guy } & \multirow{2}{*}{ Anehorage } & \multirow{2}{*}{ 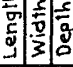 } & & & \multirow{3}{*}{ Use } & \multirow[b]{3}{*}{$\underline{z}$} & \multirow{3}{*}{$\begin{array}{l}\text { Size } \\
\text { Dia.jlonglh } \\
\text { in. ffi. }\end{array}$} & \multirow{2}{*}{\multicolumn{2}{|c|}{\begin{tabular}{|l|l|} 
Weight \\
Eoch Tolal \\
\end{tabular}}} & & & 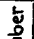 & size & Len & igth & Weight \\
\hline & & & & & & & & & & & & & & & & & & & Totol & \\
\hline 1 & & Ibs. & Ibs. & Ibs. & lbs. & 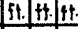 & A. ft. yds & Ibs. & & & & ibs. & lbs & & & $z$ & in & $f t$. & $f \phi$ & Ibs. \\
\hline & & & & & & & & & & & & & & Vert. & $x$ & 9 & $\frac{11}{2}$ & 5 & 45 & 30 \\
\hline & & & & & & & & & Main & & \begin{tabular}{l|l}
$1 \frac{1}{4}$ & 16 \\
\end{tabular} & 67 & 67 & Horiz. & $\mathrm{L}$ & 9 & + & $5 \frac{1}{2}$ & $49 \frac{1}{2}$ & 33 \\
\hline $8+45$ & 15,800 & 21950 & 31,600 & 43,900 & 43,900 & \begin{tabular}{l|l|l|l|l|}
7 & 6 & 6 \\
\end{tabular} & 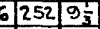 & 37,800 & Erection & 2 & \begin{tabular}{l|l}
12 \\
1
\end{tabular} & 32 & 64 & Horiz. & & 10 & $\frac{19}{3}$ & 5 & 50 & 34 \\
\hline & Factor 5.0 & Factor3.6 & Factor 2.5 & Factor 1.8 & & & & & & & & tol & 131 & Horiz. & $N$ & 4 & $\frac{14}{2}$ & 5 & 20 & 13 \\
\hline & & & & & & & & & & & & & & & & & & & $164 \frac{1}{2}$ & 110 \\
\hline & & & & & & & & & & & & & & Vert. & I & 9 & $\frac{1}{2}{ }^{\phi}$ & 4 & 36 & 24 \\
\hline & & & & & & & & & Main & & \begin{tabular}{l|l}
114 & 16
\end{tabular} & 67 & 67 & Horiz- & & 9 & $\frac{16}{2}$ & $5 \frac{1}{2}$ & $49 \frac{1}{2}$ & 33 \\
\hline$\frac{7}{6} \sqrt[30]{0}$ & 15,800 & 17,450 & 31,600 & 34,900 & 34,900 & \begin{tabular}{ll|l|l|}
77 & $6 / 5$ \\
\end{tabular} & $52107 \frac{3}{2}$ & 31,500 & | Erection & $\sqrt{2}$ & \begin{tabular}{l|l|}
1 & 12 \\
\end{tabular} & 32 & 64 & Horiz. & $M$ & 9 & $\frac{1}{2} \phi$ & 5 & 45 & 30 \\
\hline & Factor 5.0 & Factor 4.5 & Factor Z.5 & Foetor 2.3 & & & & & & & & Total & 131 & Horiz. & & 4 & & 5 & 20 & 13 \\
\hline & Fact & & & & & ri & 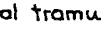 & n & & & & & & & & & & tol & $150 \frac{1}{3}$ & 100 \\
\hline
\end{tabular}

\section{STRUCTURES FOR CABLEWAYS}

ANCHORAGES FOR $7 / 8$-INCH CABLEWAY

Designed in Columbus District

PLATE 6 

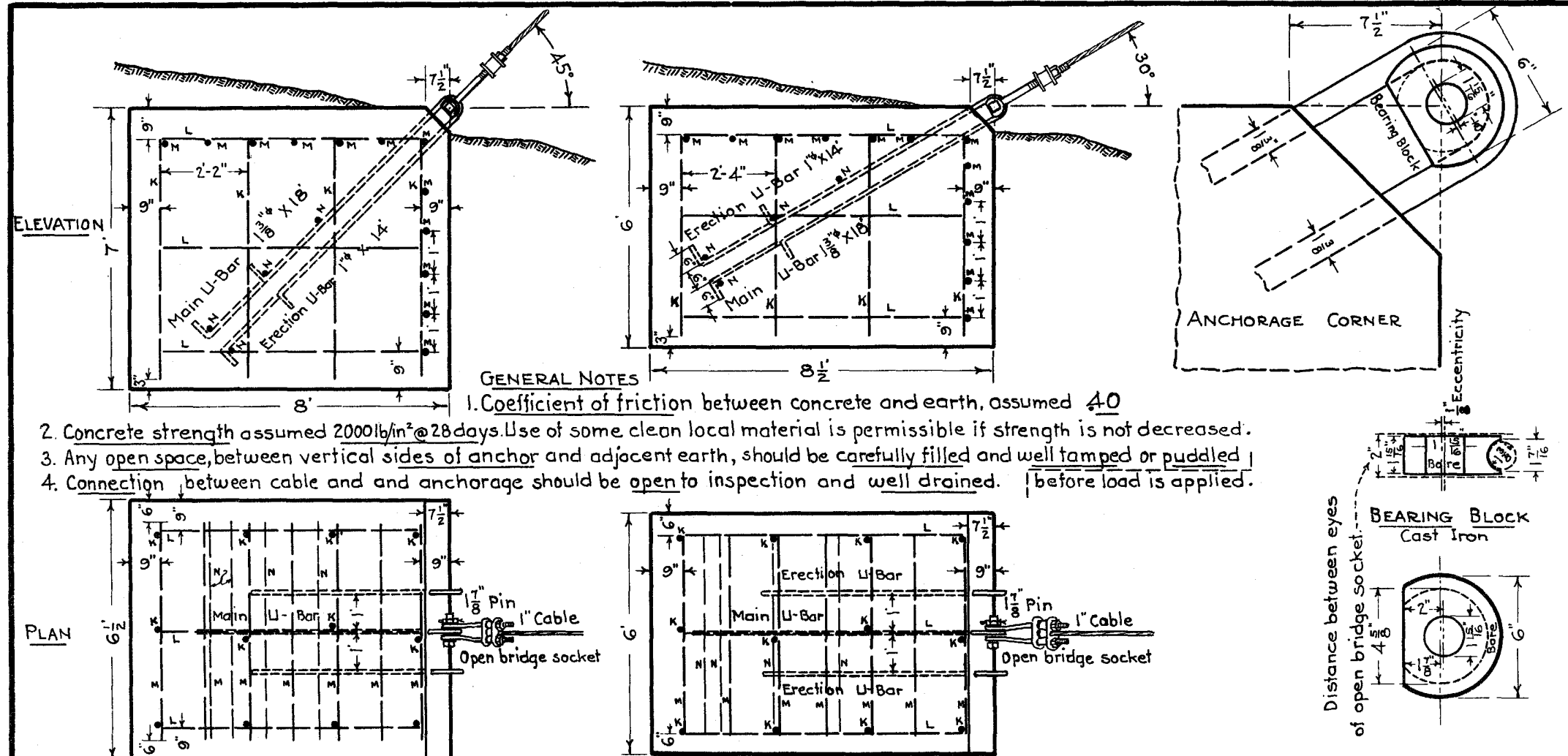

2 Concrete strength ossumed $2000 / \mathrm{l}^{2}{ }^{2}{ }^{28}$ doys. Use of some cleon local material is permissible if strength is not decreased.

3. Any open space, between vertical sides of anchor and adjocent earth, should be carefully filled and well tamped or puddled

4. Connection between cable and and anchorage should be open to inspection and well drained. before load is applied.
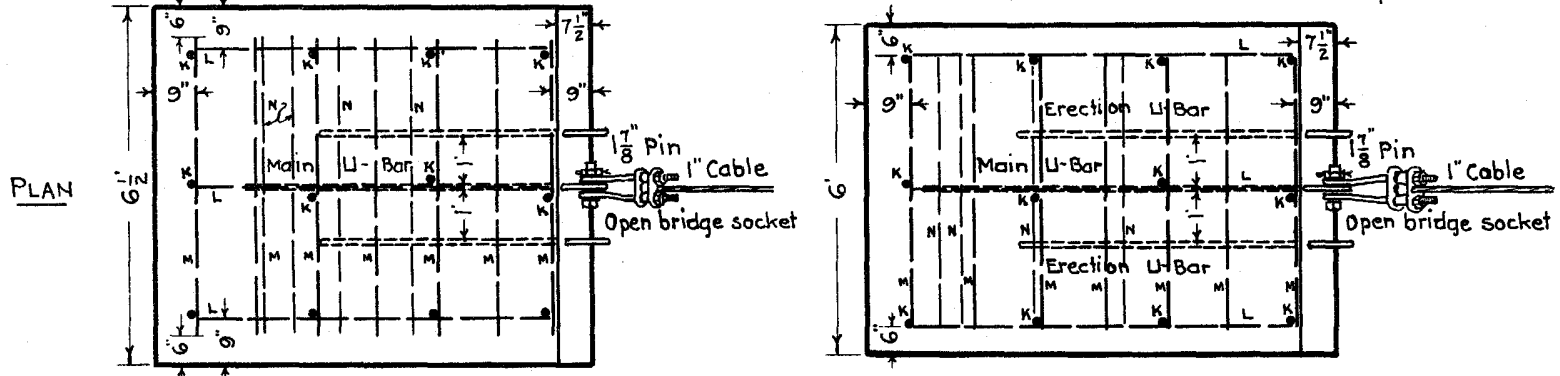

5. Where soil conditions are poor use larger anchorage or bury anchor deeper.

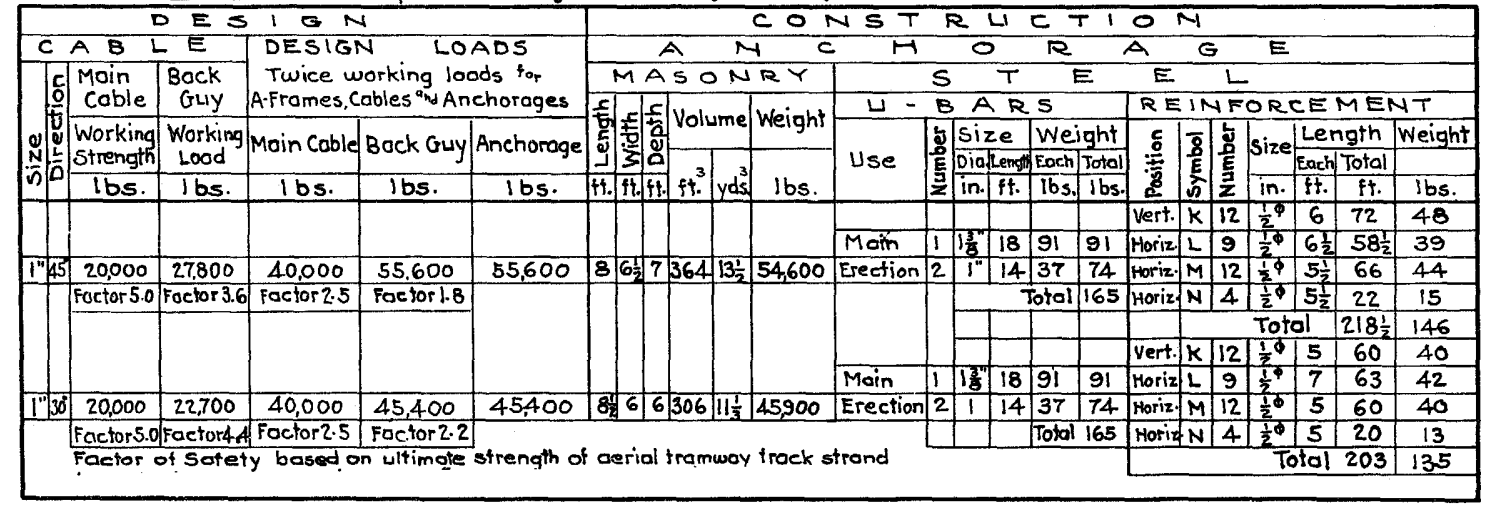

STRUCTURES FOR CABLEWAYS

ANCHORAGES FOR I-INCH CABLEWAY

Designed in Columbus District

PLATE 7 


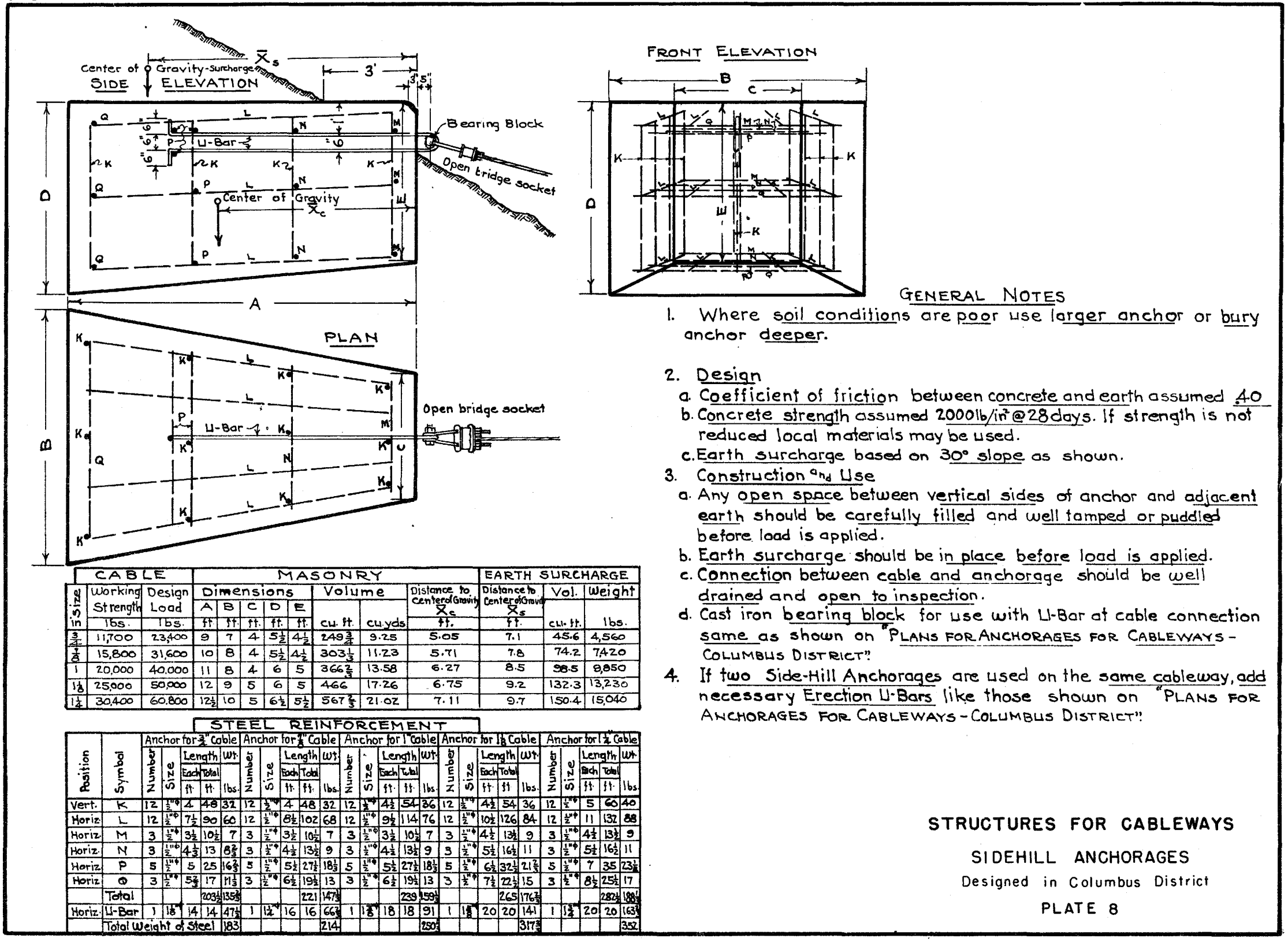



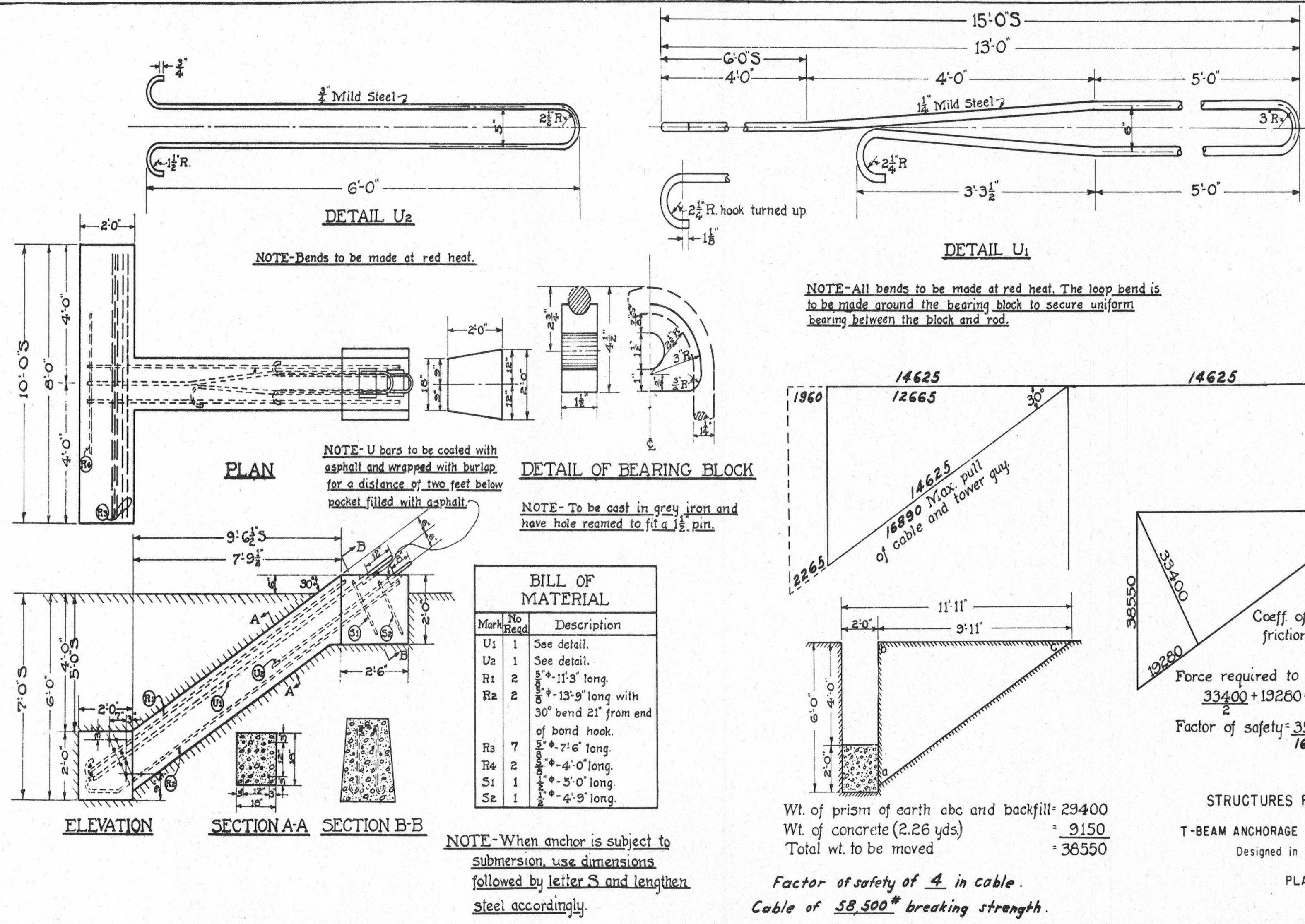

DETAIL $U_{1}$

NOTE-All bends to be made at red heat. The loop bend is to be made around the bearing block to secure uniform bearing between the plock and rod

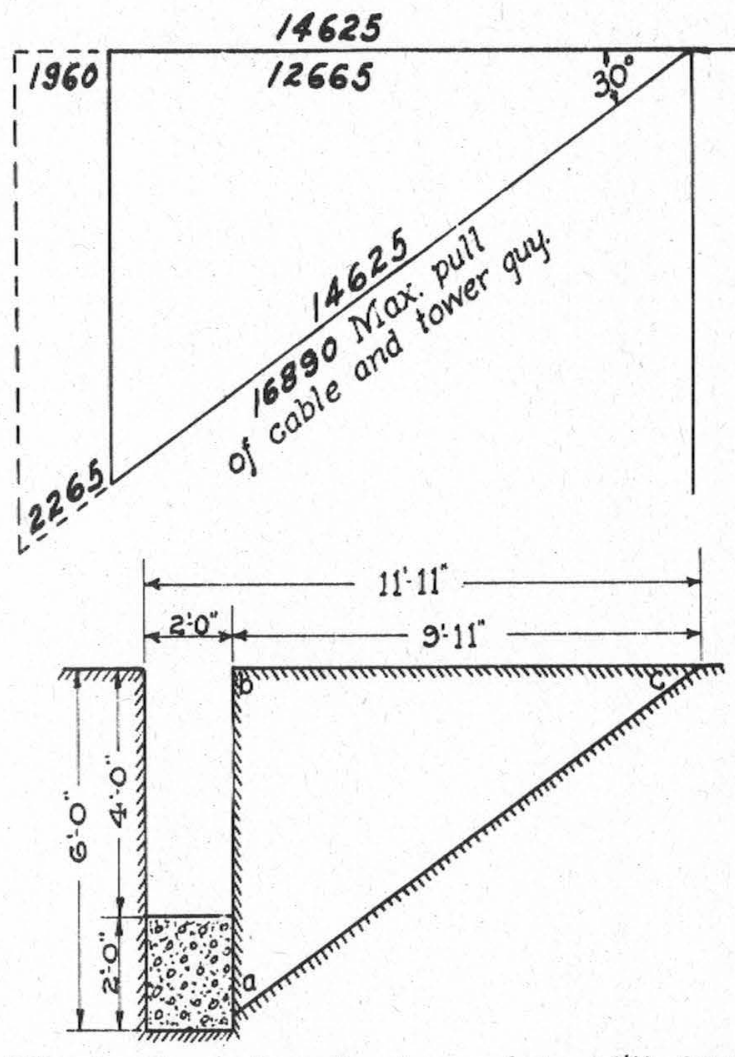

Wt. of prism of earth abc and backfill $=29400$ Wt. of concrete (2.26 yds.) $=\frac{9150}{38550}$

Total wt. to be moved

Factor of safety of 4 in cable. Cable of $58,500^{*}$ breaking strength.
14625

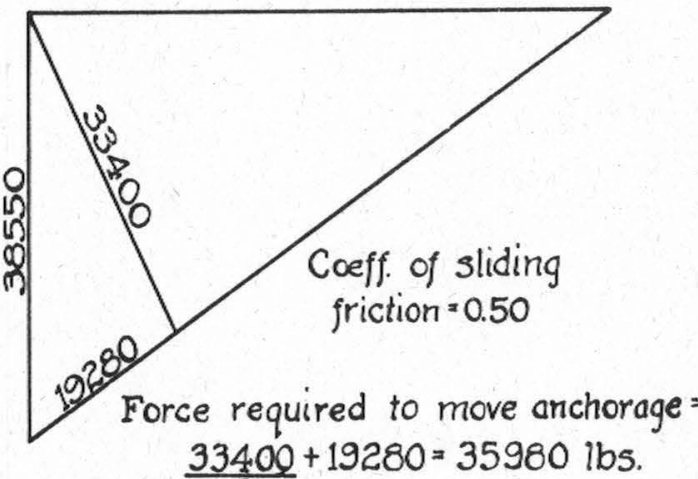
16890

STRUCTURES FOR CARLEWAYS

T-BEAM ANCHORAGE FOR $3 / 4$-INCH CABLEWAY Designed in Tacoma District

PLATE 9 


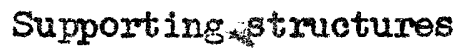

For all permanent installations the supporting structures should be designed for a length of life as great as that of the cableway they support. Although timber structures are sometimes used for supports of moderete helght, it has been found that the more perranent steel structures generally cost no more than sultable timber structures of the same helghts and require less time in erection. Concrete footings and steel anchor bolts should be used.

\section{Heights of supports}

The heights of the supports for the cableway are determined by the sag and the clearence that is required for the loaded cableway. on navigable rivers the clearance is specified in the permit issued by the Var Department. The supports should, of course, be of a helght sufficient to permit operation of a gaging car at a stage of maximum flood. Applicetion for permit should be made through the office of the Corps of Engineers having locel jurisdiction. Requirenents for clearances should be ascertained in advance and be incorporated in the design and application for permit. This requirement genergliy is specific, for example, as not less than 75 feet above low water (as designated by that agency at 120 degrees Fahrenhe1t. This requirement may be considered to apply to the clearence of the unloaded cable at the point of maximum sag (at center except for unsymetrical spens). The clearence that is provided should be from 5 to 10 feet more than that required by the permit in order to allow for possible changes after the cableway has been long in use. The permit from the War Department usually also specifies compliance with requirements that are issued in accordance with law by any depertment of the Federel Govermment for ald or protection of aerial navigation. These requirements should be ascertained in advance and used in the design of the structures. The more recent tendency in this respect is to require, for unusually high towers on or adjacent to routes of air travel, painting in alternete bands of specified colors and the installation and operetion of airways obstruction lights on the towers (see p. 3). The need for clearance of the loaded cable car above the probeble maximum highwater in order that discharge measurements may then be safely made may control in determining the heights of the supports and the allowable sag rather than the clearance required for navigation.

For installations near landing flelds or recognized air lanes, the regulations of the Civil Aeronautics Administration, Department of Commerce, should be consulted.

\section{Towers}

Designs for steel towers are generally made for the individual installations and the loads and conditions to be expected. Iight-weight angles and plates are ordinarily used, but all angles and plates should bo at least $1 / 4$-inch in thickness. The following general specifications are applicable. 


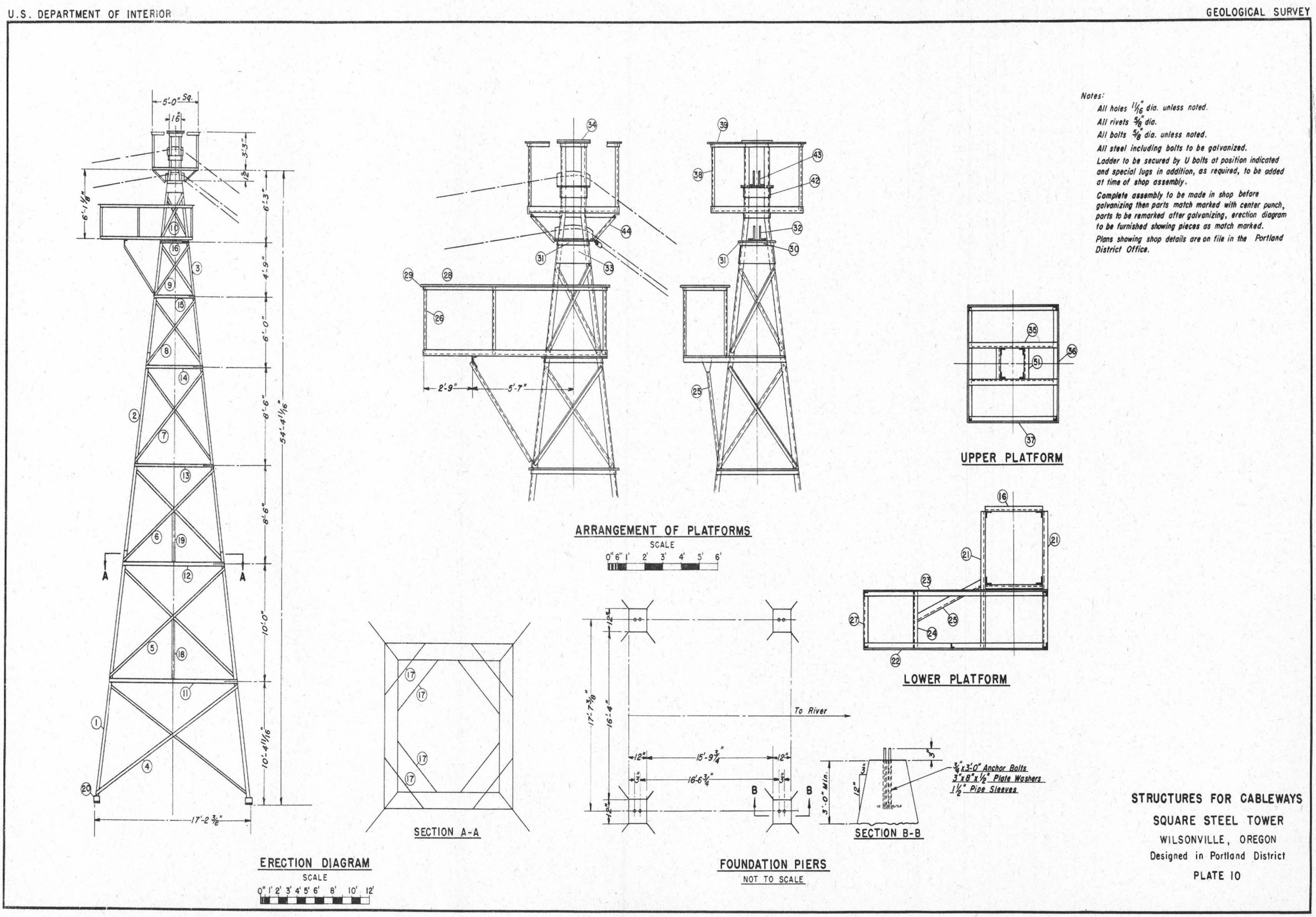


The steel to be used shall conform to the specifications of the Americen Society for Testing Materiels for Structural Steel for Bridges, serial designation A7-24 as outlined on pages 69 to 75 inclusive of the 1924 A.S.T.M. Standards. All members must be streight as shown. Iayout is to be accurate so that holes will come fair and members come true to dimensions. All bolts $5 / 8$-inch unless otherwise noted. Bolt holes are to be punched $1 / 16$-inch larger in diameter than the diameter of the bolts and wherever reasonably possible, are to be punched from the faying surface. All projections are to be removed from the faying surface before galvanizing. All members are to be plainly marked. Deteils and erection plans are to be furnished by the bidder.

Before gelvanizing, a shop assembly of each tower shall be made and all tower members match marked with center punch. After galvanizing, all parts shall be plainly merked for fleld erection before shipping.

All steel, Including field bolts, shall be galvanized by the hot dip process. The galvenizing shall consist of a continuous coating of cominercially-pure zinc of uniform thickmess so applied that it adheres firmly to the surfece of the steel. The galvanized coating shall be of first class commercial quality freo from infurious defects; it shall be non-peeling and non-cracking, and shall have sufficient toughness to resist weathering and corrosion.

Plans for square steel towers that were designed by the Portland district office for gaging stations on the Hillamette and Columbia rivers are show in plates 10 to 13. The tovers shown in the photograph, plate 1, are those for which the designs are given in plates 12 and 13. For a tower more than 60 leet in helght, a stalrway instead of a steel ladder is recomended.

The designs given in plates 10 to 13 may be adapted to other heights of towers by making necessary changes.

Steel A-trames

If the heights of the supports are not more than 40 feet, steel A-fremes may be used. If practicable, the steel should be geivanized, as in most ceses that will be less expensive than frequent repainting over a period of years.

Ileht-weight channels or column sections, such as the Carnegie Hberm or WF sections, should be used for the legs of the A-frame. The dimensions and weights of the sections would vary with the helght and the 1oad. The stability of the A-frame, acting as a column, should be invest1gated in individual cases, especialiy for long spens. Hinge-pin connections at the base of steel A-frames are generally recarmended, as the erection can be made with less difficulty and there is less liklihood of the anchor bolts being loosened by flexure of the A-frame. 


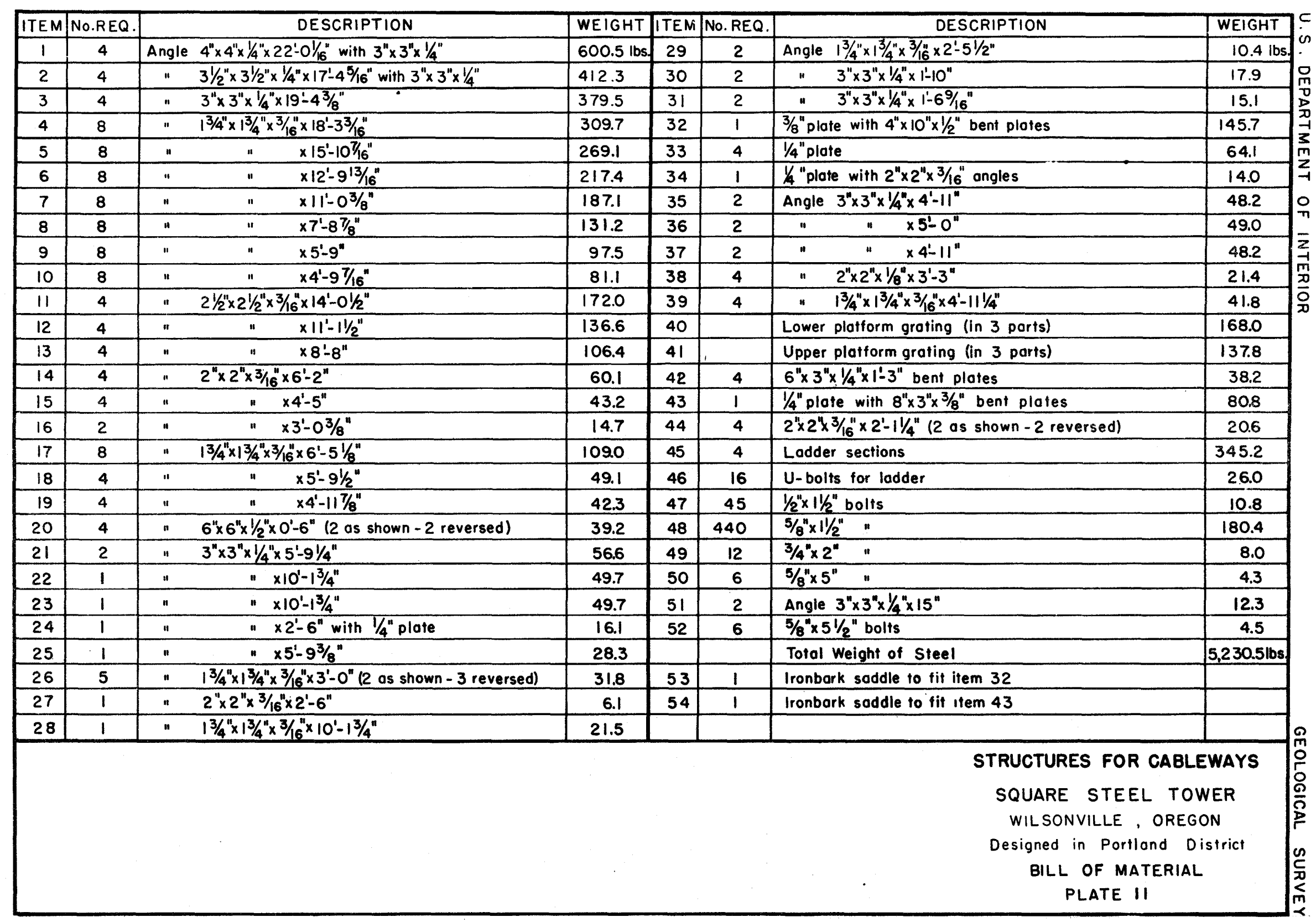




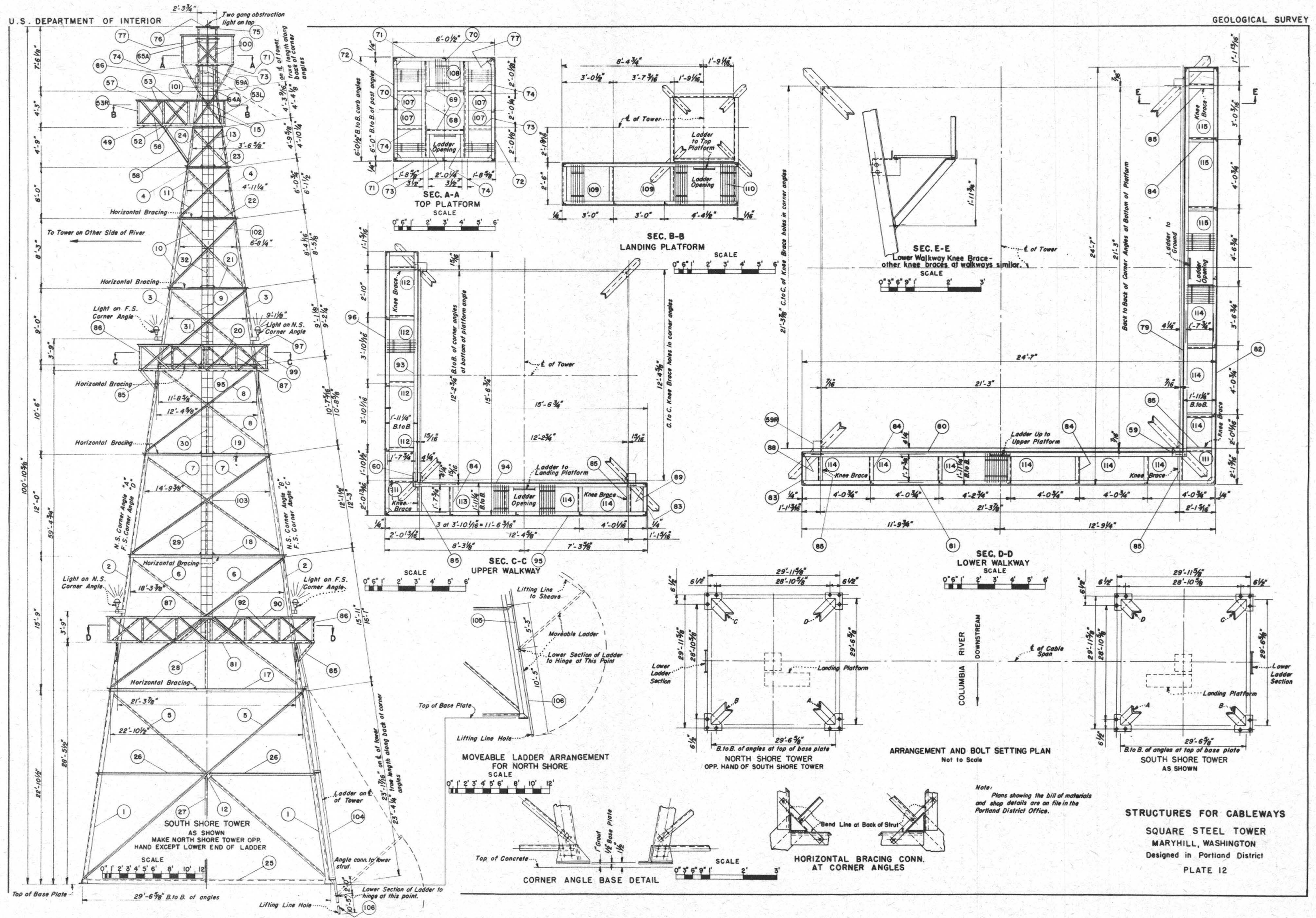


ITEM NO.66 MAKE I

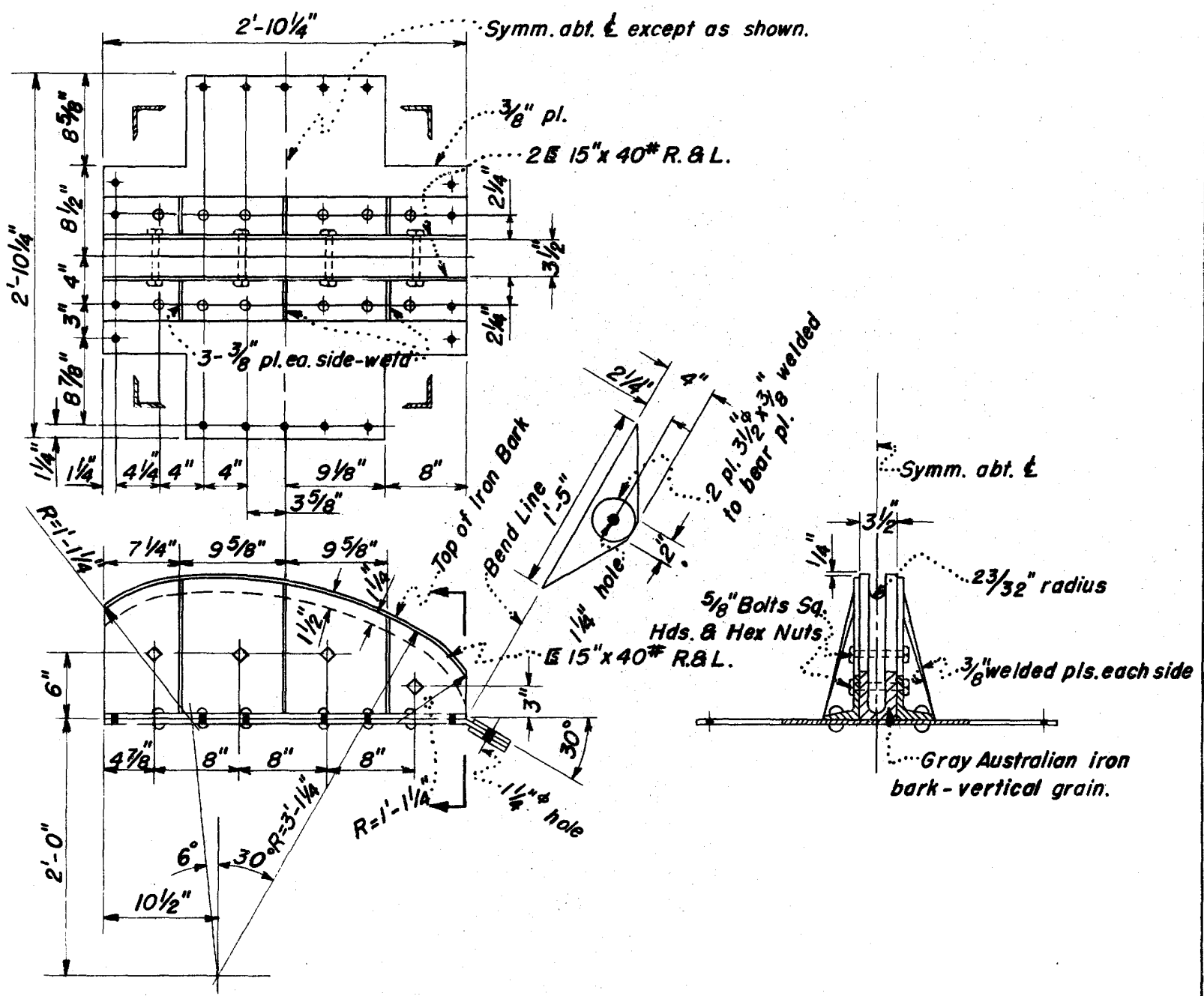

STRUCTURES FOR CABLEWAYS

SQUARE STEEL TOWER SADDLE

FOR $13 / 8-I N C H$ TRAMWAY TRACK STRAND

Designed in Portland District 


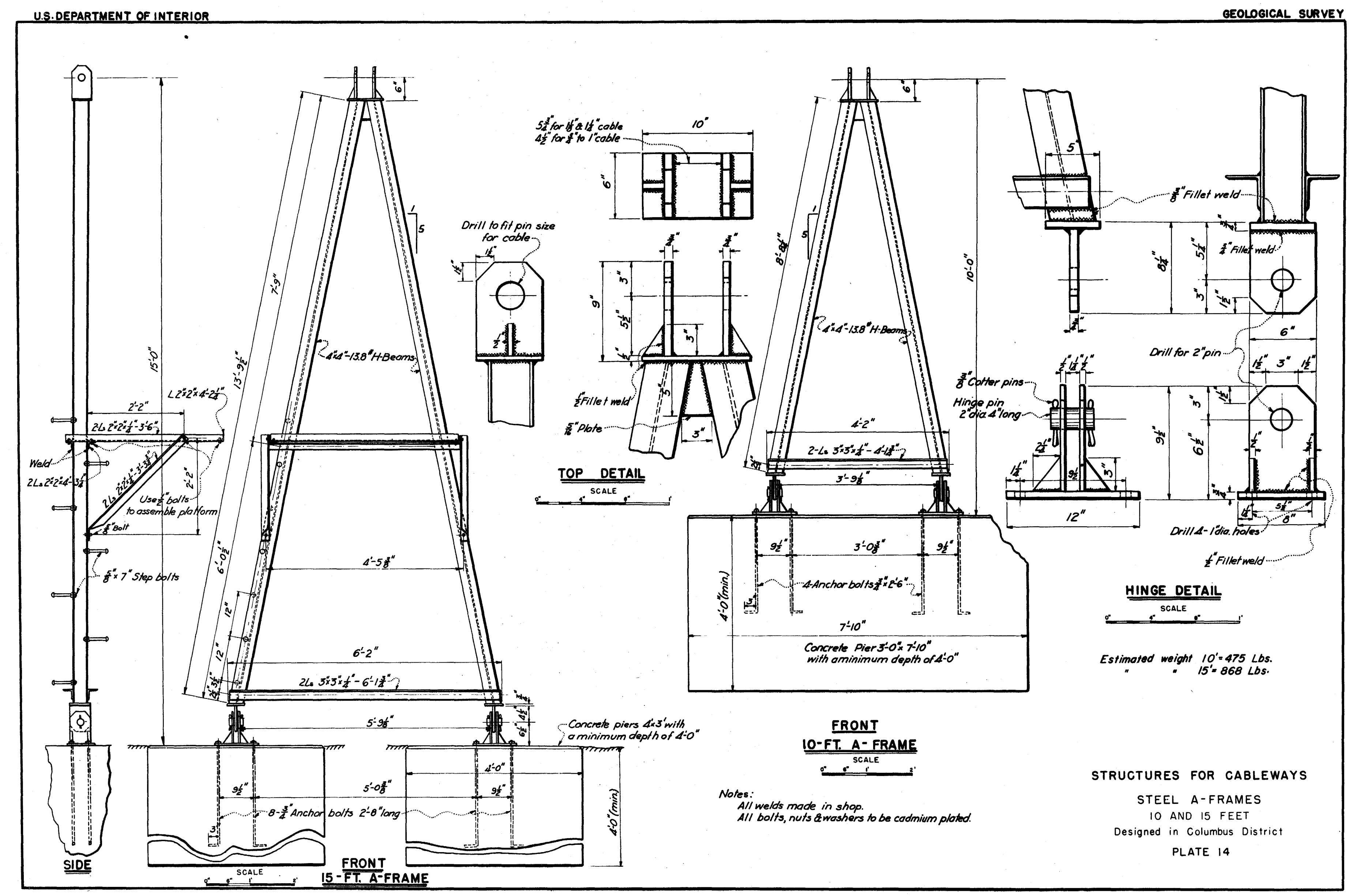




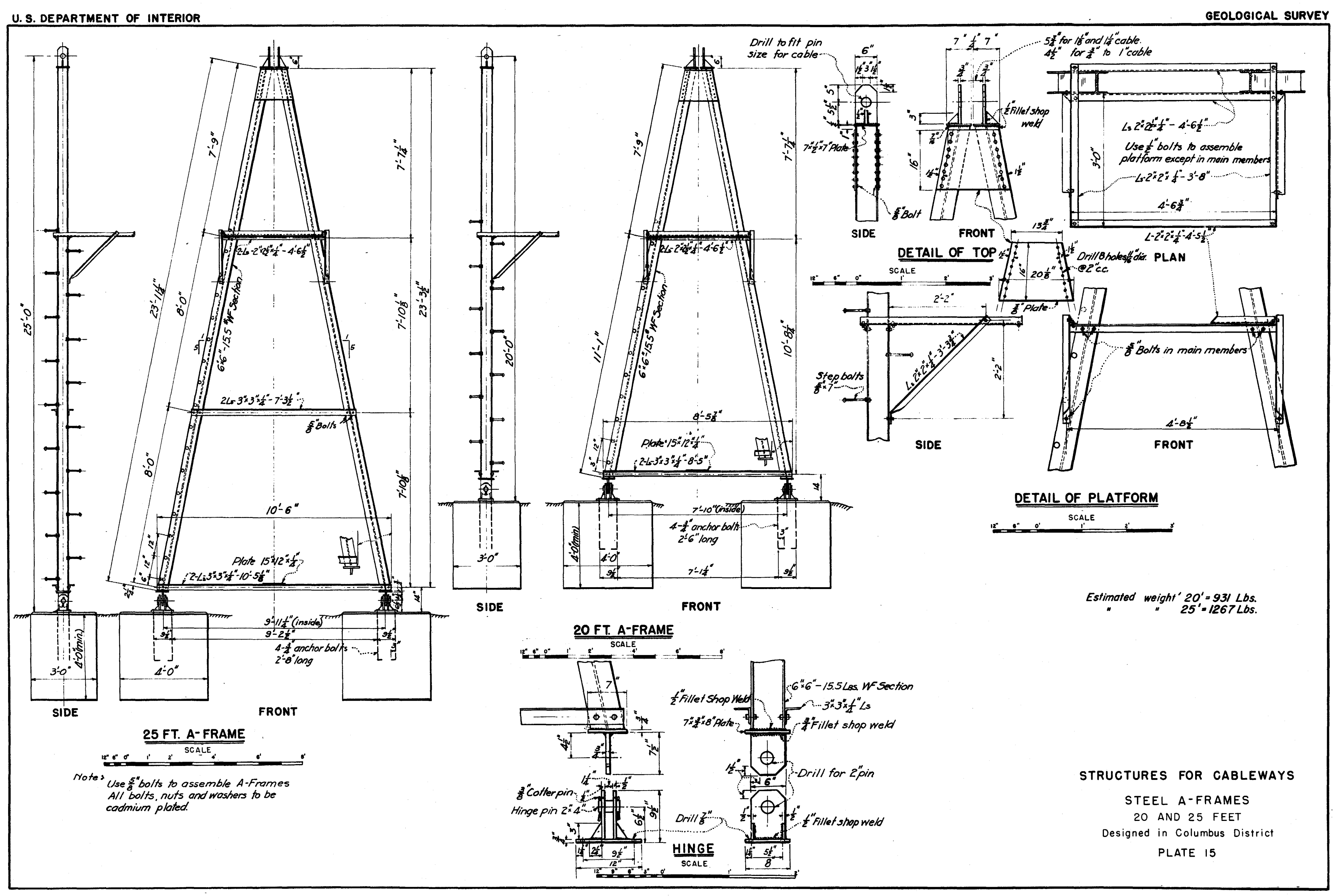




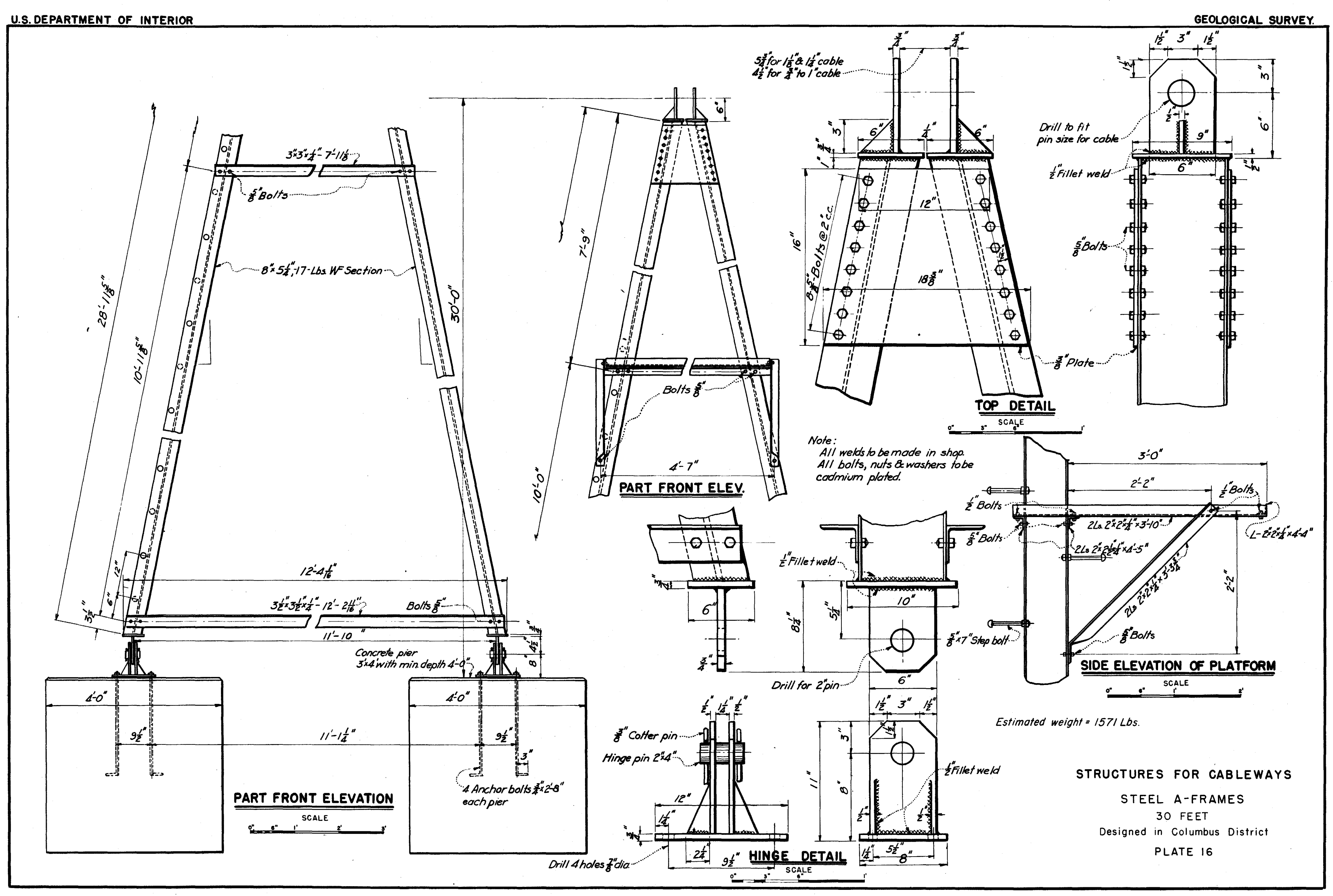




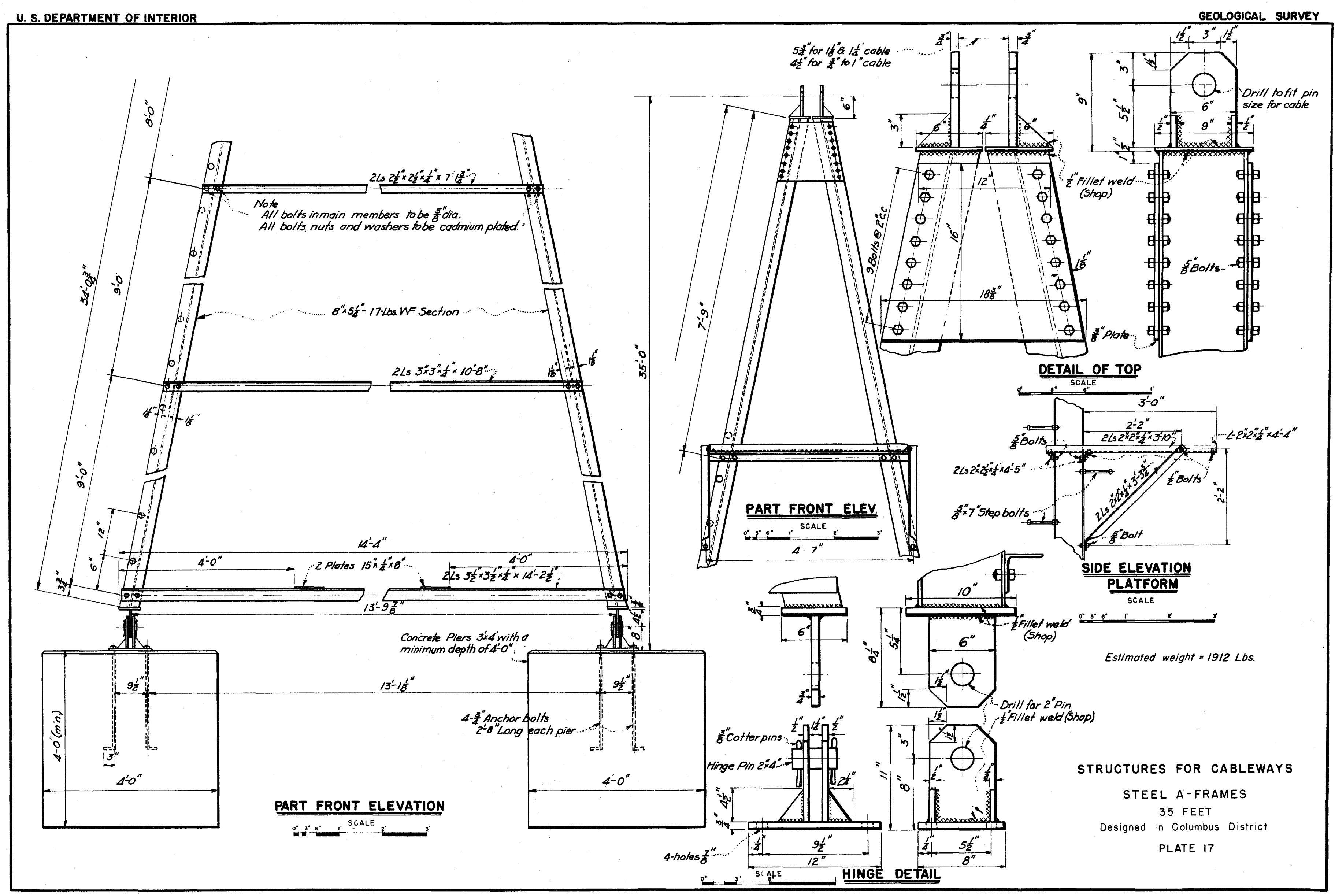




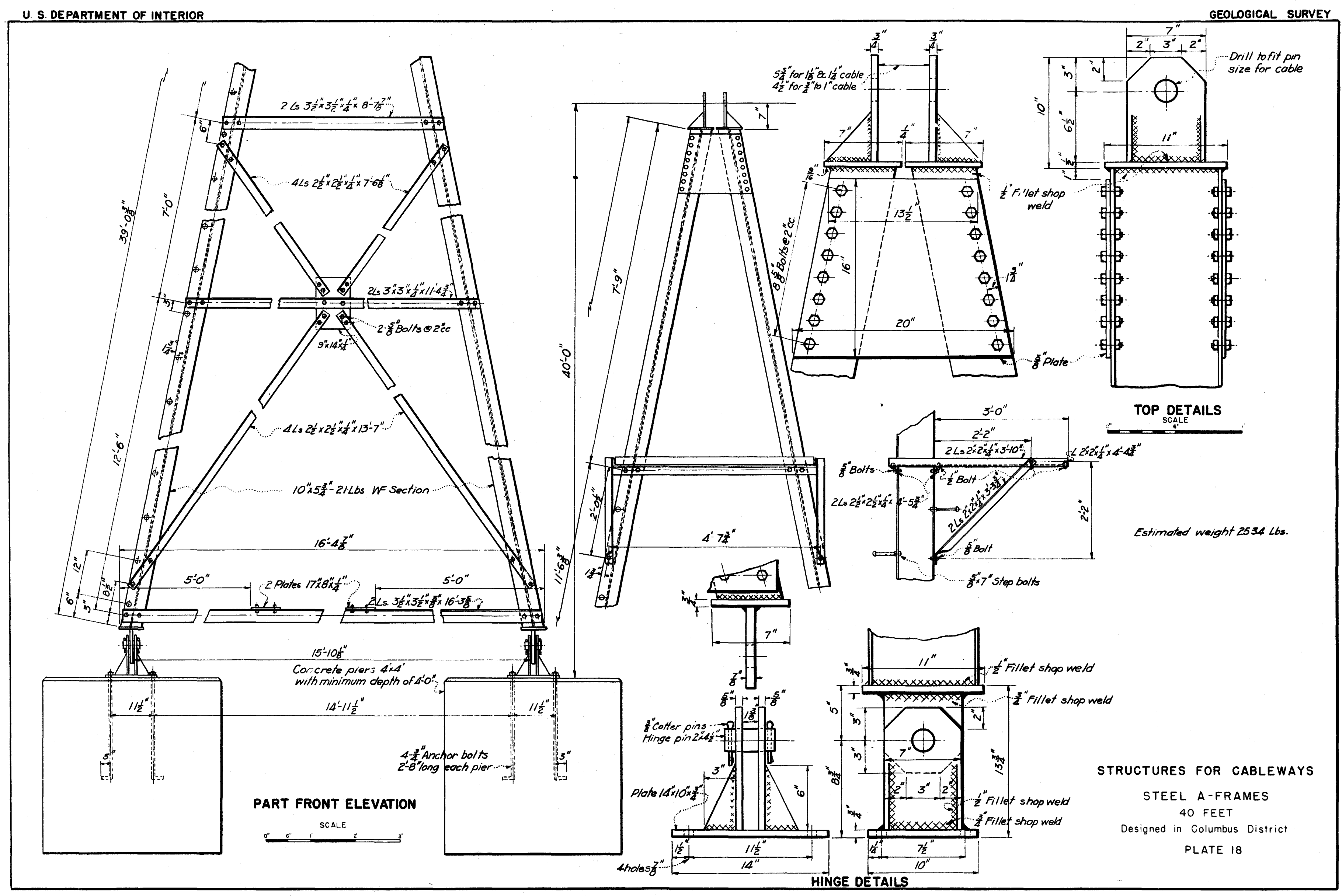




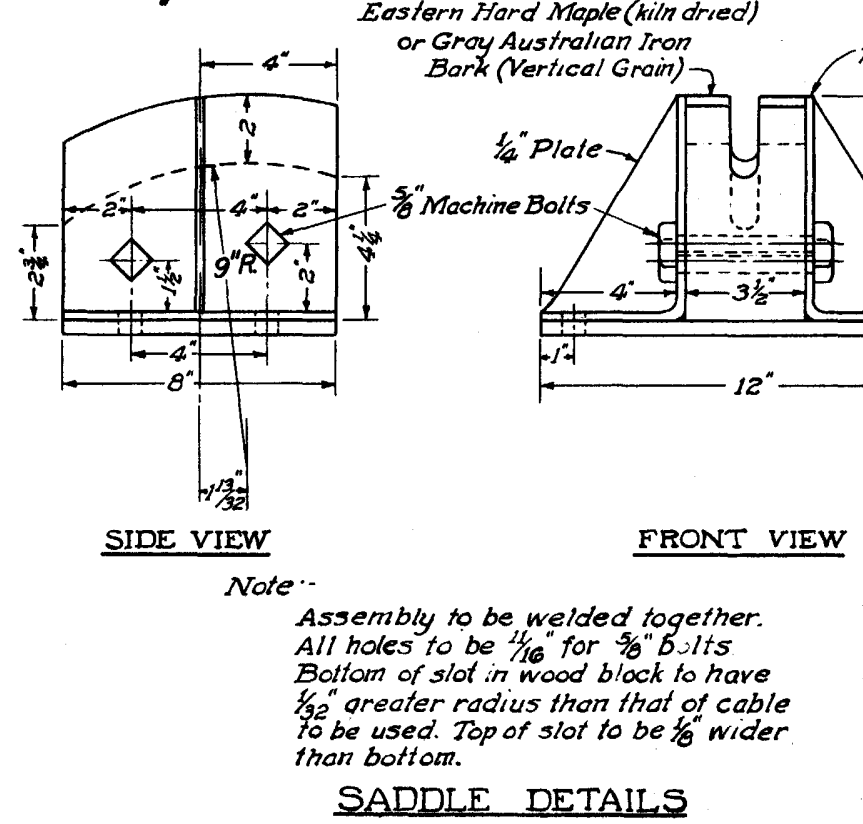

Holes 11,167

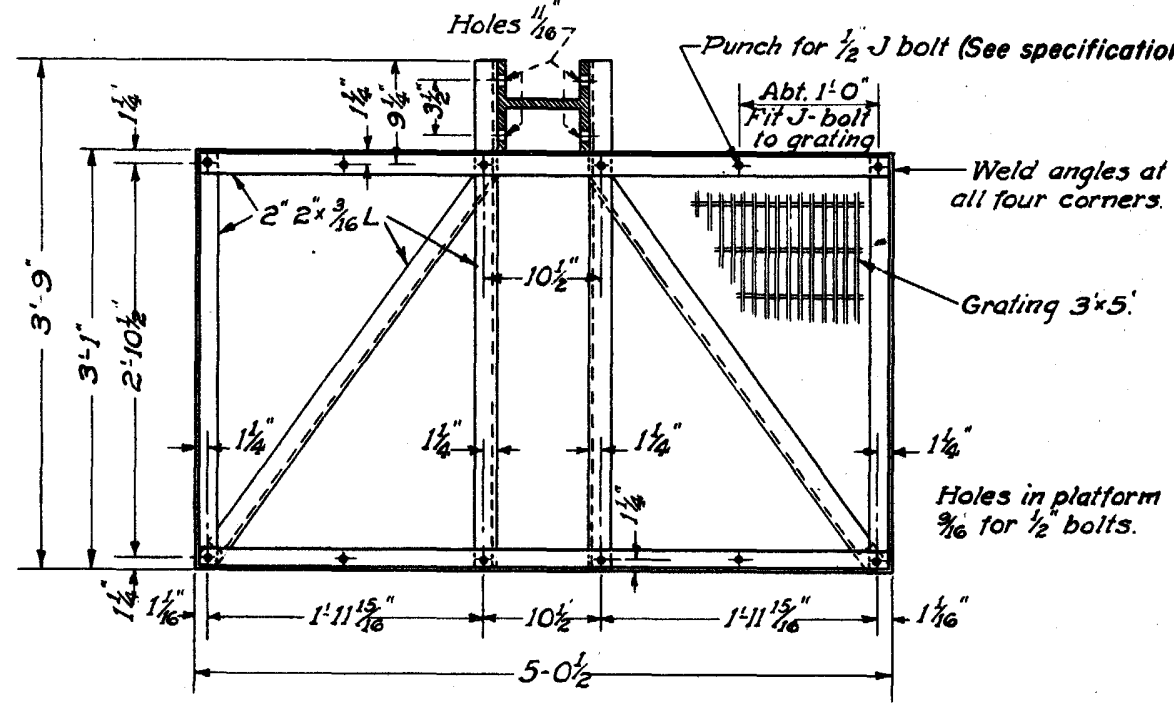

LANDING PLATFORM

Grating Specifications

Grating to conform to Irving $X$-Bar (pressu e locked) Federal Specifications R.R.G.-661a, Uan $20,1936$.

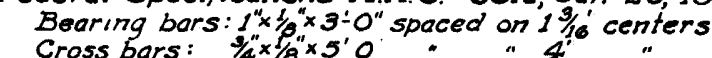
Grating to be galvanized by the hot dip process. Prefabricated grating to be attached by clips furnished by the manufacturet instead of by $\mathrm{J}$-bolts.

\section{Pin connection \\ may be used insteod}

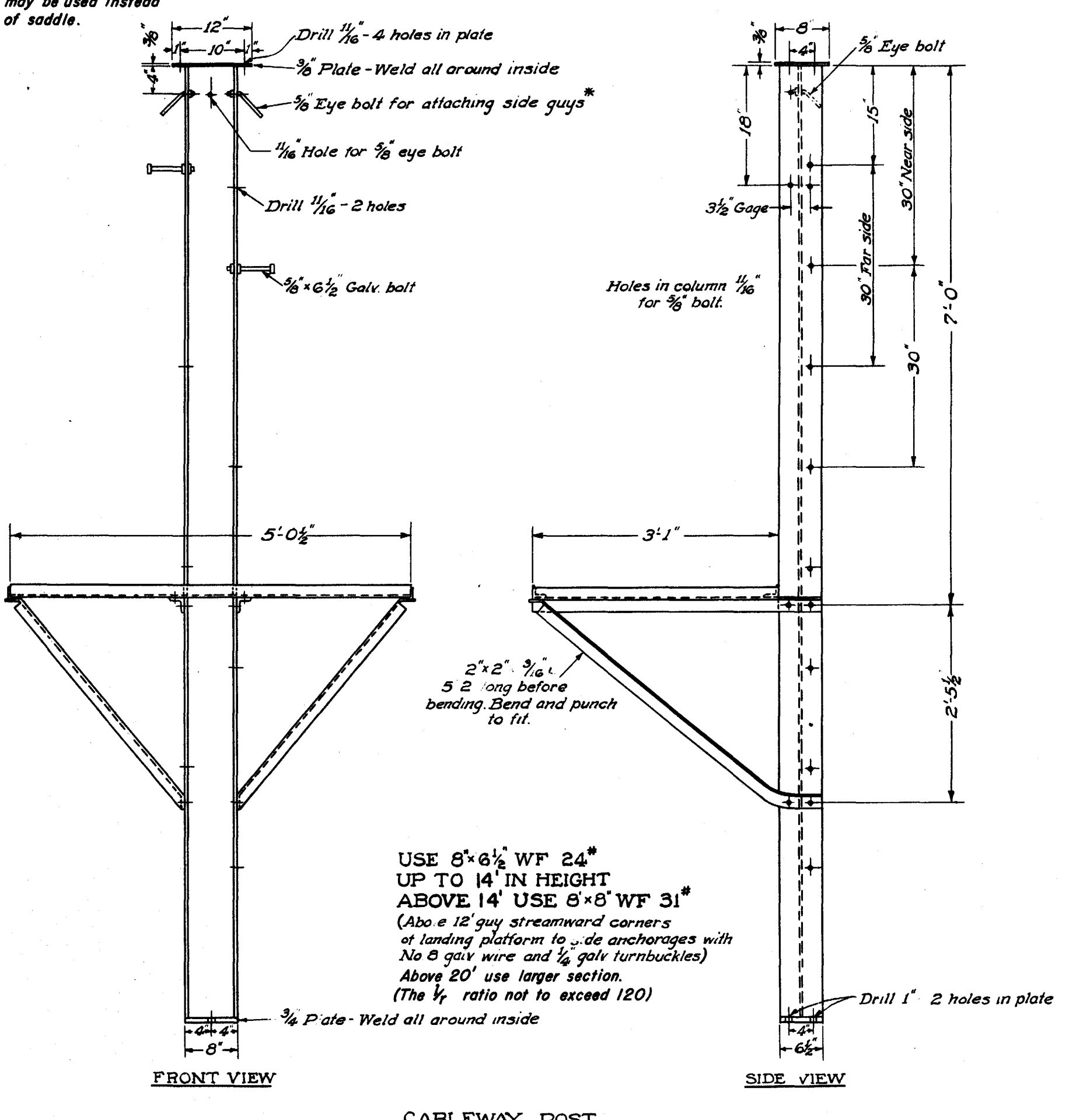

CABLEWAY POST

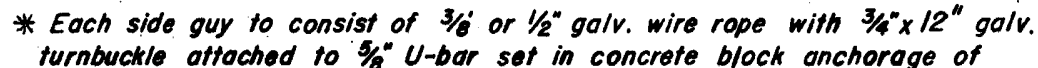
about one cubic yord in volume.
STRUCTURES FOR CABLEWAYS

STEEL POST SUPPORT Designed in Boston and Tacoma Districts PLATE 19 


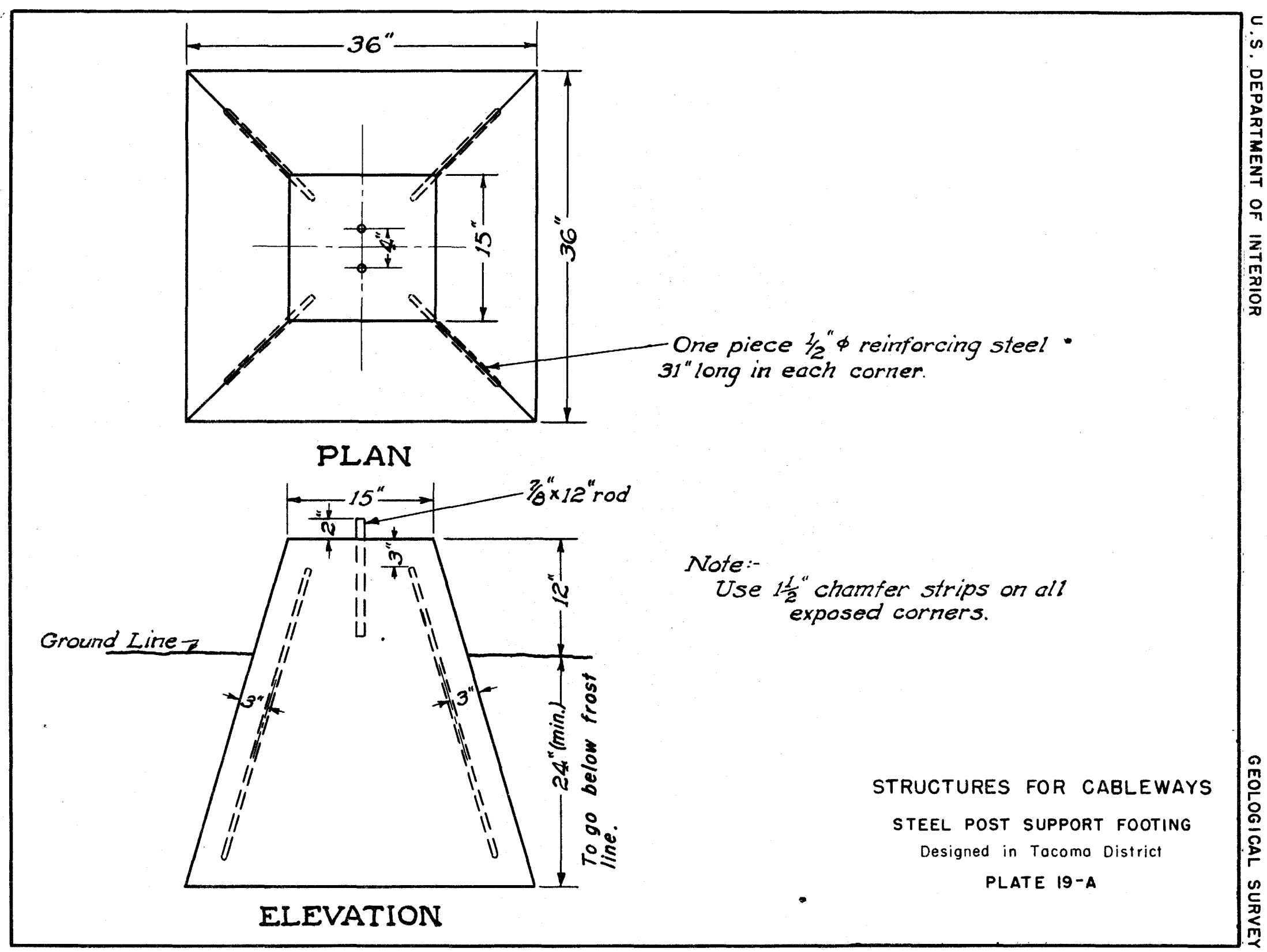




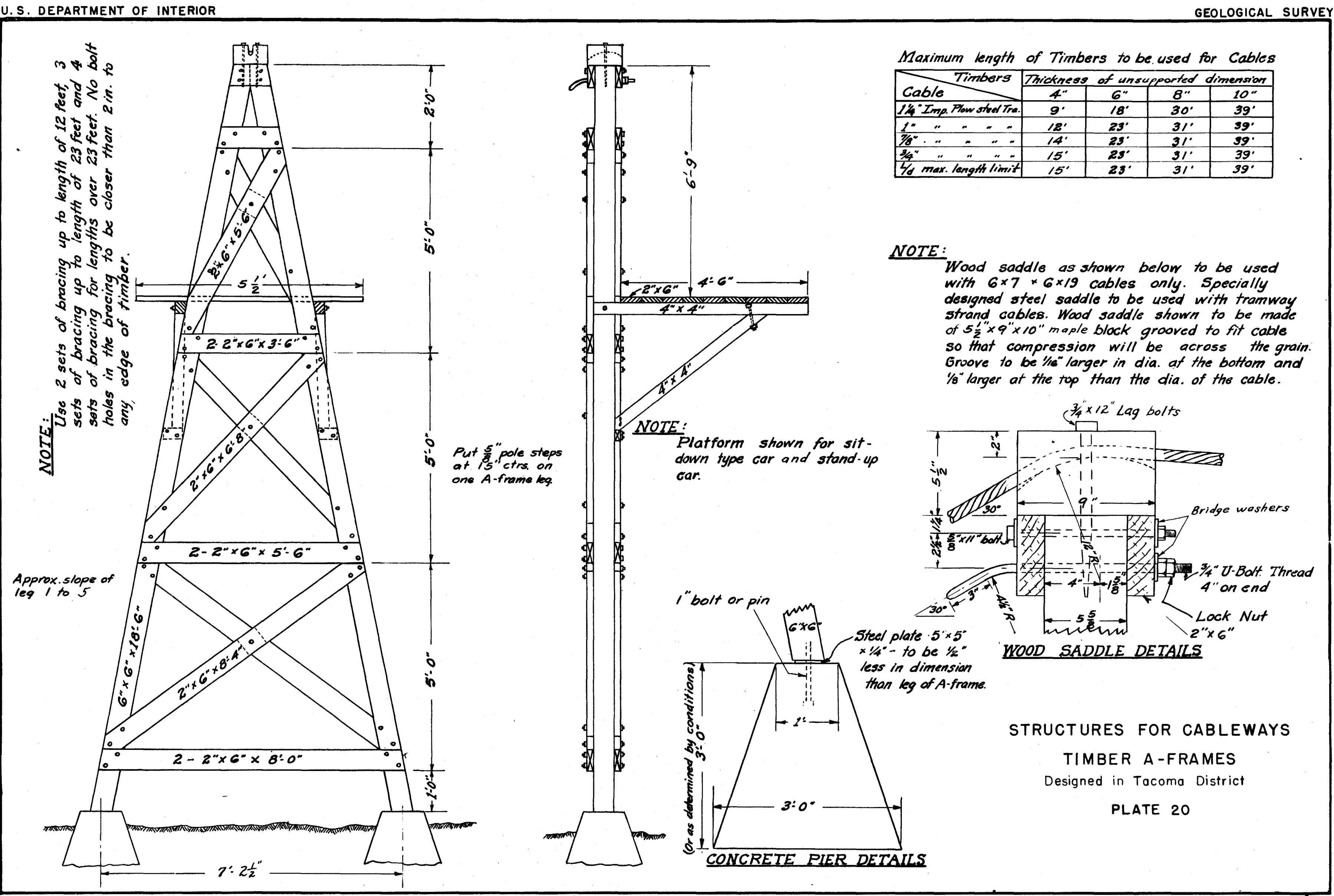


Designs for steel A-Irames wh hinge-pin connections at the base that were prepared in the Columbus alstrict office are shown in the following illustrations:

\author{
Plate 14. Steel A-frames, 10 and 15 feet. \\ Plate 15. Steel A-fremes, 20 and 25 feet. \\ Plate 16. Stool A-freme, 30 feet. \\ Plate 17. Steel A-frame, 35 feet. \\ Plate 18. Steel A-frame, 40 feet.
}

Steel details for rigid A-fremes for helghts ranging from 12 to 20 feet by increments of two feet, and for helghts ranging from 20 to 39 feet by increments of one foot, have been prepered in the Tacome district office. Those designs use light-weight channel sections. The base plates are attached to the footings by fixed anchor bolts.

\title{
Steel post support
}

The Boston and Tacoma districts heve made successful use of a single H-beam-strut support with upstream and downstream guy cables. This type of support is simple and economical, especially for short spens. The design of this type of support as used in the Tacoma district is show in plate 19, a fev changes having been made in the design that wes first prepared and used in the Boston district.

\section{Timber A-frames}

In some instances it is desirable and economicel to use timber A-frames. If the proper timber is used, such as Douglas fir or oregon pine, timber A-frames may give satisfactory service for many years. The individual pieces of the rrame after being cut and fitted, but before joined to the corapleted frame, should be treated with suitable preservatives. Helpful information in regard to the use of timber and methods of its preservation has been published by the Forest Products Iaboratory of the $U$. S. Department of Agriculture 20/. Plans for timber A-fremes designed in the Tacoma district office are shown in plate 20.

\section{Footings}

The footings should have ample bearing surface and be designed so that there will be a unfform distribution of the load. They should be placed on firm ground and, where frost is prevalent, they should extend to bedrock or to a depth of not less than two feet below the frost line. Dimensions of three feet in width and a minimum length of four feet in the direction at right angles to the cableway are sometimes specified.

20/ Hood Handbook, Forest Products Laboratory, U. S. Dept. of Agriculture. 1935. 
In most circumstances where the ground is fim, the safe bearing capacity of the soll will not be exceeded with footings of that size although precautions should be taken to aroid the possibility of unequal settlement such as might occur if one part of the footing is on ledgerock and another pert is on soll. Table 4 gives the maximm allowable soll pressure for different material as listed by Douglas 21 .

Table 4. Allowable soll pressure in tons (2,000 pounds) per square foot. Material

Maximm allovable pressure Tons per sq. ft.

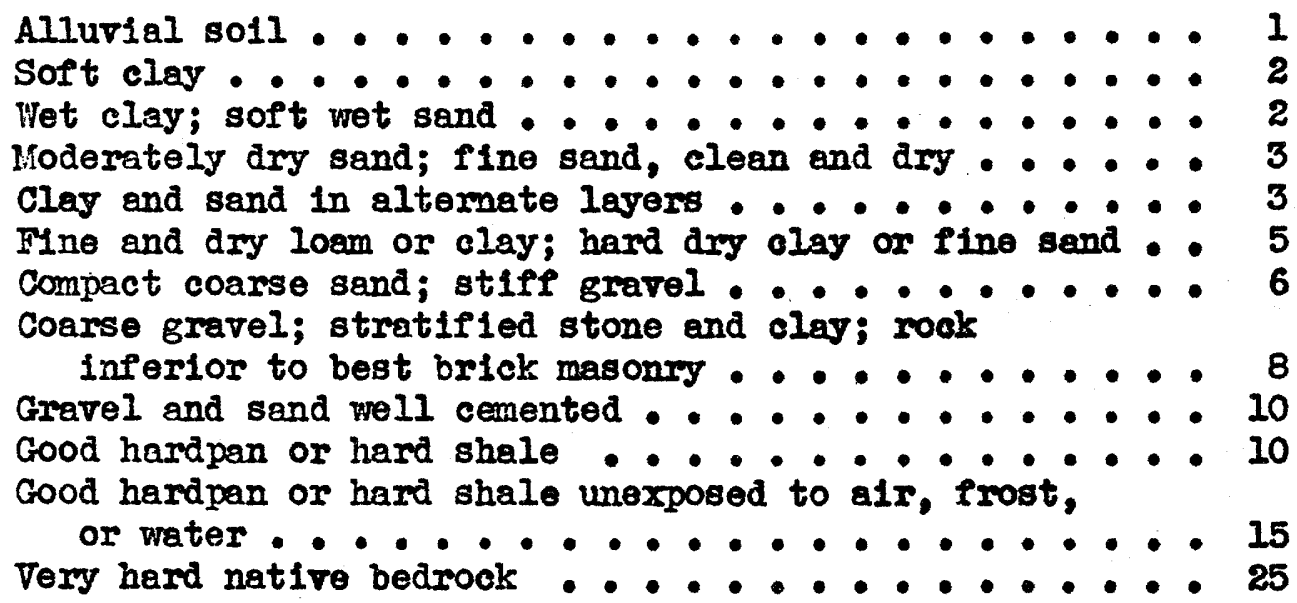

Anchor bolts should extend into the conorete for a distance of 30 times their diameter and should have 3-inch hooks at the end. Footings and anchorages for high steel A-frames and for towers carrying cableways of long spen should be individually designed for the loads to be carried and the conditions at the s1te. Designs for standard footing that may be used in ordinary circumstances are shown in the plans for A-frames.

Unless otherwise specified, the design and construction of concrete footings should be in accordance with the specifications in "Recommended Practice and Standard Specifications for Concrete and Reinforced Concrete" as given in Procerdings, ASCE, No. 6, Part 2, June 1940.

\section{Grounding}

As a safety precaution, steol towers or A-frames if near the gage should be grounded to the lower intake pipe by means of grounding connectors. If the structure is at some distance for the gage it should be grounded by burying six $100 \mathrm{ps}$ of ground wito to a depth corresponaing to that of the minimu atage of the river. the round wire should be oontinued in a trench to a connection with the tower or A-frame. If this method of making a ground connection is impracticable, four $3 / 4-1$ inch by 8-feet clean 8.1. pipes speced six feet apart, driven full length vertically and connected in parallel, should give a sufficiently good ground.

21/ Douglas, Walter J., Foundations and earthwork: Am, Civil Fngrs. Handbook. p. 7li. Fifth od. 1930. 
Several different designs of bearings at the tops of the supports are used for the wire rope or track strand, the particular design depending largely upon the height and construction of the tower or A-freme and the load to be carried. Some of the cormon methods of support are sheaves, pin connections, and saddles.

\section{Sheares}

Sheaves are commonly used on timber or steel A-fremes for the smaller sizes of wire rope. The sheave should have a solld wob, not dished, with a tread diemeter of elght inches and a U-groove of a diameter equal to the diameter of the rope. The diameter of the steel bolt that carries the sheare should be $11 / 8$ inches for $3 / 4$-inch rope and 1 1/2 inches for $7 / 8$-inch or 1 -inch rope. Sheaves with $\nabla$-shaped grooves designed for rope drive should not be used for bearing supports.

\section{Pin connections}

Pin-and-socket connections (see p. 29) shown in the designs for steel A-frames, plates 14 to 18, are cormonly used for the smaller sizes of tramway track strand as the stiffness of the strend does not permit the use of sherves. If pin-connection supports are to be used, a careful determination of the length of the clear span is necessary in order to obtain the correct sag with the A-frames in a vertical position.

Saddles

Saddles are generally used on towers (see pls. 10 to 13) and they may be used on timber or steel A-frames. They are particularly necessary for long spans and the larger sizes of tramway track strand. A cast-iron saddle is sometimes used on A-frames, but a saddle of sultable wood, such as gray Australian iron bark with the grain vertical, is preferable. The design of a saddle that was used on the towers show in plate 12 for a $13 / 8$-inch tramway track strand is shorm in plate 13.

\section{Gaging cars}

The cableway provides a track for the operation of a gaging car from which the engineer works in the process of making a discharge measurement. Two types of gaging cars are in general use; these are the type-A or sit-dorm car and the type-B or stand-up cer. A combination car that has some features of both the type-A and the type-B cars is used in some districts; a canvas shelter or galvanized sheet-steel metal roof can be installed on either type of car. Special designs of cars may be neoded. for long-spen cableways. In the type-A car, the reel is generally used at the end of the car whereas the type-B car is generelly designed for the reel at the side, although in ame type-B cars the reel may be placed at the end. 


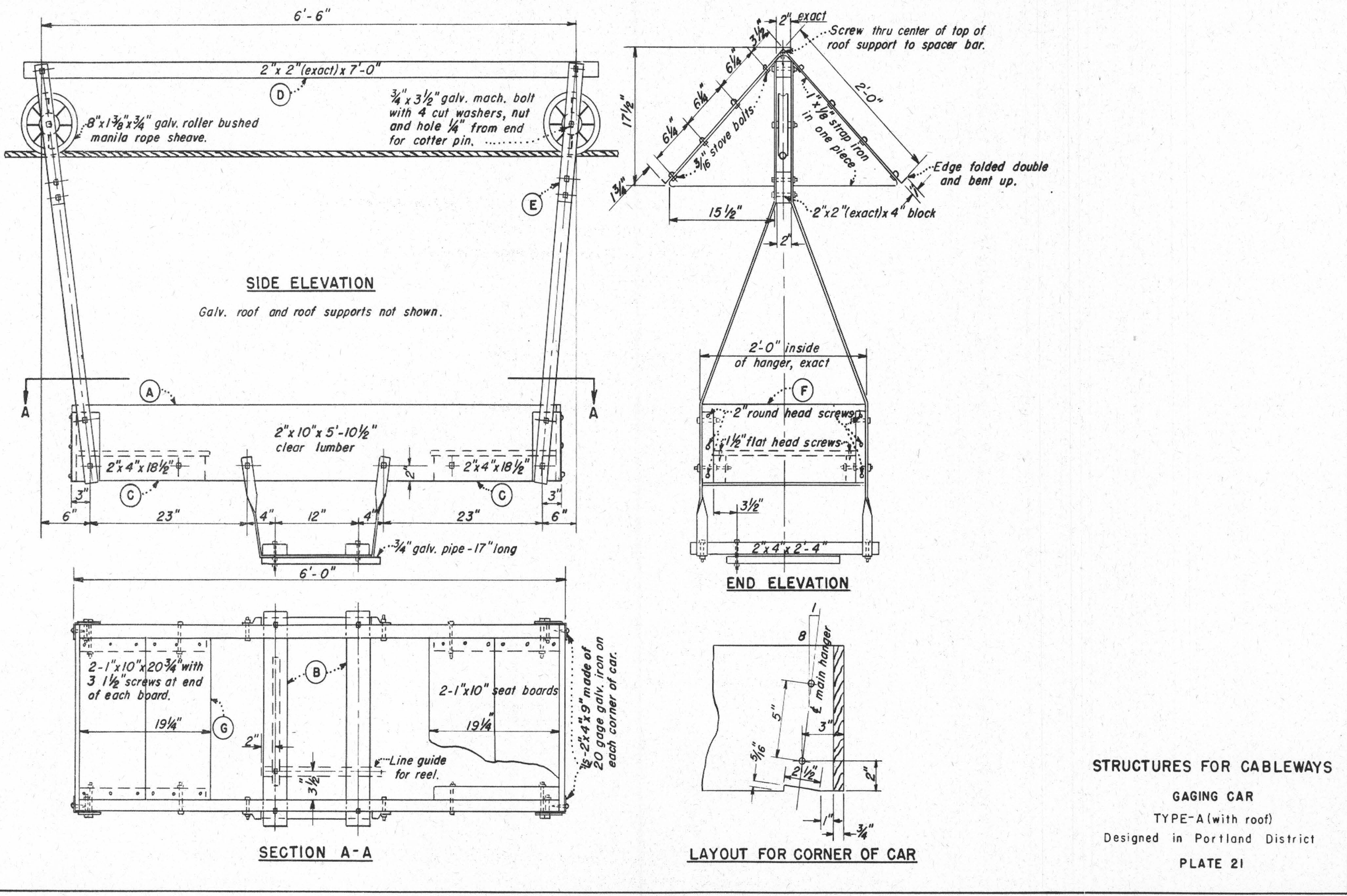


Type-A gaging car

The type-A car permits the engineer to work from a sitting position. It is provided with a seat at each end, has either one or two foot rests, and can be readily equipped for use with either a handline or a reel assembly. Plates 21 and 21 a give the dimensions, construction details, and bill of materials for a type-A gaging car that is used in the portland district.

\section{Type-B gaging car}

The type-B car is designed so that the engineer may operate the current meter from a standing position; several designs of this type of car are available. The design made in the Colurabus district that is shown in plate 22 uses structural aluminum, except for a few steel parts and a wood floor. It is of durable construction and is especially adapted for the use of heavy equipment.

The type-B car shown in plate 23 was designed in the Tacoma district and is made of wood, except for the hangers and other hardware. With this car, the engineer can also operate the current meter from a sitting position if desired. The design includes a sheet-metal roof that may be used with this and other types of gaging cars. Another design of a type-B car that is used in the Tucson district is shown in plate 24.

Accessories

Among the accessories that are commonly used with gaging cars, the sounding protractor, the puller, and the brake are perhaps the most useful. A brake is very essential for a car operated on a cableway having a deep sag. One method of providing a brake by means of a counterweight is described on page 3 .

In discharge measurements of rivers that are deep and swift where the sounding weight and the current meter are carried downstream by the action of the current, an accurate measurement of the vertical angle made by the suspension line is essential to the correct determination of the vertical depth. A triangular type of sounding protractor $22 /$ for measuring vertical angles is generally used on type-B cars.

Geging-car pullers provide a convenient means of moving the gaging car and holding it at any desired position along the cableway; various designs of pullers are used by Survey engineers. The type of puller designed and used in the Tucson district is shown in plate 25. A cast-aluminum puller which has the advantage of lightness of weight is used in some districts.

22/ See "Sounding protractor," U. S. Geol. Survey Water-Supply Paper 888, p. 206. 


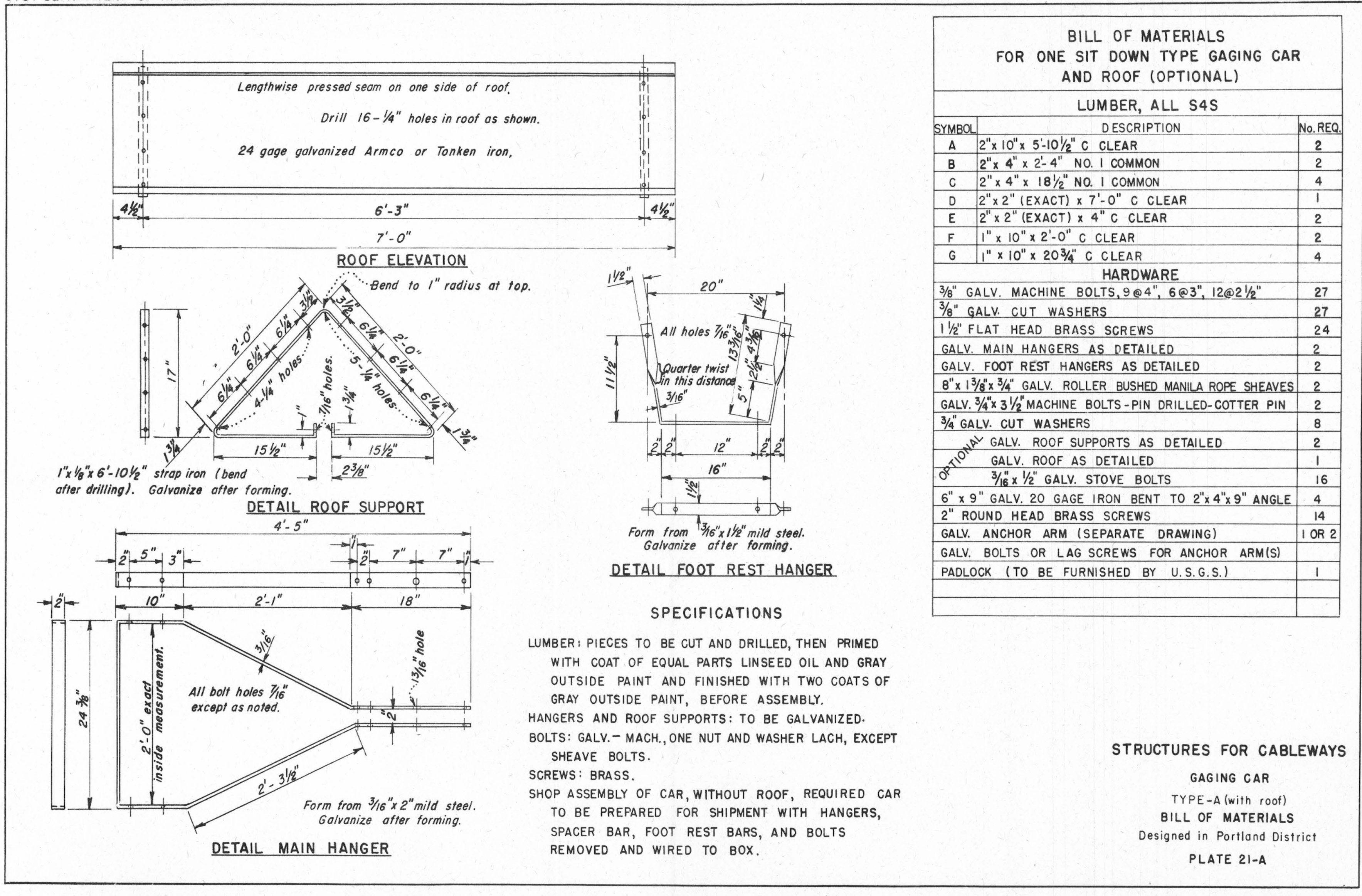




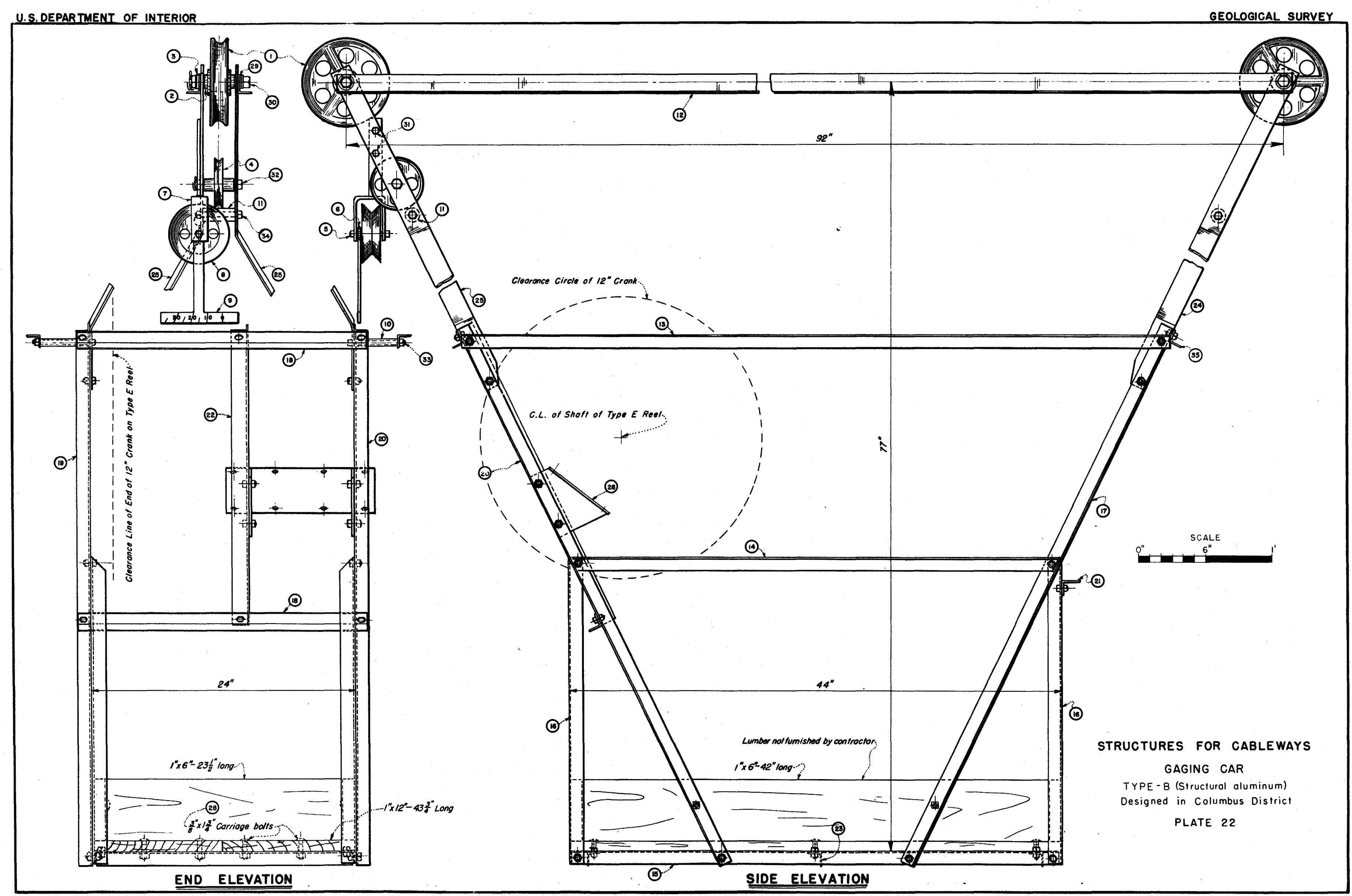




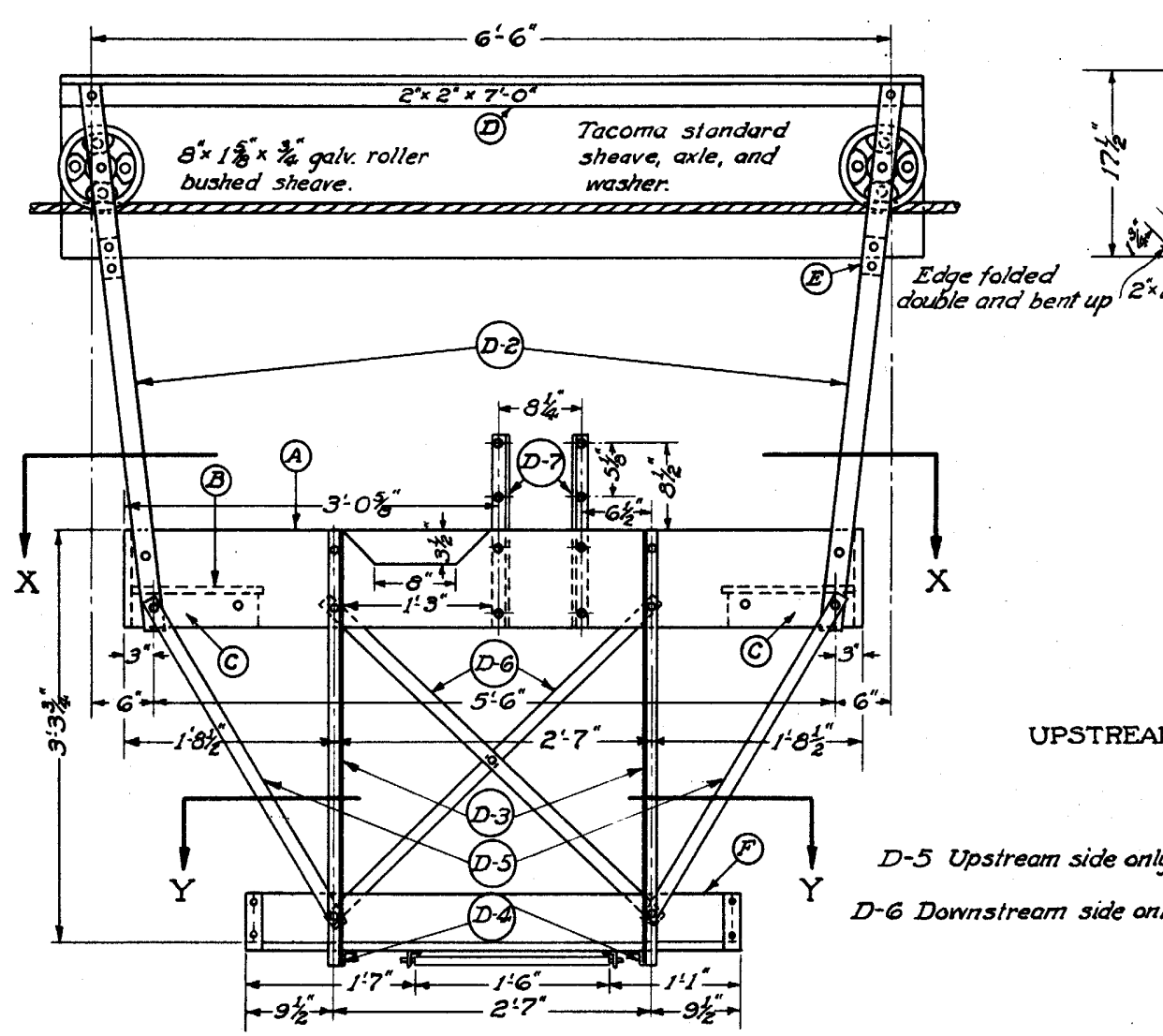

SIDE ELEVATION
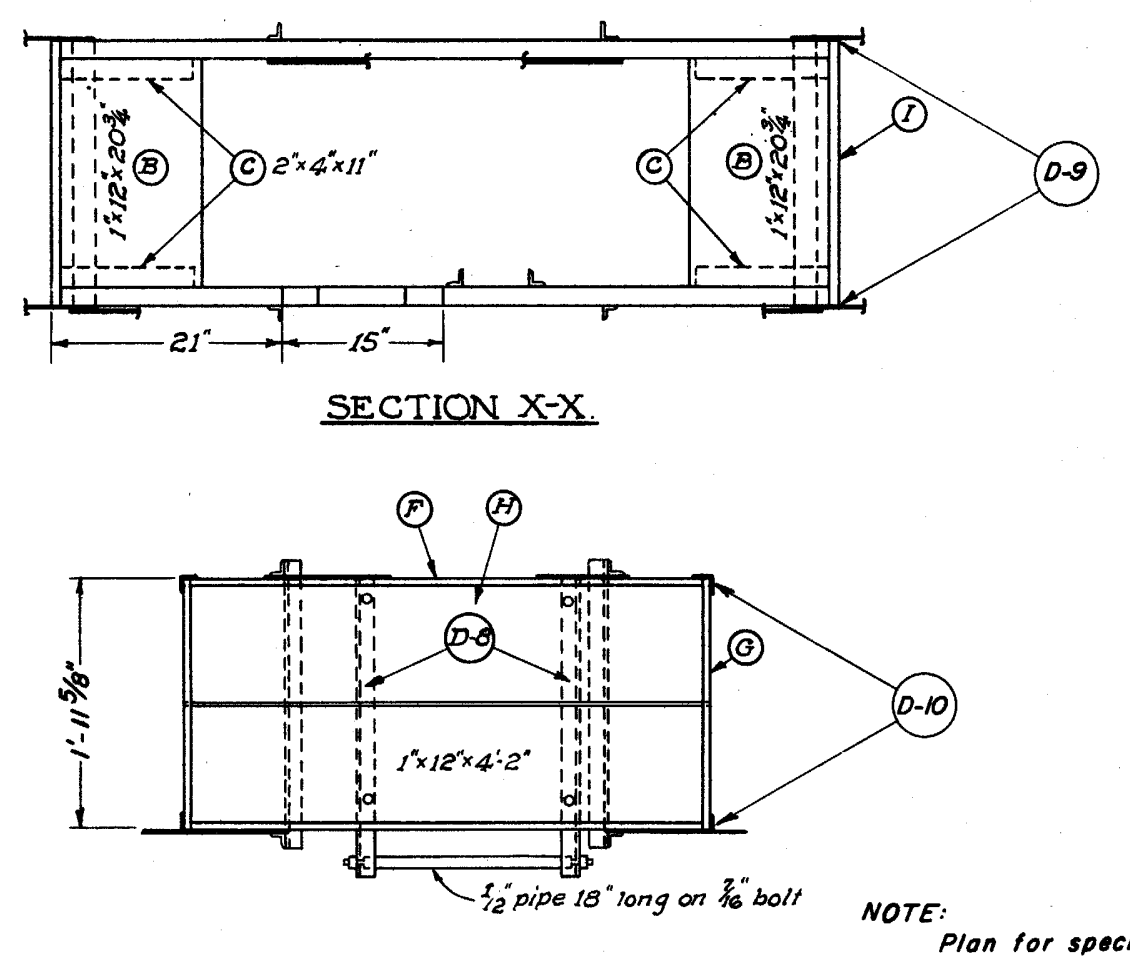

SECTION $Y-Y$

Note

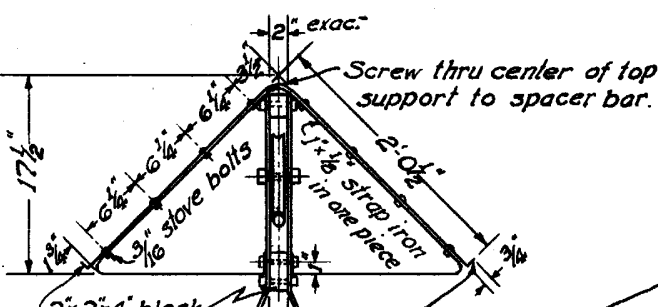

roct.

For snow country change the dimension ROOF ELEVATION

from the last hole to edge of the roof

trom is "to 2 th" and bend the folded
edge down (180 from position shown above)

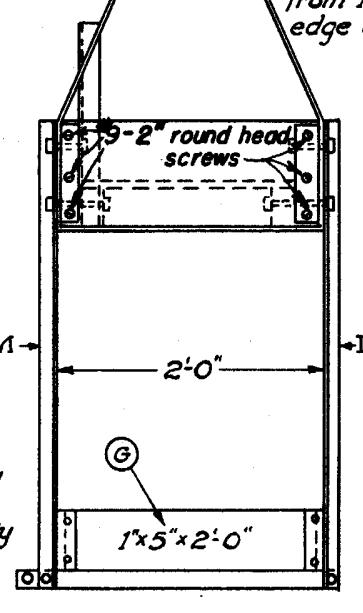

END ELEVATION

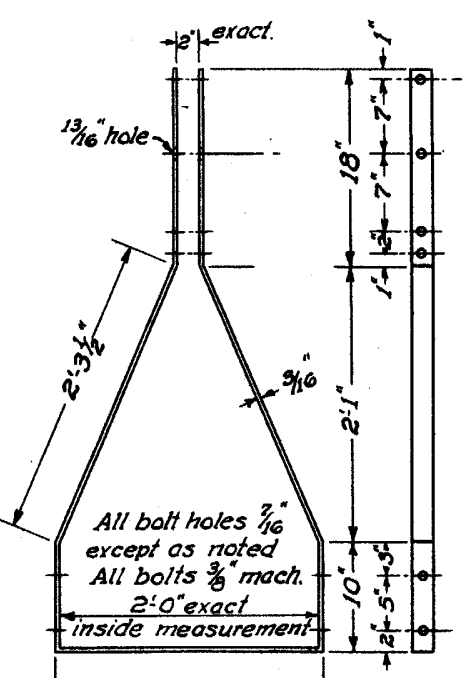

$$
\square z^{\prime} 03^{\prime \prime}-\frac{1}{4}
$$

DETAIL MAIN HANGER 2Required-Mark D-2.

Plon for special support permitting use of Confield reel with See Tacomo
axle and washer.

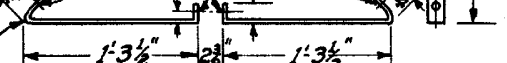

“6:-103" strap iron (bend atter drilling DETAIL ROOF SUPPORT Required -Mark D-1.

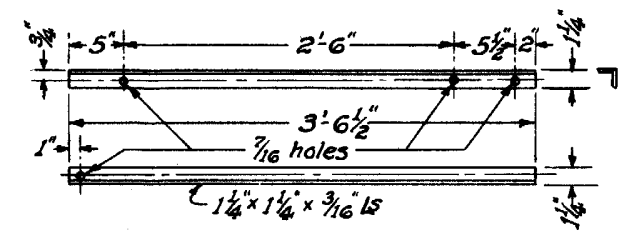
DETAIL LOWER HANGER

DETAIL FLOOR ANGLES

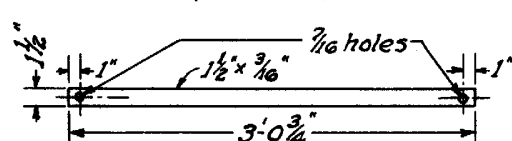

$\frac{\text { DETAIL HANGER BRACE }}{\text { 2Required }- \text { Mark }}$

$\frac{\text { DETAIL HANGER BRACE }}{2 \text { Required - Mark } D-6 \text {. }}$
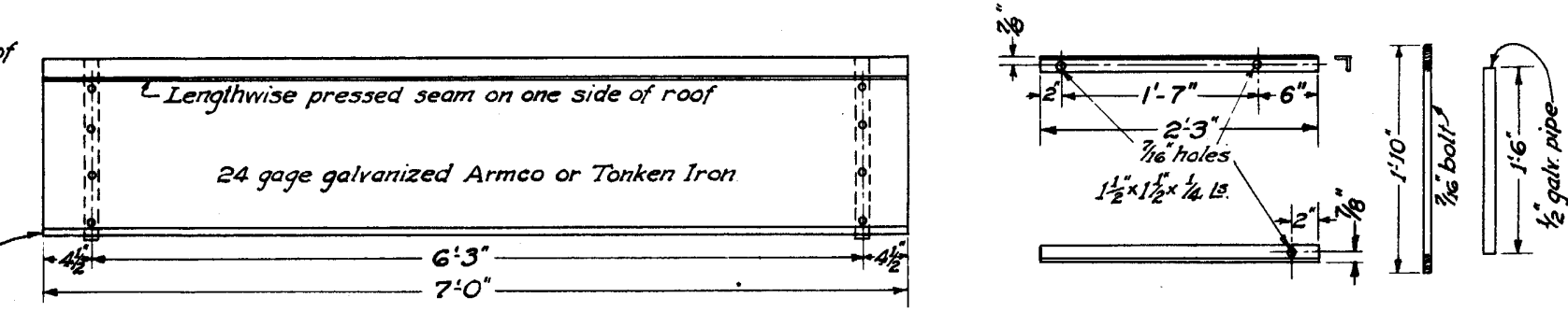

DETAIL PIPE SUPPORT PIPE \& BOLT 1 Required Mark D-8

BILL OF MATERIALS

ONE STAND-UP TYPE GAGING CAR

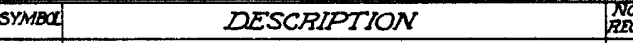

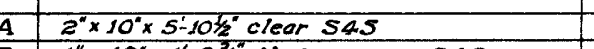

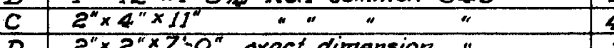
$D \quad 2^{\prime \prime} \times 2^{\prime \prime x} \times 7^{*} 0^{*}$ exact alimension

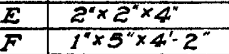

DETAIL REEL SUPPORT 2.Required-1L.H. - 1R.H-Mark D-

$$
\text { 1. }
$$

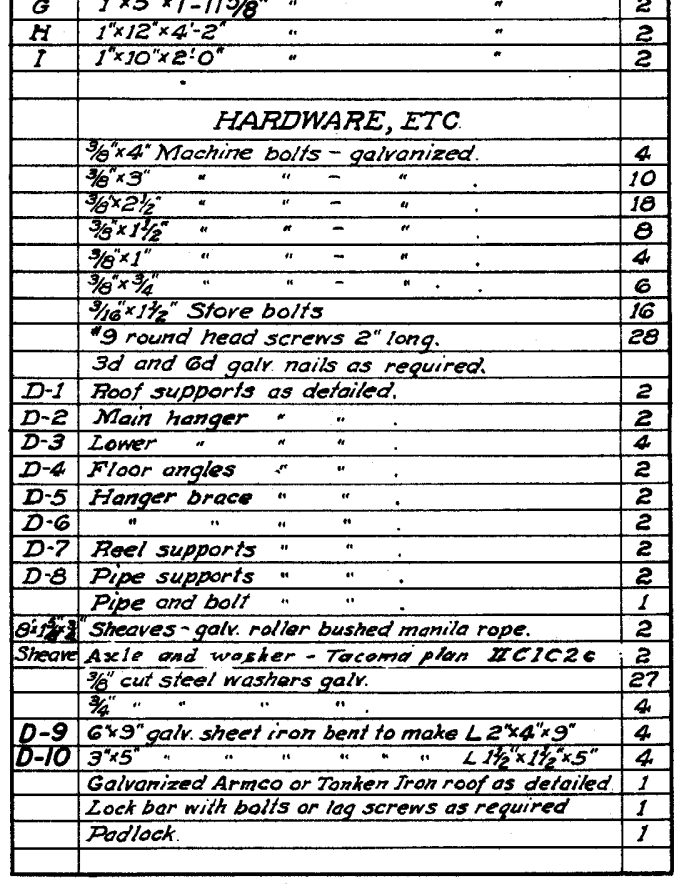
NOTES

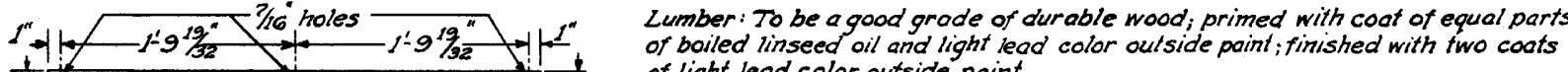
Melal surfaces: All metal parts to be galvanized by the hot-dip process after berding and drilling.

STRUCTURES FOR CABLEWAYS

GAGING CAR

TYPE-B (with roof)

Designed in Tacoma Distric PLATE 23 


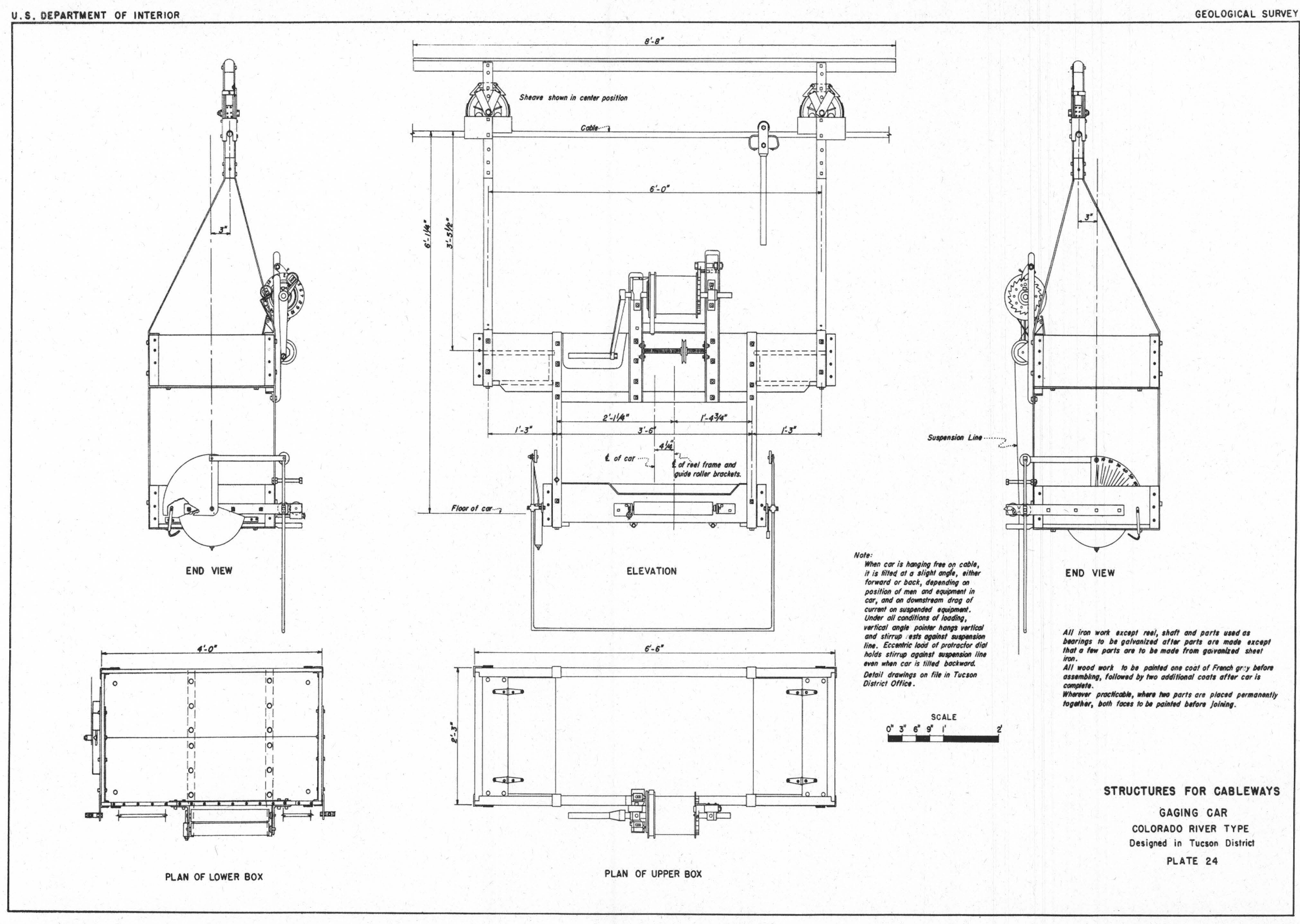




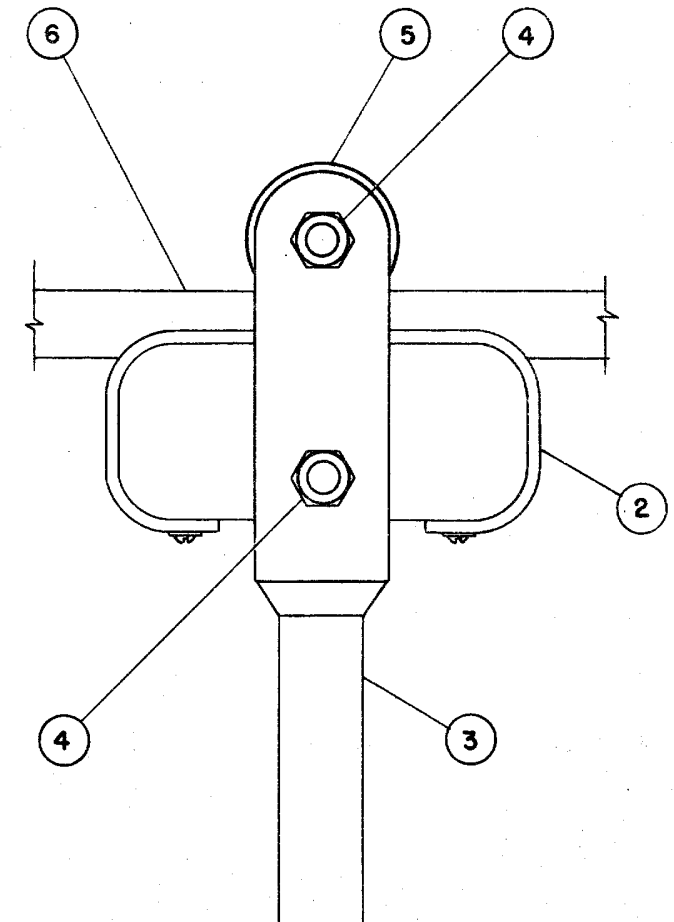

Note:

Detoil drawings on file in Tucson District Office.

(5)

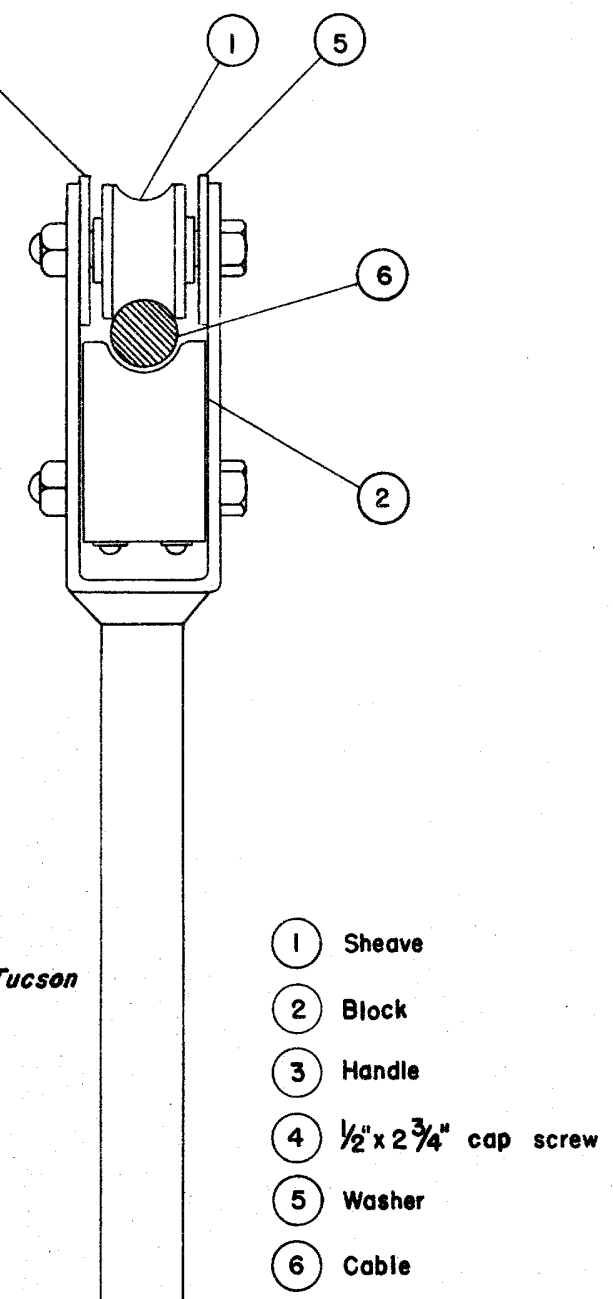

SCALE

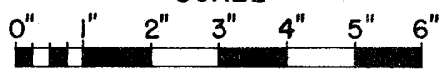

STRUCTURES FOR CABLEWAYS

GAGING CAR PULLER COLORADO RIVER TYPE

Designed in Tucson District 